\title{
Driving GDNF expression: The green and the red traffic lights
}

\author{
Ana Saavedra ${ }^{\mathrm{a}, *}$, Graça Baltazar $^{\mathrm{b}}$, Emília P. Duarte ${ }^{\mathrm{c}, \mathrm{d}}$ \\ ${ }^{a}$ Department of Cell Biology, Immunology and Neurosciences, Faculty of Medicine, University of Barcelona, Carrer Casanova 143, 08036 Barcelona, Spain \\ ${ }^{\mathrm{b}}$ Health Sciences Research Centre, University of Beira Interior, Covilhã, Portugal \\ ${ }^{\mathrm{c}}$ Centre for Neuroscience and Cell Biology, University of Coimbra, Coimbra, Portugal \\ ${ }^{\mathrm{d}}$ Department of Zoology, University of Coimbra, Coimbra, Portugal
}

\section{A R T I C L E I N F O}

Article history:

Received 7 December 2007

Received in revised form 18 June 2008

Accepted 3 September 2008

\section{Keywords:}

Activity dependence

Development

GDNF

GDNF gene

Endogenous expression

Inflammation

Injury

Neuron-glia cross-talk

Neuroprotection

Nigrostriatal system

Parkinson's disease

Signalling pathways

\begin{abstract}
A B S T R A C T
Glial cell line-derived neurotrophic factor (GDNF) is widely recognized as a potent survival factor for dopaminergic neurons of the nigrostriatal pathway that degenerate in Parkinson's disease (PD). In animal models of PD, GDNF delivery to the striatum or the substantia nigra protects dopaminergic neurons against subsequent toxin-induced injury and rescues previously damaged neurons, promoting recovery of the motor function. Thus, GDNF was proposed as a potential therapy to PD aimed at slowing down, halting or reversing neurodegeneration, an issue addressed in previous reviews. However, the use of GDNF as a therapeutic agent for PD is hampered by the difficulty in delivering it to the brain. Another potential strategy is to stimulate the endogenous expression of GDNF, but in order to do that we need to understand how GDNF expression is regulated. The aim of this review is to do a comprehensive analysis of the state of the art on the control of endogenous GDNF expression in the nervous system, focusing mainly on the nigrostriatal pathway. We address the control of GDNF expression during development, in the adult brain and after injury, and how damaged neurons signal glial cells to up-regulate GDNF. Pharmacological agents or natural molecules that increase GDNF expression and show neuroprotective activity in animal models of PD are reviewed. We also provide an integrated overview of the signalling pathways linking receptors for these molecules to the induction of GDNF gene, which might also become targets for neuroprotective therapies in PD.
\end{abstract}

(c) 2008 Elsevier Ltd. All rights reserved.

\section{Contents}

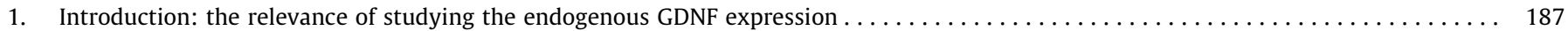

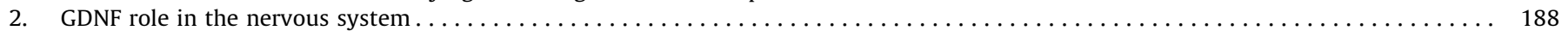

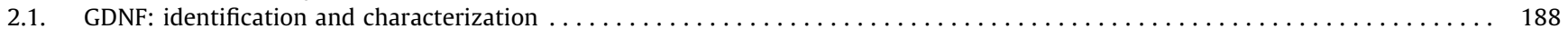

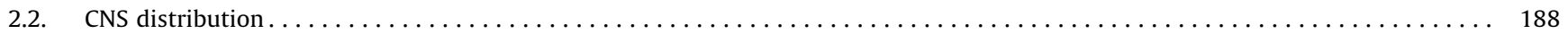

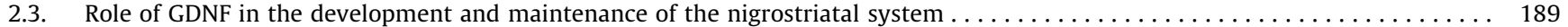

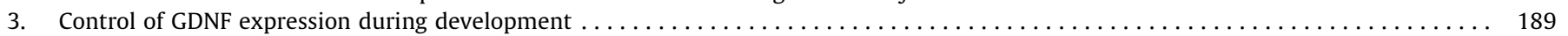

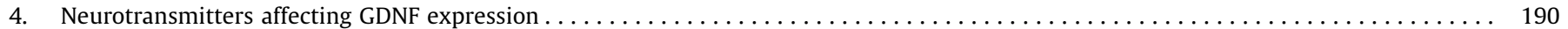

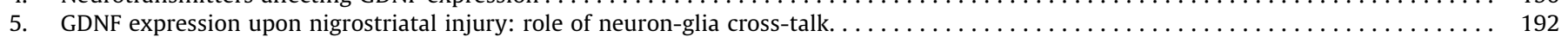

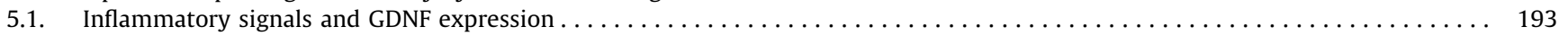

\footnotetext{
* Corresponding author. Tel.: +34 934021912; fax: +34 934021907.

E-mail address: anasaavedra@ub.edu (A. Saavedra).

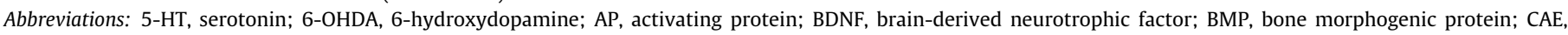

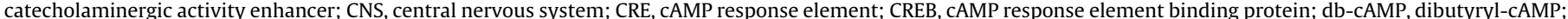

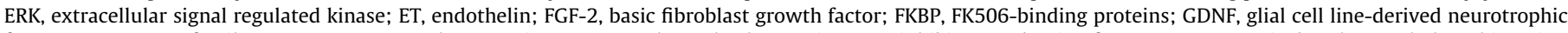

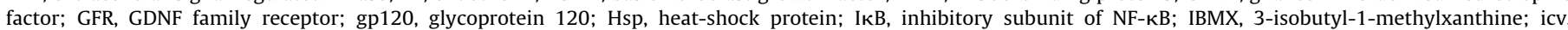

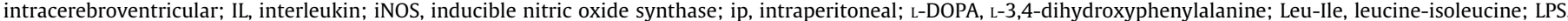

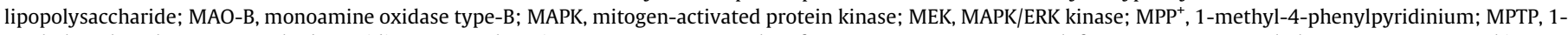

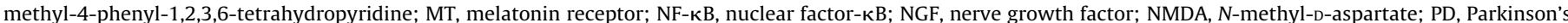

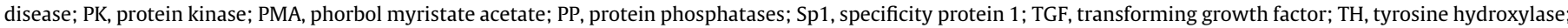
TNF, tumor necrosis factor; TPA, 12-O-tetradecanoylphorbol 13-acetate; VPA, valproic acid; VTA, ventral tegmental area.
} 


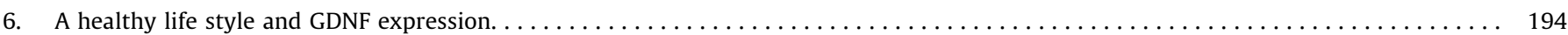

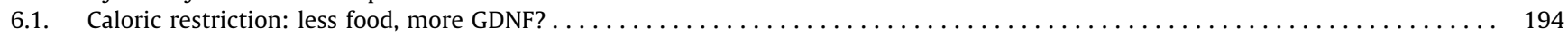

6.2. Physical exercise and GDNF expression in the nigrostriatal system $\ldots \ldots \ldots \ldots$

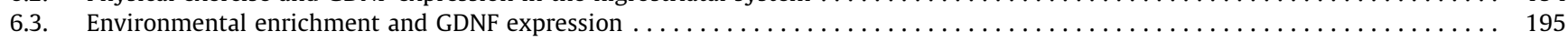

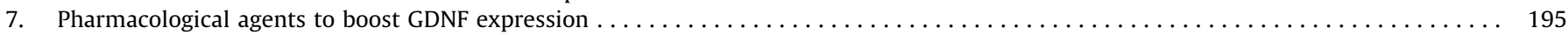

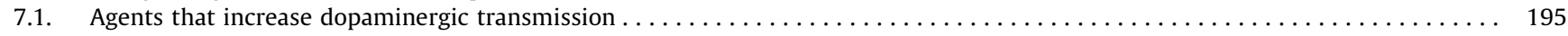

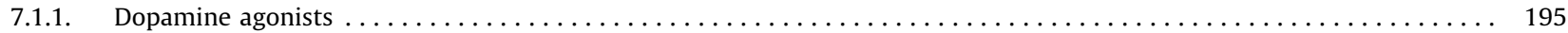

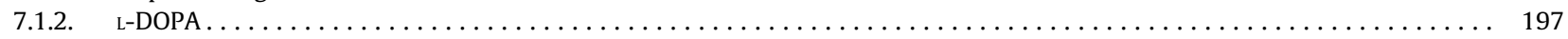

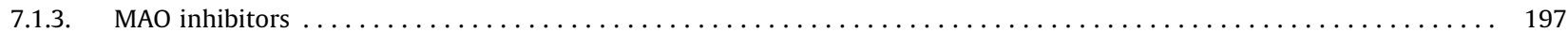

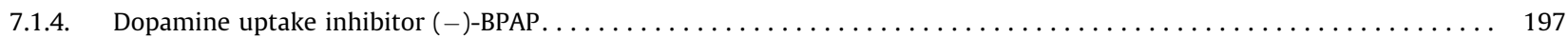

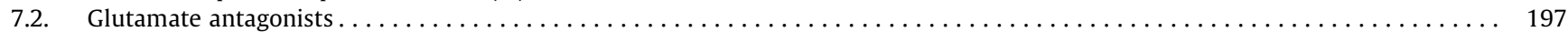

7.3. Anti-depressants, anti-psychotics and $\operatorname{mood}$ stabilizers $\ldots \ldots \ldots \ldots \ldots$

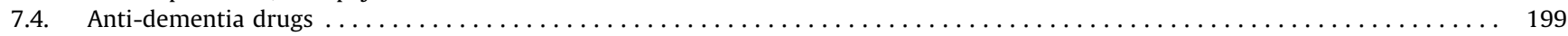

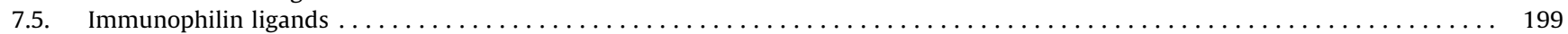

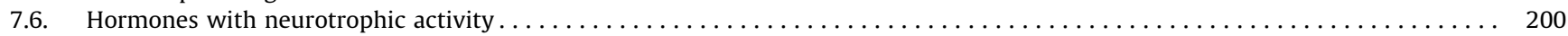

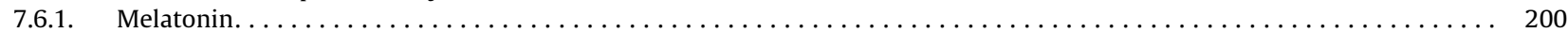

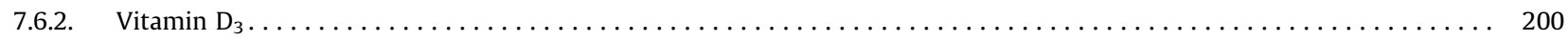

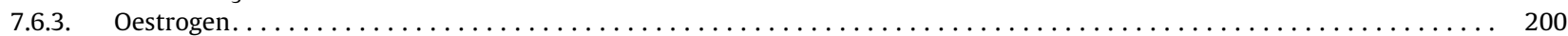

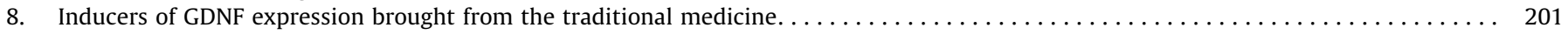

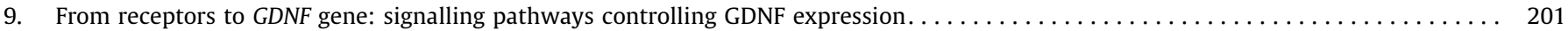

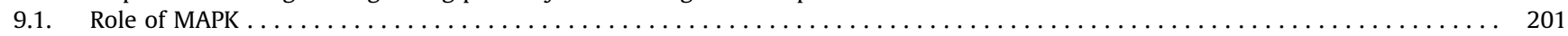

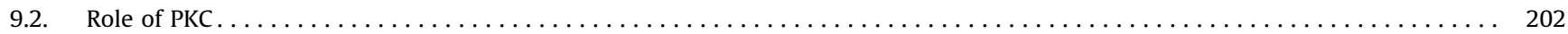

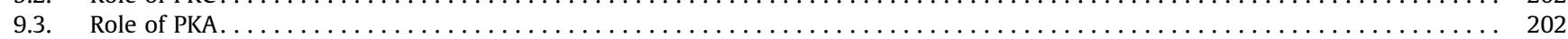

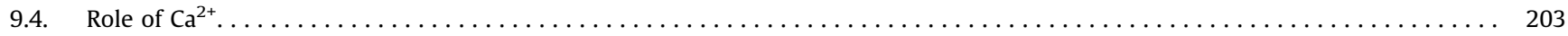

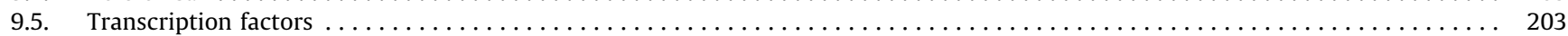

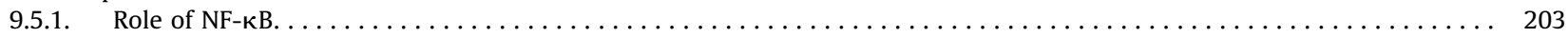

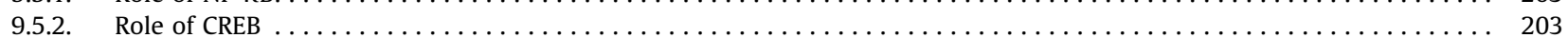

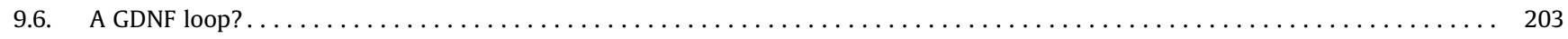

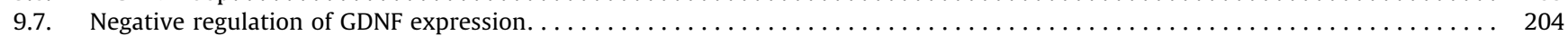

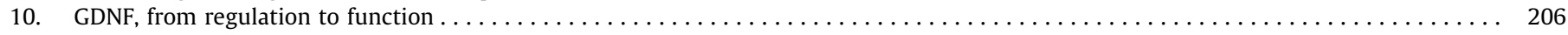

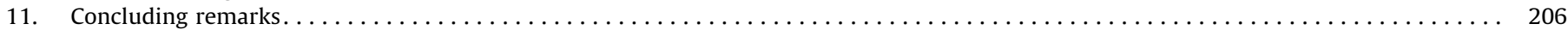

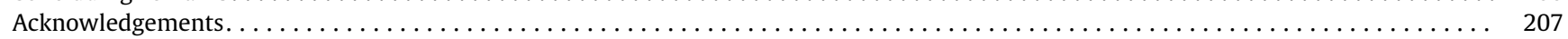

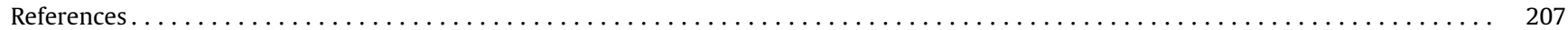

\section{Introduction: the relevance of studying the endogenous GDNF expression}

The slow and progressive loss of dopaminergic neurons from the substantia nigra in Parkinson's disease (PD) makes it amenable to treatments that protect the remaining dopaminergic neurons and/or prevent the death of injured ones. This issue becomes an important challenge when the effectiveness of the most potent symptomatic treatment for $\mathrm{PD}$, the administration of the dopamine precursor L-DOPA (L-3,4-dihydroxyphenylalanine), decreases over time and patients start to develop disabling side effects (reviewed by Lim, 2005). Therefore, the search for new symptomatic treatments, as well as for neuroprotective and neurorestorative strategies is currently underway (reviewed by $\mathrm{Wu}$ and Frucht, 2005).

Neurotrophic factors have emerged as key factors in the survival and phenotypic differentiation of neuronal cells during development, in the maintenance of mature neurons in the adult brain, as well as in their protection/repair upon injury (Benn and Woolf, 2004). It was proposed that changes in the levels of neurotrophic factors, due to alterations in the synthesis, release or activity associated with ageing or genetic factors, might be involved in the neuronal loss observed in neurodegenerative diseases as PD (reviewed by Siegel and Chauhan, 2000; Mattson and Magnus, 2006). In fact, brain-derived neurotrophic factor (BDNF) mRNA (Howells et al., 2000) and protein levels (Mogi et al., 1999; Parain et al., 1999), as well as nerve growth factor (NGF) levels (Mogi et al., 1999) are reduced in PD substantia nigra. Large reductions in basic fibroblast growth factor (bFGF or FGF-2) content were reported in surviving PD substantia nigra neurons (Tooyama et al., 1993), while no differences were found in the striatal levels between controls and PD patients (Mogi et al., 1996).
Concerning glial cell line-derived neurotrophic factor (GDNF), postmortem studies investigating its distribution in the human parkinsonian brain have yielded conflicting results (Hunot et al., 1996; Chauhan et al., 2001; Mogi et al., 2001). Since GDNF expression is reduced in the adult brain, the use of techniques that enhance the detection of low copy mRNA transcripts may be crucial for accurate quantification of its expression. Recently, using real-time PCR, Backman et al. (2006) described the GDNF isoform II as the predominant transcript in the putamen of human subjects, whereas only the expression of GDNF isoform I is modestly increased in the putamen of PD patients with marked nigral neuronal loss (Backman et al., 2006).

Despite the conflicting results on neurotrophic factor levels in the striatum and substantia nigra in PD, it has been suggested that the replacement of such factors may prevent the progression of the disease (Levy et al., 2005). GDNF is a promising therapeutic agent for the treatment of neurodegenerative diseases, in particular PD. In fact, many studies in animal models (reviewed by Soderstrom et al., 2006) and some studies in PD patients show that GDNF delivery can have trophic effects and restore motor function (Gill et al., 2003; Slevin et al., 2005), although some problems need to be overcome before GDNF therapy for PD becomes a reality (Sherer et al., 2006). For instance, the delivery of GDNF to the central nervous system (CNS) is challenging because GDNF is unable to cross the blood-brain barrier (Kastin et al., 2003; Kirik et al., 2004). A possibility to overcome this limitation is to conjugate or fuse GDNF with other molecules that enable it to cross the blood-brain barrier. Fusion with viral proteins, conjugation with antibodies for transferrin or insulin receptors, or with a fragment of the tetanus toxin have been demonstrated to provide an efficient way of delivering GDNF to the CNS (Albeck et al., 1997; Dietz et al., 2006; Larsen et al., 2006; Boado et al., 2007; Xia et al., 2008). Molecules 
that induce GDNF expression or enhance its signalling may prove to be an alternative therapeutic option for PD. Interestingly, it was suggested that XIB4035, a non-peptidyl small molecule that acts as a GDNF family receptor (GFR) $\alpha 1$ agonist and mimics the neurotrophic effects of GDNF in Neuro-2A cells, might have beneficial effects for the treatment of PD (Tokugawa et al., 2003). More recently, the oral administration of PYM50028, a novel non-peptide neurotrophic factor inducer, to 1-methyl-4-phenyl-1,2,3,6-tetrahydropyridine (MPTP)-lesioned mice resulted in a significant elevation of striatal GDNF and attenuated the loss of dopaminergic neurons from the substantia nigra (Visanji et al., 2008).

Finding molecules like XIB4035 or PYM50028, capable of stimulating GDNF expression/signaling, may prove beneficial to the treatment of PD. The development of small molecules that specifically activate the GDNF receptor and can be administered systemically would overcome most of the problems associated with the delivery of GDNF protein into the brain, with GDNF expression induced by viral vectors, or with the use of encapsulated GDNF producing cells (Bespalov and Saarma, 2007). In addition, or as an alternative, pharmacological stimulation of endogenous GDNF synthesis using low-molecular weight drugs capable of activating GDNF expression is another potential choice for the treatment of PD. To accomplish that, however, it is necessary to understand the regulation of GDNF expression in order to identify therapeutic targets able to modulate endogenous GDNF expression and release.

The aim of the present work is to review and integrate the available data on the control of the endogenous expression of GDNF, both in physiological conditions (during development and normal activity of the nervous system) and upon brain injury, focusing mainly on the nigrostriatal system. The communication between neurons, astrocytes, and microglial cells will be addressed to identify intercellular signals that regulate GDNF expression and/ or release. The large number of compounds, both endogenous and pharmacological agents, found to trigger or modulate GDNF expression will be described. An overview of the signalling pathways leading to the regulation of GDNF gene transcription will also be presented. To our knowledge, the present review is the first one attempting a comprehensive analysis of the control of GDNF expression in the nervous system.

\section{GDNF role in the nervous system}

\subsection{GDNF: identification and characterization}

GDNF was identified and purified from the B49 glioma cell line based on its ability to promote the survival of dopaminergic neurons in dissociated rat mesencephalic cultures, and to increase their neurite length and cell size, as well as the high affinity dopamine uptake, without significantly affecting non-dopaminergic neurons or glial cells (Lin et al., 1993). GDNF is a glycosylated, disulfide-bonded homodimer, with a molecular weight of 33$45 \mathrm{kDa}$, while the monomer has a molecular weight of $16 \mathrm{kDa}$ after deglycosylation (Lin et al., 1994). Sequence data suggest that GDNF is synthesized as an inactive 211 amino acids-long pre-proGDNF, and then processed to the mature protein with 134 amino acids (Lin et al., 1993).

GDNF is the founding member of the GDNF family of neurotrophic factors, which additionally includes three other structurally related members, neurturin (Kotzbauer et al., 1996), persephin (Milbrandt et al., 1998), and artemin (Baloh et al., 1998). The members of the GDNF family belong to the transforming growth factor (TGF)- $\beta$ superfamily because they contain seven cysteine residues in the same relative spacing as the other members of the superfamily, despite the a low sequence homology (Lin et al., 1993).
GDNF family ligands signal through a multicomponent receptor complex comprising the transmembrane Ret tyrosine kinase and a member of a family of glycosylphosphatidylinositol (GPI)-anchored cell surface proteins, the GFR $\alpha$. To date, four members of this family have been identified (GFR $\alpha 1-4$ ), the preferential binding occurring between GDNF and GFR $\alpha 1$, neurturin and GFR $\alpha 2$, artemin and GFR $\alpha 3$, and persephin and $\mathrm{GFR} \alpha 4$. In the Ret/GFR $\alpha$ receptor complex, ligand binding is performed by the GFR $\alpha$ and the intracellular signalling by Ret. Additionally, there is a Ret-independent signalling pathway, using GFR $\alpha 1$-associated Src kinase activation, and GFR $\alpha$ has been shown to use also neural cell adhesion molecules (NCAM) as signalling receptors for GDNF family ligands (reviewed by Sariola and Saarma, 2003). In addition to the known receptors GFR $\alpha 1$ and Ret, GDNF signalling requires heparan sulphate glycosaminoglycans (reviewed by Sariola and Saarma, 2003), but recent findings suggest that the contribution of heparin and heparan sulphate does not occur during the GDNF-GFR $\alpha 1$ engagement (Alfano et al., 2007). An evidence for the involvement of heparan sulphates in GDNF signalling comes also from studies showing that a marine-derived acidic oligosaccharide activates GDNF signalling as assessed by Ret phosphorylation and neurite outgrowth in PC12-treated cells (Wang et al., 2007). Other recent finding suggests that integrin $\beta 1$, an other adhesion molecule, is also involved in GDNF signalling (Cao et al., 2008).

\subsection{CNS distribution}

Using in situ hybridization and reverse transcription-PCR, GDNF transcripts were identified in many different regions of the developing and adult brain, as well as in peripheral tissues, indicating that GDNF may have multiple actions. In the rat nervous system, GDNF mRNA is present in the thalamus, hippocampus, cerebellum, cortex, striatum, and spinal cord (Stromberg et al., 1993; Choi-Lundberg and Bohn, 1995; Pochon et al., 1997; Trupp et al., 1997). In the rat striatum, GDNF mRNA is present at highest levels during early postnatal development (Schaar et al., 1993; Stromberg et al., 1993; Blum and Weickert, 1995; Choi-Lundberg and Bohn, 1995), and GDNF protein is also present in the striatum early in the development (Lopez-Martin et al., 1999; Oo et al., 2005). In adult rats, the levels of GDNF mRNA are significantly higher in the ventral striatum than in the dorsal striatum (Barroso-Chinea et al., 2005). The levels of GDNF mRNA in the substantia nigra are much lower than in the striatum (ChoiLundberg and Bohn, 1995; Oo et al., 2005), which suggests a role for GDNF mainly as a target-derived neurotrophic factor for dopaminergic neurons. In fact, after intrastriatal injection in adult rats, both unlabelled and ${ }^{125}$ I-labelled GDNF are transported to dopaminergic cell bodies in the substantia nigra pars compacta, suggesting that in the adult nigrostriatal system GDNF acts endogenously as a target-derived factor for dopaminergic neurons (Tomac et al., 1995). Going further, Barroso-Chinea et al. (2005) reported that the ventral tegmental area (VTA) and the rostromedial substantia nigra (SNrm) contain GDNF but not GDNF mRNA. Immunocytochemistry studies performed after colchicine injection in the lateral ventricle show that VTA and SNrm cells are immunonegative for GDNF, suggesting that GDNF in dopaminergic soma comes from their striatal target (BarrosoChinea et al., 2005), an observation consistent with previous findings. In the adult human CNS, GDNF mRNA is detected in the striatum, hippocampus, cortex, and spinal cord (Springer et al., 1994).

Northern blot, PCR, and in situ hybridization analysis detect GFR $\alpha 1$ and Ret in many GDNF-responsive regions of the embryonic and adult rat nervous system, including in the dopaminergic 
neurons from the substantia nigra (Treanor et al., 1996; Nosrat et al., 1997; Trupp et al., 1996, 1997).

Altogether, these findings suggest a role for GDNF in the targetderived support of dopaminergic neurons, and the potential involvement in the support of other neuronal populations. Indeed, although first described as a selective neurotrophic molecule for nigral dopaminergic neurons in vitro, other central and peripheral nervous system neurons, including spinal motoneurons, sympathetic and sensory neurons, are responsive to GDNF (Henderson et al., 1994; Arenas et al., 1995; Buj-Bello et al., 1995; Trupp et al., 1995; Hearn et al., 1998; Heuckeroth et al., 1998).

GDNF mRNA is also widely expressed outside the nervous system in developing rats, including in kidney, lung, stomach, gonads, and skin (Suter-Crazzolara and Unsicker, 1994; Trupp et al., 1995). This is consistent with GDNF having several roles outside the nervous system. These include its action as a morphogen during kidney development (reviewed by Costantini and Shakya, 2006), as mice lacking GDNF do not have kidneys (Moore et al., 1996; Pichel et al., 1996; Sanchez et al., 1996), or in the regulation of spermatogenesis (Naughton et al., 2006 and references therein).

\subsection{Role of GDNF in the development and maintenance of the nigrostriatal system}

Since GDNF was identified as a trophic factor for dopaminergic neurons (Lin et al., 1993), it was surprising to find that newborn mice deficient for GDNF, GFR $\alpha 1$, or Ret showed no apparent deficits in midbrain dopaminergic neurons (reviewed by Enomoto, 2005). However, due to the absence of enteric neurons and kidneys, these mice die soon after birth, whereas the developmental programmed cell death of dopaminergic neurons from the substantia nigra occurs later on postnatal life. This event has a biphasic time-course, with an initial peak on postnatal day 2 , and a second one on postnatal day 14 (Burke, 2003). In fact, GDNF selectively supports the viability of postnatal nigral dopaminergic neurons in culture by preventing apoptosis with both regional specificity for the substantia nigra vs. VTA, and cellular specificity for the dopaminergic phenotype (Burke et al., 1998).

To be able to examine the role of GDNF in the development of the dopaminergic nigrostriatal system and overcome the limitation produced by the death soon after birth of GDNF-deficient mice, Granholm et al. (2000) transplanted foetal dopaminergic neurons from the ventral mesencephalon of GDNF-/-, GDNF+/-, and wild-type mice into the dopamine-denervated striatum of adult wild-type mice. Using this approach, they demonstrated that the postnatal development of dopaminergic neurons is severely disturbed in the absence of GDNF, as shown by the markedly reduced number of dopaminergic neurons and fibre outgrowth, indicating that GDNF is required for postnatal maturation of midbrain dopaminergic neurons. The hypothesis that GDNF is a limiting striatal target-derived neurotrophic factor for developing substantia nigra dopaminergic neurons is also supported by the observation that the intrastriatal administration of GDNF during the period of ontogenetic cell death suppresses apoptosis of nigral dopaminergic neurons (Oo et al., 2003). Furthermore, neutralizing endogenous GDNF by the application of GDNF antibodies to the striatum enhances cell death during the first period of cell death (Oo et al., 2003). More recently, in a double transgenic mouse model, it was shown that selective GDNF overexpression in the striatum throughout the development increases the number of surviving dopaminergic neurons in the substantia nigra following the first phase of cell death (Kholodilov et al., 2004).

Although neurochemical and behavioural measures suggested that reduction of GDNF gene expression in the GDNF+/- mutant mice does not alter the nigrostriatal dopaminergic system, and therefore that endogenous GDNF may not be critical for the development and functioning of the nigrostriatal dopaminergic system (Gerlai et al., 2001), more recent studies point towards the opposite direction. Using a conditional GDNF-null mouse to suppress GDNF expression in the adult, Pascual et al. (2008) clearly demonstrate that GDNF is crucial for adult catecholaminergic neuronal survival. After GDNF ablation, mice showed a progressive hypokinesia and a selective decrease of brain tyrosine hydroxylase (TH) mRNA, together with a specific and extensive catecholaminergic neuronal death, affecting most notably the locus coeruleus, the substantia nigra and the VTA. The importance of GDNF for the development and maintenance of the nigrostriatal pathway is also strengthened by findings showing that Retdeficient mice present progressive and adult-onset loss of dopaminergic neurons specifically in the substantia nigra pars compacta, degeneration of dopaminergic nerve terminals in the striatum, and pronounced glial activation (Kramer et al., 2007). Furthermore, temporary blockade of Ret expression in embryos using Ret antisense oligonucleotides (Ret-AS-ODN) leads to reduced striatal dopamine content and a decrease in TH positive fibres in the striatum. Additionally, some dopaminergic neurons in the substantia nigra undergo apoptotic cell death following the RetAS-ODN treatment suggesting that normal function of Ret is required in vivo for the maturation of dopaminergic neurons, for cell survival and fibre innervation (Li et al., 2006b).

A role for GDNF in modulating the pattern of dopaminergic innervation is also suggested by results obtained with rat postnatal organotypic slice co-cultures prepared from substantia nigra, striatum and cortex since addition of GDNF to these cultures increases the number of dopaminergic neurons, and the number of dopaminergic processes innervating the striatum (Jaumotte and Zigmond, 2005). Using organotypic cultures from the ventral mesencephalon of GDNF-deficient mice, Bjerken et al. (2007) observed also that although midbrain dopaminergic neurons from GDNF knockout mice survive in the absence of GDNF, the addition of GDNF increased nerve fibre outgrowth possibly because of the augmented astrocytic stimulation observed in the presence of GDNF in these cultures. Moreover, GDNF levels seem to be crucial to the maintenance of dopaminergic neurons during the ageing process since the age-related decrease in substantia nigra $\mathrm{TH}$ immunostaining observed in wild-type mice is accelerated in GDNF+/- mice (Boger et al., 2006).

Altogether, these studies strongly suggest that GDNF plays an essential role in the development of the dopaminergic nigrostriatal system, and that even a slight disturbance in the make-up of this system due to GDNF deficits might compromise dopaminergic survival in the adulthood.

\section{Control of GDNF expression during development}

Despite the advances in understanding the role of GDNF in the development and maintenance of the nigrostriatal system, our knowledge of how GDNF expression is regulated during these processes is still in a very embryonic stage. Very recently, it was described that the overexpression of Pitx3 in SH-SY5Y cells and primary ventral mesencephalic cultures significantly increases GDNF and BDNF mRNA levels and elevates their protein levels (Peng et al., 2007). Since Pitx3 is a transcription factor with an important role in the growth and differentiation of dopaminergic neurons (reviewed by Smidt et al., 2004) this finding may represent the very first step, as far as we are aware, for unravelling how GDNF expression is regulated during the development of the nigrostriatal system.

In contrast, the regulation of GDNF expression during kidney development is much better understood. GDNF signalling through 
Table 1

Positive and negative regulatory molecules on GDNF expression/signalling during kidney development

\begin{tabular}{ll}
\hline Positive regulatory factors & Negative regulatory factors \\
\hline Six1 & Foxc1 \\
Six2 & Foxc2 \\
Pax2 & Slit2/Robo2 \\
Eya1 & BMP4 \\
Sall1 & Sprouty1 \\
Growth/differentiation factor 11 & \\
Hox11 & \\
\hline
\end{tabular}

the Ret receptor is required for the normal growth of the ureteric bud during kidney development, and GDNF is the growth factor most extensively implicated in ureteric bud branching morphogenesis (reviewed by Costantini and Shakya, 2006). The key role of GDNF and its receptors in kidney development was initially revealed by the targeted gene disruption of GDNF, Ret, or GFR $\alpha 1$ (reviewed by Enomoto, 2005). Further evidence for the importance of GDNF has come from the study of molecules found to regulate, positive or negatively, the level, timing or spatial extent of GDNF expression during kidney development (Table 1). Mutations in the genes encoding those molecules result in abnormalities due to altered GDNF expression (reviewed Bouchard, 2004; Costantini and Shakya, 2006).

A great deal of information on the regulation of GDNF expression during development comes from studies on the developing kidney. This is because, with few exceptions, many genes that play a crucial role in early kidney development, such as Pax2, Eya1, Six1, Six2, Sall1, Foxc1, Wt1, and the Hox11 genes, encode transcription factors that, organized in a complex network, are involved in the regulation of GDNF gene (Brodbeck and Englert, 2004).

Some studies point to a possible activation of the GDNF gene by the transcription factors Six1 and Six2 (Xu et al., 1999; Wellik et al., 2002). In fact, chromatin immunoprecipitation and microinjection assays reveal binding and activation of GDNF intron 1 by the Six 1 protein (Li et al., 2003), and Six 4 seems to cooperate with Six 1 in the metanephric mesenchyme to regulate the level of GDNF expression (Kobayashi et al., 2007). Six2 also activates GDNF expression, and two Six2 binding sites in the GDNF promoter were identified (Brodbeck et al., 2004). The activation complex of GDNF may also include the Pax2 protein, since Pax2 binds to the $5^{\prime}$-untranslated region of GDNF exon 1, and can transactivate the expression of reporter genes, which can explain the observation that GDNF expression is missing in Pax2 knockout animals (Brophy et al., 2001).

Knockout mice for the transcriptional regulator Eya1 show loss of GDNF expression (Xu et al., 1999). However, it is unlikely that the effect of Eya 1 on GDNF is direct since Eya 1 needs a member of the Six protein family for nuclear translocation (Ohto et al., 1999). In fact, Eya1 probably functions at the top of the genetic hierarchy controlling kidney organogenesis, acting as a key regulator for GDNF expression during metanephric induction, and interacting with Six1 and Pax2 to regulate the ureteric outgrowth and branching (Sajithlal et al., 2005). The homeodomain transcription factor Sall1 also seems to play a role in GDNF regulation since in the absence of Sall1, the levels of GDNF are reduced, which correlates with an incomplete ureteric bud outgrowth (Nishinakamura et al., 2001).

However, the deletion of a signalling molecule encoding the TGF- $\beta$ family member growth/differentiation factor 11 can also result in loss of GDNF expression (Esquela and Lee, 2003). Many genes crucial to kidney development are evolutionarily conserved, and correspond to orthologous genes that regulate eye development in Drosophila. It should also be stressed that many of these genes are involved in the formation of more than one organ (reviewed by Brodbeck and Englert, 2004), so it might therefore be worthy to investigate them for a possible role on the control of GDNF expression during the development of the nigrostriatal system.

In addition to these positive regulatory factors, evidence for factors that can down-regulate GDNF expression during kidney development is also available. Mouse knockout studies have identified two negative regulatory mechanisms that modulate GDNF expression during urogenital development. Deletion of the transcription factors FoxC1 and FoxC2 causes an anterior expansion of GDNF expression, implying that these factors normally restrict the domain of GDNF expression (Kume et al., 2000). Other studies have identified a different signalling system that is also required to limit the regional GDNF expression, the secreted factor Slit2 and its receptor Robo2. Knocking out Slit2 or Robo2 results in a slight anterior expansion of the GDNF expression, and thus the Robo2/Slit2 pathway defines the anterior boundary of the metanephric mesenchyme (Grieshammer et al., 2004). Additional negative regulators of Ret/GDNF signalling include the bone morphogenic protein (BMP) 4, and Sprouty1. BMP4 suppresses the effects of ectopic GDNF in vitro (Brophy et al., 2001), and loss of the receptor tyrosine kinase antagonist Sprouty1 causes defects in kidney development in mice due to increased sensitivity of the Wolffian duct to GDNF/Ret signalling, which induces supernumerary ureteric buds (Basson et al., 2005). However, neither Sprouty nor BMP4 affect the GDNF expression pattern.

\section{Neurotransmitters affecting GDNF expression}

Afferent activity regulates the expression of neurotrophic factors (Hughes et al., 1999) and therefore dopamine is a likely candidate to control GDNF expression in the nigrostriatal system (Fig. 1). In line with this, mice lacking D2 receptors (D2R-/-) show reduced levels of GDNF in the striatum (Bozzi and Borrelli, 1999). Also in agreement with these data, D1 and D2 agonists increase the synthesis of GDNF in mesencephalic and striatal neuronal cultures (Guo et al., 2002), and in astroglial cultures (Ohta et al., 2000, 2003, 2004). Exposure to dopamine, apomorphine, or the specific D1 agonist SKF-38393 increases GDNF production in a foetal human astrocyte cell line (Kinor et al., 2001). In addition, dopamine increases GDNF secretion in rodent primary astrocyte cultures (McNaught and Jenner, 2000).

Trophic actions promoted by dopamine agonists appear to be brain region-specific. While cultured foetal striatal cells respond to apomorphine treatment by increasing BDNF and GDNF, hippocampal cells are unable to respond (Guo et al., 2002). Conditioned medium from substantia nigra astroglial cultures treated with D3 agonists show remarkably increased levels of GDNF and BDNF, while no changes are observed in medium from striatal or cortical astroglia (Du et al., 2005). Moreover, D2R-/- mice show a 40-50\% reduction of GDNF mRNA in the major target areas of substantia nigra/VTA dopaminergic neurons, whereas GDNF mRNA levels are unaltered in other brain areas receiving dopaminergic innervation (Bozzi and Borrelli, 1999). Conversely, the knockout mice present changes in the expression of neurotrophin-4 (NT-4) in other brain areas. There are no changes in the NT-4 mRNA levels in the substantia nigra but the levels in the parietal cortex, an area receiving innervation from the VTA, are substantially reduced (Bozzi and Borrelli, 1999). Collectively, these findings support the idea that dopamine regulates the expression of GDNF and other neurotrophic factors. Therefore, depletion of dopamine upon nigrostriatal injury would lead to a decrease in GDNF expression, unless other factors related to the response to neuronal injury modulate GDNF expression. Among them might be pro-inflammatory molecules, as discussed later. 


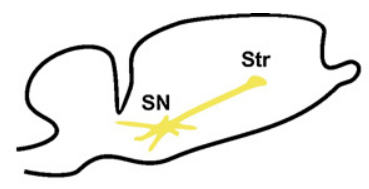

Normal
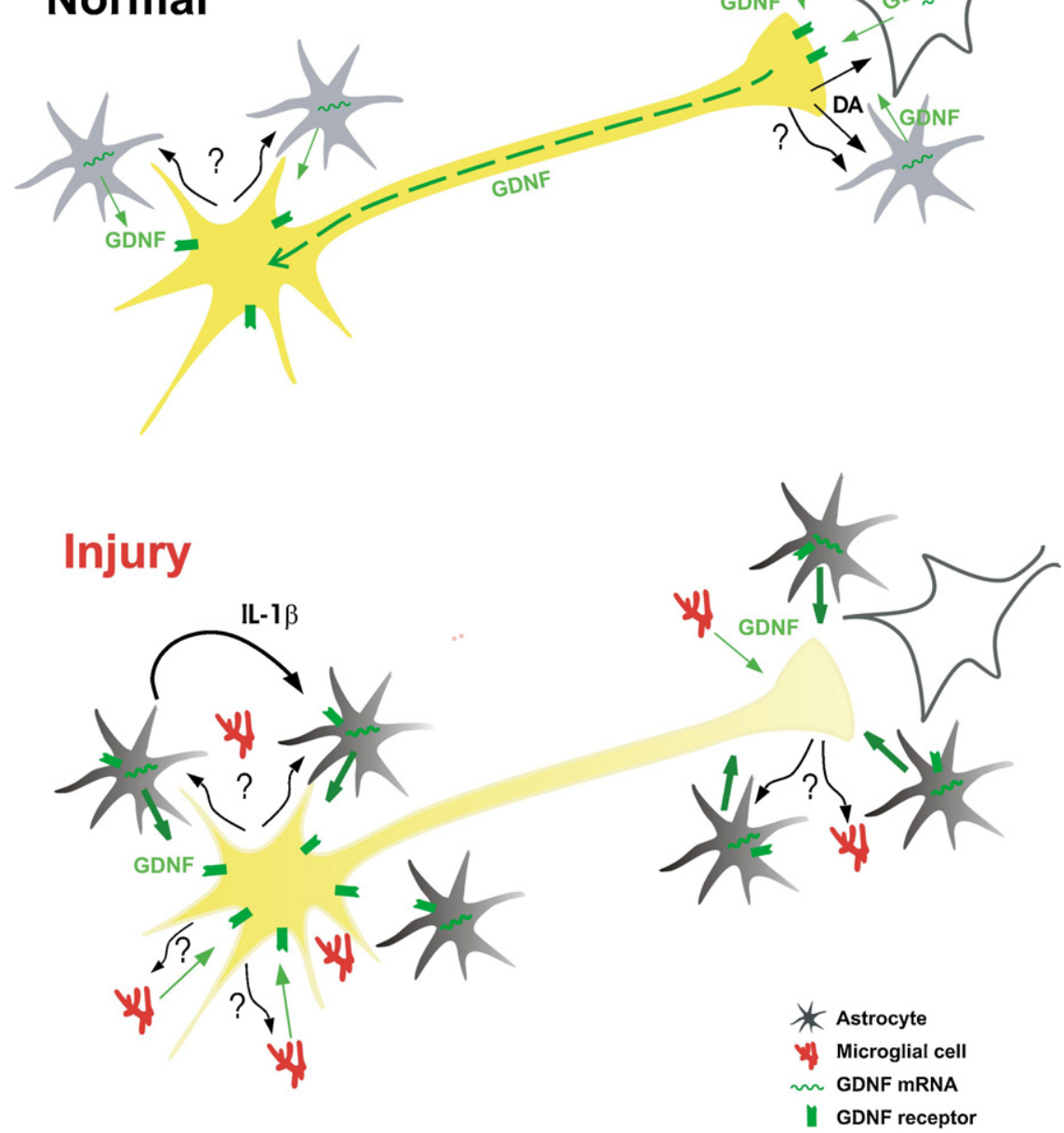

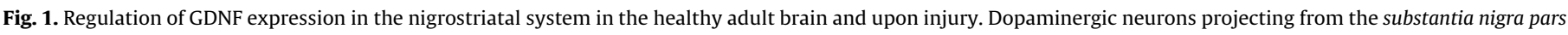

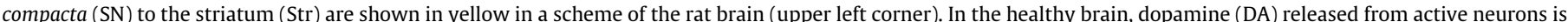

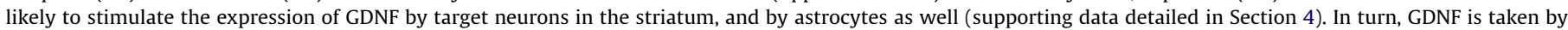

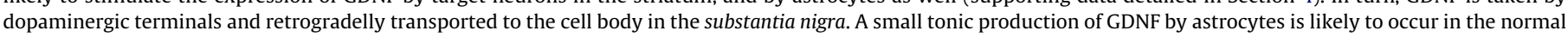

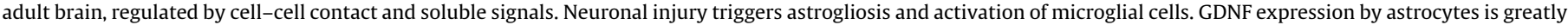

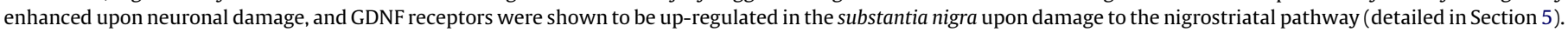
Interleukin-1 $\beta$ (IL-1 $\beta$ ), and other, still unidentified, soluble factors mediate GDNF up-regulation upon dopaminergic injury.

Upon dopaminergic lesion, the expression of GDNF induced by the afferent activity is lost. In this situation, dopamine receptor agonists, mimicking endogenous dopamine, promote neuroprotection through an increase in GDNF expression. Dopamine receptor agonists protect mouse striatal neurons against 6hydroxydopamine (6-OHDA) toxicity (Iida et al., 1999), and neuroblastoma SH-SY5Y cells and mesencephalic cultures from the toxicity of 1-methyl-4-phenylpyridinium $\left(\mathrm{MPP}^{+}\right)$, the active metabolite of MPTP (Presgraves et al., 2004). D2 agonists are also effective against the excitotoxicity evoked by glutamate agonists in mesencephalic neurons (Sawada et al., 1998b). Although other mechanisms have been proposed, such as the induction of antioxidant defences (Iida et al., 1999), the neuroprotection afforded by dopamine or dopamine receptor agonists has been associated with their ability to promote the expression of several neurotrophic factors. In fact, D3 receptor preferring agonists protect mesencephalic neurons against a $\mathrm{MPP}^{+}$lesion by increasing the secretion of both GDNF and BDNF (Du et al., 2005).

Serotonin (5-HT) is another monoamine shown to promote GDNF mRNA expression in rat C6 glioma cells. This increase involves transactivation of FGF receptors via 5-HT2 receptor (Tsuchioka et al., 2008).

Recent data show that adenosine is also able to promote GDNF transcription and increase GDNF release in primary cultures of rat astrocytes, through the activation of $A_{2 B}$ receptors (Yamagata et al., 2007). The adenosine-induced increase in the expression of neuroprotective molecules such as NGF (Ciccarelli et al., 1999) and GDNF probably represents a neuroprotective response since adenosine levels increase dramatically upon injury (Parkinson et al., 2002). 
In addition to dopamine, serotonin, or adenosine, other neurotransmitters control GDNF expression. Sub-seizure doses of the glutamate receptor agonists $N$-methyl-D-aspartate (NMDA) or kainate increase GDNF mRNA levels in the adult rat striatum, and similar findings come from striatal astrocyte cultures (Ho et al., 1995). Moreover, glutamate induces the expression of GDNF mRNA and the release of GDNF protein in a concentration-dependent manner in cultured rat astrocytes (Yamagata et al., 2002). Altogether, these results indicate that activation of glutamate receptors is able to modulate GDNF expression and suggest a role for GDNF in neuronal plasticity.

Furthermore, at excitotoxic concentrations, glutamate or glutamate receptor agonists might bring on the contribution of reactive astrocytes to the increase in GDNF expression. GDNF mRNA increases in the striatum of rats after pilocarpine-induced seizures (Schmidt-Kastner et al., 1994), whereas other studies show that GDNF mRNA is up-regulated in the hippocampus following kainate-induced seizures (Humpel et al., 1994; Trupp et al., 1997). The mRNA levels of GDNF receptors Ret and GFR $\alpha 1$ are also up-regulated in the hippocampus following kainate-induced seizures (Trupp et al., 1997; Reeben et al., 1998). In addition, an enhancement of GDNF mRNA in reactive astrocytes occurs upon administration of excitatory amino acids to the striatum (Bresjanac and Antauer, 2000; Marco et al., 2002), and these changes in GDNF mRNA levels can reflect an endogenous trophic response of striatal cells to the excitotoxic insult. In sum, these observations support a role for the activation of glutamate receptors in GDNF expression in response to excitotoxic injury.

\section{GDNF expression upon nigrostriatal injury: role of neuron- glia cross-talk}

Nervous tissue responds to injury up-regulating protective and repairing mechanisms (reviewed by Benn and Woolf, 2004). Damaged neurons change their own gene expression and stimulate nearby astrocytes and microglial cells to provide support. In the intact adult brain, GDNF expression is largely neuronal, as astroglial cells were not found to express detectable GDNF (Blum and Weickert, 1995; Pochon et al., 1997; Bizon et al., 1999; Bresjanac and Antauer, 2000). Upon injury, glial cells appear to become the predominant source of trophic substances. It should be noted that, besides GDNF (Bresjanac and Antauer, 2000; Nakagawa and Schwartz, 2004; Chen et al., 2006a), other trophic factors are up-regulated in the injured nigrostriatal system, namely, BDNF, FGF and NGF (Nakajima et al., 2001; Yurek and Fletcher-Turner, 2002; Nakagawa et al., 2005; Chen et al., 2006a). The neuronal expression of trophic factors associated with injury is a rapid and transient activity-dependent expression, whereas a delayed and more persistent injury-induced expression occurs in glial cells (Hughes et al., 1999).

The selective damage of nigrostriatal dopaminergic neurons in animal models of PD alters mRNA and/or GDNF protein levels, both in the striatum and in the substantia nigra (Fig. 1), although some contradictory findings exist. In the striatum, an increase in GDNF mRNA or protein levels has been observed after 6-OHDA-induced (Zhou et al., 2000; Nakajima et al., 2001; Yurek and FletcherTurner, 2001, 2002; Hida et al., 2003) or MPTP-induced injury (Tang et al., 1998). However, other authors have failed to detect changes in striatal GDNF levels after 6-OHDA lesion (Stromberg et al., 1993; Smith et al., 2003; Anastasia et al., 2007) or MPTP treatment (Inoue et al., 1999; Collier et al., 2005). These conflicting results might arise from differences in the injury models and protocols, or different time points analysed. In general, GDNF protein levels increase in the first 2-3 weeks after the 6-OHDA lesion and decrease thereafter, such that at 6 or 12 weeks, no up- regulation is detected, or decreased levels are observed (Nakajima et al., 2001; Yurek and Fletcher-Turner, 2002). Moreover, the neurotrophic response to injury depends on the age of the animals. In general, young animals show a greater capacity to up-regulate neurotrophic factors (Yurek and Fletcher-Turner, 2001; Collier et al., 2005).

Fewer studies focus on nigral GDNF expression after nigrostriatal lesions, yielding also conflicting results. Some studies found no changes in GDNF expression upon MPTP-induced (Inoue et al., 1999) or 6-OHDA-induced injury (Yurek and Fletcher-Turner, 2001 ). Later on, the same authors reported a transient increase in GDNF levels in the midbrain 3 days after lesion, whereas at 12 weeks a down-regulation was observed (Yurek and FletcherTurner, 2002). Decreased nigral GDNF protein levels were also reported 2 weeks after a 6-OHDA lesion (Anastasia et al., 2007). Gene expression profiles, obtained with cDNA microarrays, show GDNF up-regulation in the substantia nigra and striatum after MPTP intoxication (Grunblatt et al., 2001a; Mandel et al., 2002), and in striatal astrocytes from 6-OHDA lesioned rats (Nakagawa and Schwartz, 2004). We have shown that mild damage to dopaminergic neurons in neuron-glia cultures from substantia nigra, but not extensive damage, induces GDNF up-regulation in astrocytes (Saavedra et al., 2006). Since GDNF up-regulation is not observed in cultures previously treated with 6-OHDA, we propose that GDNF induction in astrocytes requires signalling from injured dopaminergic neurons that are still capable of signalling (Saavedra et al., 2006).

It is unknown whether the endogenous production of GDNF might be effective in protecting nigrostriatal dopaminergic neurons, and contribute to the very slow progression of PD. It should be noted that the data showing dopaminergic protection and repair in animal models of PD involved the delivery of exogenous GDNF, encapsulated GDNF producing cells, or the transduction of viral-encoded GDNF (e.g. Bilang-Bleuel et al., 1997; Gash et al., 2005; Sajadi et al., 2006).

It was proposed that changes in the levels of neurotrophic factors, due to alterations in the synthesis, release or activity, associated with ageing or genetic factors, might be involved in the neuronal loss observed in neurodegenerative diseases as PD (reviewed by Siegel and Chauhan, 2000; Mattson and Magnus, 2006). Post-mortem studies investigating GDNF distribution in the human parkinsonian brain have yielded conflicting results. In situ hybridization studies failed to detect GDNF mRNA in the human midbrain (Hunot et al., 1996), and no significant differences were found in GDNF content in the caudate-putamen and substantia nigra between PD and control samples (Mogi et al., 2001). Since the levels of other growth factors are decreased in PD brains, it was suggested that the unchanged levels of GDNF in PD might be due to compensatory production by glial cells (Mogi et al., 2001). However, using immunohistochemistry, large reductions in GDNF content are reported in surviving PD substantia nigra neurons (Chauhan et al., 2001). More recently, using real-time PCR, modest but significantly increased levels of a GDNF isoform were found in the putamen of PD patients with marked nigral neuronal loss (Backman et al., 2006). Whatever might be the endogenous changes of neurotrophic factors in PD, a therapy with GDNF might prevent the progression of the disease and restore function (Gill et al., 2003; Slevin et al., 2005).

Astrocytes are key elements in the brain response to injury. Activated astrocytes up-regulate antioxidant molecules, membrane transporters, and trophic factors that support neuronal and glial survival, and tissue repair (reviewed by Liberto et al., 2004). Recent reports suggest that astrocytes can be important targets for the development of neuroprotective drugs (Chen et al., 2005b; Darlington, 2005). Supporting this view, most of the works 
reviewed here about the regulation of GDNF expression were performed in astrocyte or glial cell line cultures and fewer studies used mesencephalic (Guo et al., 2001, 2002; Nitta et al., 2004) or hippocampal neuronal cultures (Lenhard et al., 2002; Nitta et al., 2004; Cen et al., 2006). Furthermore, as discussed later, astrocytic GDNF production has been proposed to explain the neuroprotective/therapeutic effects of several compounds, including apomorphine, selegiline, riluzole, anti-depressants, melatonin, or vitamin $\mathrm{D}_{3}$.

Microglia, the resident immune cells of the brain, proliferate and become immunocompetent, with the ability to secrete a number of cytotoxic and trophic molecules (reviewed by Block and Hong, 2005). Up-regulation of GDNF by astrocytes or microglial cells occurs in several injury models (Liberatore et al., 1997; Batchelor et al., 1999; Bresjanac and Antauer, 2000; Satake et al., 2000; Wei et al., 2000; Miyazaki et al., 2001; Ikeda et al., 2002; Marco et al., 2002; Hashimoto et al., 2005a). This switch in the production of GDNF from neurons to glial cells may provide a local mechanism to limit neuronal loss and promote regeneration. Therefore, it is important to understand the cross-talk among neurons, astrocytes, and microglia leading to glial GDNF expression after injury.

Although a great deal of evidence indicates that nigrostriatal injury may induce GDNF expression in both astrocytes and microglial cells, it is not completely understood how damaged neurons signal glia. Moreover, it is unclear whether similar or different mechanisms control GDNF expression in the striatum and in the substantia nigra, in physiological conditions and after injury. The intercellular signals involved in the communication between damaged neurons and glial cells are potential therapeutic targets aimed at up-regulating the endogenous expression of neurotrophic factors.

\subsection{Inflammatory signals and GDNF expression}

Pro-inflammatory molecules are among the candidate signals involved in the intercellular talk that induces glial GDNF expression after injury. Indeed, elevated GDNF expression is observed in response to lipopolysaccharide (LPS) and to the proinflammatory cytokines IL-1 $\beta$, IL-6, tumor necrosis factor (TNF)- $\alpha$ and TNF- $\beta$ in C6 cells (Appel et al., 1997; Verity et al., 1998) and in U-87MG glioblastoma cells (Verity et al., 1999). In cultured astrocytes both exogenous TNF- $\alpha$, via TNF receptors, and endogenously produced TNF- $\alpha$ induce GDNF expression, suggesting that an autocrine loop contributes to the production of neurotrophic factors in response to inflammation (Kuno et al., 2006). LPS also increases GDNF mRNA expression in rodent primary astrocyte cultures (Remy et al., 2003; Kuno et al., 2006) as well as GDNF secretion (McNaught and Jenner, 2000). However, both LPS and TNF- $\alpha$ trigger a significant decrease in the mRNA level of GFR $\alpha 1$ (Remy et al., 2003). In vivo, a high dose of LPS improves locomotor function after spinal cord injury in rats greater than a low dose, which is consistent with the expression of GDNF in microglia/macrophages (Hashimoto et al., 2005c). These results are in accordance with LPS-induced GDNF mRNA expression in microglial cultures (Tanaka et al., 2008). This suggests that repair of CNS injuries can occur through GDNF produced by activated microglia/macrophages. The stimulatory effect of TNF- $\alpha$, TNF- $\beta$, IL-1 $\beta$ and LPS seems to be restricted to glial cells since SK-N-AS neuroblastoma cells respond to these pro-inflammatory agents repressing GDNF release (Verity et al., 1999).

Having in mind evidences that the transcription factor nuclear factor- $\kappa \mathrm{B}(\mathrm{NF}-\kappa \mathrm{B})$ can regulate GDNF expression (Woodbury et al., 1998; Baecker et al., 1999; Tanaka et al., 2000), the effect of proinflammatory agents on GDNF expression is in agreement with the fact that IL-1 $\beta$, TNF- $\alpha$, and LPS activate NF- $\kappa B$ (Moynagh et al., 1993; Xie et al., 1994; Diehl et al., 1995). Moreover, NF-кB-DNA binding increases in U-87MG glioblastoma cells upon IL-1 $\beta$ treatment whereas dexamethasone significantly represses GDNF release (Verity et al., 1999). Furthermore, the putative NF-кB binding site of the GDNF gene effectively binds nuclear protein in the mouse astroglial cell line TGA-3 after IL-1 $\beta$ treatment (Tanaka et al., 2000). Taken together, these results suggest that NF- $\mathrm{B}$ activation is responsible for increased GDNF expression in response to IL-1 $\beta$. In contrast, results from microglia cultures show that LPS-induced GDNF expression is a Jun N-terminal kinase (JNK)-dependent but NF- $\kappa$ B-independent phemonenon (Tanaka et al., 2008).

Conflict might arise when comparing the positive impact of IL$1 \beta$ on GDNF levels in glial cell lines (Appel et al., 1997; Verity et al., $1998,1999)$, or in mouse astrocyte cell cultures prepared from neonatal cortices (Appel et al., 1997), with the lack of effect of IL-1 $\beta$ on GDNF expression in striatal astrocyte cultures or when injected intrastriatally in mice (Ho and Blum, 1997). In line with this, data from our group indicates that IL-1 $\beta$ is not involved in GDNF upregulation in striatal cultures exposed to conditioned medium from $\mathrm{H}_{2} \mathrm{O}_{2}$ - or L-DOPA-challenged substantia nigra neuron-glia cultures (unpublished results), whereas we have shown that IL-1 $\beta$ mediates GDNF up-regulation in substantia nigra cell cultures in response to $\mathrm{H}_{2} \mathrm{O}_{2}$ or L-DOPA (Saavedra et al., 2007). Altogether, the data suggests that regulation of GDNF expression can be different in different cell types and/or brain regions (Fig. 1).

In summary, there is evidence that inflammatory stimuli induce GDNF expression in astrocytes. The rapid appearance of cytokines after injury suggests that TNF- $\alpha$ and IL- $1 \beta$ may in part regulate injury-induced glial GDNF synthesis/release, providing neurotrophic support to GDNF-responsive neurons under inflammatory conditions in the CNS.

Considering signal molecules that can stimulate astrocytic GDNF production after injury, we should also mention endothelins (ETs). Brain ETs were proposed to be involved in responses to injury since altered expression of ETs in reactive astrocytes is observed in many pathological conditions (reviewed by Schinelli, 2006). ETs are suggested to play a role in functional changes in astrocytes after brain injury because activation of their ET receptors stimulates several astrocytic pathophysiological responses leading to 'reactive astrocytes' such as hypertrophy, proliferation, and production of neurotrophic substances (refer to Koyama et al., 2003a,b for references). A proteomic analysis also found that ET-1 induces changes of proteins involved in cytoskeletal reorganization, cell adhesion, signal transduction, and differentiation during reactive gliosis (Egnaczyk et al., 2003).

Treatment of rat cultured astrocytes with ET-1 increases GDNF mRNA levels and stimulates the release of GDNF (Koyama et al., 2003a). This occurs via $\mathrm{ET}_{\mathrm{B}}$ receptors since the effect is inhibited by an $\mathrm{ET}_{\mathrm{B}}$ receptor antagonist but not by an $\mathrm{ET}_{\mathrm{A}}$ receptor antagonist. Similar observations were done in vivo since intracerebroventricular (icv) administration of $\mathrm{Ala}^{1,3,11,15}$-ET-1, an $\mathrm{ET}_{\mathrm{B}}$ receptor agonist, for 7 days increases GDNF mRNA in the rat hippocampus while increasing BDNF level in the striatum (Koyama et al., 2003b). The Ala ${ }^{1,3,11,15}$-ET-1-induced increases in GDNF and BDNF mRNA levels are accompanied by increases in immunoreactive GDNF and BDNF. Increases in glial fibrillary acid protein- and vimentinpositive astrocytes are also observed in the same regions, but no neurodegeneration or activation of microglia/macrophages are registered suggesting that $\mathrm{Ala}^{1,3,11,15}$-ET-1 can activate astrocytes by itself. In cultured rat astrocytes, Ala ${ }^{1,3,11,15}$-ET-1 also increases GDNF as well as BDNF mRNA levels (Koyama et al., 2003b). These results suggest that activation of brain $\mathrm{ET}_{\mathrm{B}}$ receptors induces reactive astrocytes and triggers GDNF and BDNF expression. Therefore, the finding that ET-1/ET ${ }_{\mathrm{B}}$ activation increases GDNF 
expression suggests a role for ET-1 on astrocytic GDNF expression after brain injury.

\section{A healthy life style and GDNF expression}

\subsection{Caloric restriction: less food, more GDNF?}

It is well documented that caloric restriction and reduced meal frequency/intermittent fasting can protect against diabetes, cardiovascular disease and cancer, and increase life span in rodents. Although less is known about the influence of meal size and frequency on neurological disorders, some studies show that caloric restriction and intermittent fasting diets are neuroprotective and improve functional outcome in animal models of stroke, Parkinson's and Huntington's disease (reviewed by Mattson, 2005). Moreover, data from epidemiological studies suggest that individuals with low-calorie, low-fat diets may have reduced risk of PD (Logroscino et al., 1996).

The mechanisms involved in the beneficial effects of caloric restriction and reduced meal frequency/intermittent fasting on health and disease susceptibility are being uncovered. They are thought to be linked with beneficial responses to mild cellular stress. Those dietary manipulations may prolong the health span of the nervous system by acting upon important metabolic and cellular signalling pathways to stimulate the production of protein chaperones, antioxidant enzymes, and neurotrophic factors that help cells to deal with stress and resist disease (Martin et al., 2006).

Focusing on the role played by neurotrophic factors on the positive effect of caloric restriction and reduced meal frequency/ intermittent fasting, most studies have implicated BDNF (reviewed by Mattson, 2005). However, GDNF may also be coming into play. Dietary restriction in adult mice protects against the dysfunction and degeneration of nigrostriatal dopaminergic neurons induced by MPTP, and deficits in motor function decrease markedly in those animals (Duan and Mattson, 1999). When a non-metabolizable analogue of glucose (2-deoxy-D-glucose) is administered ad libitum to mice to mimic dietary restriction, a reduction of damage to dopaminergic neurons in the substantia nigra and improved behavioural outcome following MPTP treatment are observed. Moreover, treatment with 2-deoxy-D-glucose protects cultured dopaminergic cells against oxidative and metabolic insults relevant to the pathogenesis of PD (Duan and Mattson, 1999). Although this study did not address GDNF levels, more recent observations raise the hypothesis that increased GDNF levels upon dietary restriction might also contribute to the protection of dopaminergic neurons observed in this model. This hypothesis arises from recent observations. A low-calorie diet reduces the loss of dopaminergic neurons from the substantia nigra, the severity of neurochemical deficits, and motor dysfunction in a non-human primate model of PD (Maswood et al., 2004). Furthermore, monkeys maintained for 6 months on a $30 \%$ caloric restriction diet exhibit significantly higher levels of GDNF in the caudate nucleus compared with control monkeys, suggesting that the protective effect of reduced calorie diet may result from up-regulation of GDNF expression and consequent activation of neuroprotective signal transduction pathways in dopaminergic neurons (Maswood et al., 2004). Since a caloric restriction diet increases the amount of endogenous GDNF in the brain of monkeys, it suggests that it may be possible to ameliorate PD, at least partially, through dietary manipulations. It should also be stressed that, likely due to, and consistent with the observation that caloric restriction attenuates MPTP-induced depletion of dopamine, the distance moved and speed of movement increased more than 2-fold in caloric restricted monkeys compared with those on control diet (Maswood et al., 2004). Based on an evolutionary perspective, and on experimental data, it was speculated that the neuroprotective effects of caloric restriction could be due to the induction of growth factors by increased motor activity (Finch, 2004). In fact, activation of the same cellular and molecular pathways that occur in response to mild dietary restriction and intermittent fasting-induced stress can occur in response to physical exercise and cognitive stimulation (Mattson et al., 2004). Therefore, the impact of physical exercise and cognitive stimulation on GDNF expression will be discussed next.

\subsection{Physical exercise and GDNF expression in the nigrostriatal system}

Among environmental factors that up-regulate the expression of GDNF, and might therefore protect against PD, are physical exercise and environmental enrichment. In fact, enriched environmental conditions and increased physical activity are neuroprotective in models of nigrostriatal system injury (Bezard et al., 2003b; Faherty et al., 2005; Steiner et al., 2006; Jadavji et al., 2006; Yoon et al., 2007).

Physical exercise increases the expression of GDNF in the nigrostriatal system (Cohen et al., 2003; Faherty et al., 2005). Unilateral cast of a limb in rats, which forces the animal to rely on the use of the contralateral limb, significantly increased GDNF protein levels in the striatum contralateral to the overused limb, but not in the ipsilateral striatum (Cohen et al., 2003), suggesting that striatal activity up-regulates GDNF. The increase in GDNF levels was transient, reaching a maximum at 3 days after casting, and returning to normal levels despite continued forced limb use.

Exercise-induced expression of GDNF was correlated with the protection of dopaminergic neurons against MPTP toxicity (Faherty et al., 2005), and the prevention of motor impairment due to a 6-OHDA lesion (Cohen et al., 2003). Sparing of dopaminergic neurons from toxin action, assessed by measuring dopamine, its metabolites and transporters in the striatum, or THpositive cells in the substantia nigra, strongly supports a neuroprotective role for physical exercise. These studies raised the hypothesis (Smith and Zigmond, 2003) that up-regulation of GDNF might mediate, or at least contribute to, the protection of the nigrostriatal pathway, and the improvement of motor function observed in many studies of forced limb use or running-wheel exercise in both the 6-OHDA (Mabandla et al., 2004; Tillerson et al., 2001, 2003) and the MPTP (Fisher et al., 2004; Tillerson et al., 2003) models of PD. However, exercise of the affected limb is protective only when initiated in a time window after toxic injury. Complete behavioural and neurochemical sparing is achieved when exercise of the affected limb begins immediately after the lesion, whereas no sparing occurs when exercise begins 7 days after 6-OHDA lesion (Tillerson et al., 2001). Furthermore, the data from animal models might parallel observations of beneficial effects of exercise on motor and non-motor symptoms in PD patients (Lehman et al., 2005; reviewed by Gage and Storey, 2004; Logroscino et al., 2006). In addition, epidemiological studies show a negative correlation between the regular practice of exercise and the prevalence of PD in humans, at least in males (Tsai et al., 2002; Chen et al., 2005a). Thus, exercise might constitute a neuroprotective therapy for PD contributing to slow the progressive degeneration of dopaminergic neurons. However, few studies examined GDNF expression upon exercise in healthy animals (Cohen et al., 2003; Faherty et al., 2005), and only one reports the effect of exercise on GDNF expression in lesioned animals that might underlie sparing of dopaminergic neurons, sprouting and regeneration of the remaining terminals, and improved behaviour (Faherty et al., 2005).

Animals exercised on the running-wheel prior or after a unilateral striatal 6-OHDA lesion, showed a faster motor recovery compared to non-exercised animals. However, exercise had no significant effects on the density of striatal dopamine transporters or on the number of 
TH-positive cells in the substantia nigra (O'Dell et al., 2007). The authors argued that the exercise-induced enhancement of motor recovery in PD models might not be a consequence of the protection or rescue of dopaminergic neurons. It was proposed that exerciseinduced facilitation of motor recovery may occur due to increased dopaminergic transmission at dopaminergic synapses, or to adaptations at other sites within the basal ganglia circuitry (O'Dell et al., 2007) that occur upon changes in dopaminergic synapses (Bezard et al., 2003a). Nevertheless, the report by O'Dell et al. is compatible with the idea that exercise protects dopaminergic neurons from injury. While most studies were carried out with lesions causing an extensive dopaminergic lost (Cohen et al., 2003; Faherty et al., 2005; Tillerson et al., 2001, 2003), O’Dell et al. (2007) used low doses of 6-OHDA to induce a small graded lesion of dopaminergic terminals aimed at mimicking the progressive degeneration at the onset of PD symptoms in patients. In their model, spontaneous recovery occurred after the 6-OHDA lesion, even in the non-exercised animals, but exercise in the running-wheel markedly accelerated the process.

On the other hand, the increase in dopaminergic transmission, proposed to underlie the exercise-induced facilitation of motor behaviour, might also involve GDNF. GDNF was shown to enhance dopamine biosynthesis due to phosphorylation and increased activity of TH (Kobori et al., 2004; Salvatore et al., 2004), and increased activation of the enzyme producing BH4 (5,6,7,8tetrahydrobiopterin), a cofactor for TH (Bauer et al., 2002). This enhancement of dopamine synthesis likely leads to an increase in quantal release as observed in postnatal dopaminergic neurons in culture (Pothos et al., 1998). Furthermore, GDNF increases dopamine release owing to the enhancement of the excitability of midbrain dopaminergic neurons, which is associated with the inhibition of A-type $\mathrm{K}^{+}$channels (Yang et al., 2001), and potentiates the activation of $\mathrm{Ca}^{2+}$ channels and excitatory transmission in midbrain neurons (Wang et al., 2003).

The neuroprotective effects of exercise on the nigrostriatal system might also be due to other neurotrophic factors, which are known to be up-regulated by exercise and to ameliorate damage in other brain areas, as BDNF and FGF-2 in the hippocampus (Neeper et al., 1995; Gomez-Pinilla et al., 1997; Cotman and Berchtold, 2002). In addition, peripheral factors increased by exercise and capable of crossing the blood-brain barrier, like insulin growth factor-1 (Carro and Torres-Aleman, 2006) or $\mathrm{Ca}^{2+}$ (Sutoo and Akiyama, 2003), might contribute to exercise-induced neuroprotection and/or function improvement. For instance, increases in brain $\mathrm{Ca}^{2+}$, subsequent to the peripheral increase due to exercise, increase dopamine levels in the striatum (Sutoo and Akiyama, 2003). In addition, exercise increases anti-inflammatory molecules in the plasma that might alleviate conditions contributing to dopaminergic damage (Cadet et al., 2003).

In conclusion, although the beneficial effects of exercise on the preservation or recovery of nigrostriatal-dependent motor functions are unquestionable, both in animal models and in PD patients, the mechanisms and the neuronal circuitry involved are not yet completely understood. How does exercise increases GDNF expression? This issue was not addressed directly. However, since GDNF production is activity dependent, dopamine is known to stimulate GDNF expression, and exercise was shown to increase dopamine in the striatum (Sutoo and Akiyama, 2003), one may envisage that increased dopamine receptor binding during activity of striatal circuitry may mediate GDNF expression.

\subsection{Environmental enrichment and GDNF expression}

Environmental enrichment (a combination of increased social interaction, learning, and exercise) increases GDNF mRNA in the substantia nigra and in the striatum and totally protects against MPTP-induced parkinsonism (Faherty et al., 2005). Moreover, adult mice raised in an enriched environment for only 2 months are significantly more resistant to MPTP compared with mice raised in a standard environment since they show only a $40 \%$ dopaminergic cell loss after MPTP treatment, in contrast to the $75 \%$ loss observed in mice raised in a standard environment (Bezard et al., 2003b). In addition, enriched environment increases the expression of BDNF in the striatum (Bezard et al., 2003b), but the effect of enriched environment on the levels of GDNF was not addressed in this study. Previously, an enriched environment was shown to induce the expression of GDNF and to increase the phosphorylation of the transcription factor cAMP response element binding protein (CREB), while reducing the spontaneous apoptosis in the rat hippocampus by $45 \%$, and protecting against kainate-induced seizures and excitotoxic injury (Young et al., 1999). These results support that a stimulating environment has a positive impact on brain health, and are consistent with clinical evidence showing an association between higher educational accomplishment and reduced risk of PD-related dementia (Glatt et al., 1996).

Growing evidence show the possibility of reducing the risk for age-related neurodegenerative disorders through dietary and behavioural changes inducing neuronal plasticity and survival. One can conclude that dietary manipulations, physical exercise and cognitive stimulation, which might induce GDNF up-regulation, represent novel drug-free approaches for disease prevention and treatment.

\section{Pharmacological agents to boost GDNF expression}

It is interesting to notice that many pharmacological agents that have proven useful in the symptomatic treatment of PD are increasingly recognized as modulators of GDNF expression, as well of other neurotrophic factors, raising the possibility that their beneficial effects are also mediated by the induction of trophic factors and subsequent protection/rescuing of dopaminergic neurons. In this section, we will focus on the effect on GDNF expression of drugs already used or with potential interest to treat $\mathrm{PD}$ and other neurodegenerative diseases or neurological disorders.

\subsection{Agents that increase dopaminergic transmission}

As mentioned in Section 4, dopaminergic activity is able to promote GDNF expression. Since the main characteristic of PD is the striatal dopamine deficit, most therapeutic approaches involve the stimulation of dopaminergic transmission, either by using the dopamine precursor L-DOPA, dopamine receptor agonists, or dopamine uptake and dopamine metabolism inhibitors (Fig. 2). Therefore, it is not surprising that these agents induce GDNF expression in the nigrostriatal system.

\subsubsection{Dopamine agonists}

Several dopamine agonists are used in the management of PD as replacement for the endogenous dopamine. Apomorphine, a D1/D2 dopamine receptor agonist, is currently used as an anti-parkinsonian drug (reviewed by Subramony, 2006). Administration of apomorphine to patients reduces the need for other antiparkinsonian medication, induces a significant reduction in dyskinesias and a marked improvement in the quality of life (Manson et al., 2001). Besides the increase in dopaminergic transmission, the beneficial effects of this agonist on PD patients might involve neuroprotection through a wide range of mechanisms in addition to its antioxidant actions (reviewed by Kyriazis, 


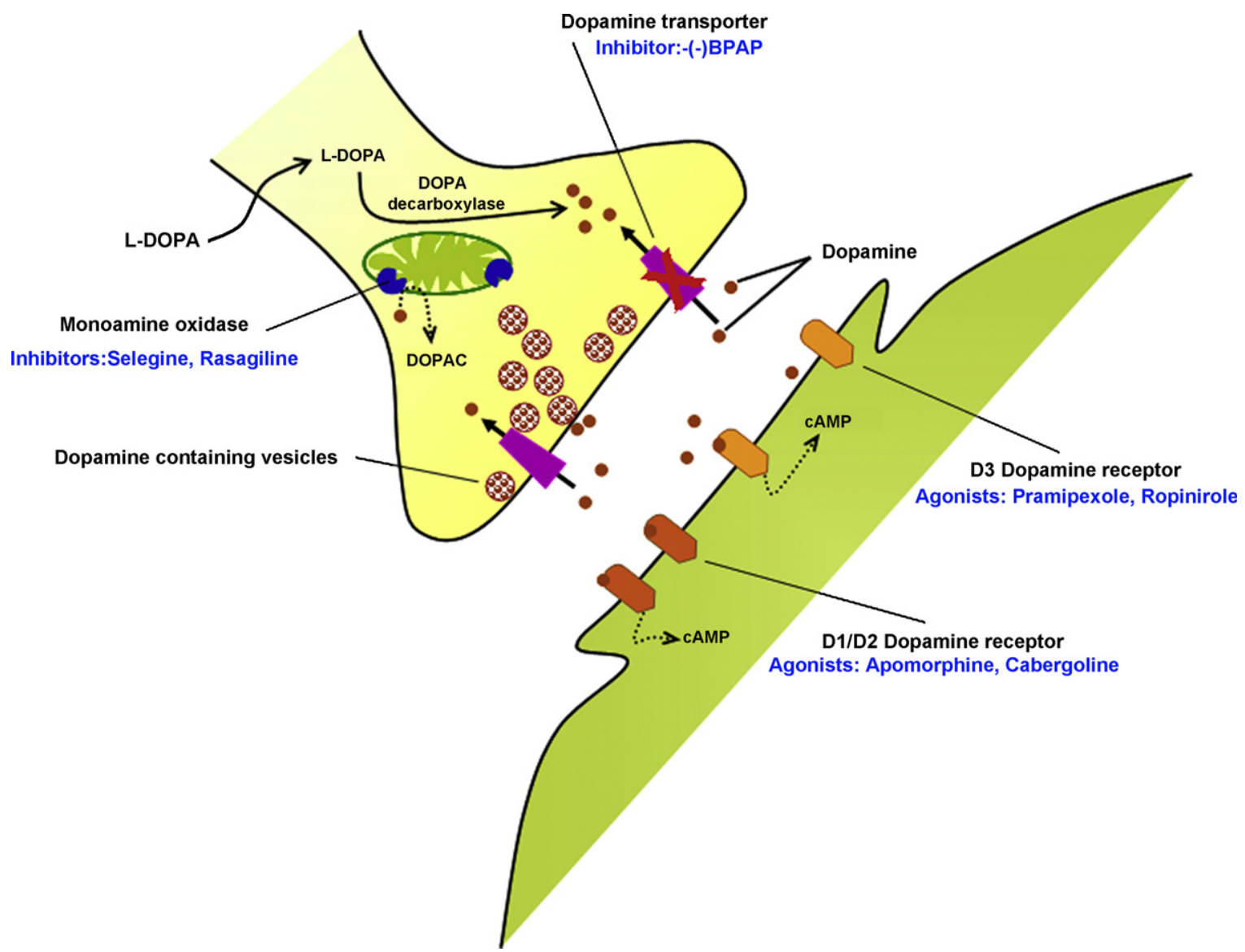

Fig. 2. Schematic overview of pathways leading to an increase in dopaminergic transmission and their regulation by agents known to increase GDNF expression.

2003). Apomorphine up-regulates the expression of several neurotrophic factors, including GDNF. It increases GDNF mRNA levels and the amount of GDNF protein in the culture medium from mouse astrocytes (Ohta et al., 2000; Shimazu et al., 2003a) and mesencephalic cells (Guo et al., 2002). Furthermore, apomorphine stimulates the synthesis and release of GDNF and BDNF in striatal cultures, and effectively prevents dopaminergic neuron loss in vitro (Guo et al., 2002). These neurotrophic effects might contribute to the reported effects of apomorphine against MPTP-induced striatal dopaminergic neurodegeneration in mice (Grunblatt et al., 2001b) and provide another potential mechanism for the anti-parkinsonian action of this drug in PD patients.

Besides the increase in GDNF and BDNF levels, treatment with apomorphine also increases FGF-2 expression in striatal astrocytes, both at the mRNA and protein level, an effect correlated with the activation of D1 and D2 receptors (Li et al., 2006a). FGF-2 exerts a potent neuroprotective action on nigral dopaminergic neurons in the MPTP mouse model of PD (Otto and Unsicker, 1990, 1993; Chadi et al., 1993). FGF-2 also increases dopaminergic graft survival and function in a rat model of PD (Takayama et al., 1995). Moreover, fibroblasts genetically engineered to produce FGF-2 and implanted into the striatum attenuate the damage caused by intrastriatal injection of 6-OHDA (Shults et al., 2000). More recently, FGF-2 was reported to protect against rotenone-induced cell death in both SH-SY5Y cells and cultured dopaminergic neurons (Hsuan et al., 2006).

The neuroprotective properties of FGF-2 might be related, at least partially, to the effect of FGF-2 on GDNF expression. Indeed, FGF family members increase GDNF mRNA expression and release in C6 glioma cells (Suter-Crazzolara and Unsicker, 1996; Verity et al., 1998) and in U-87MG glioblastoma cells (Verity et al., 1999). In addition, FGF- 2 up-regulates GDNF and GFR $\alpha 1$ expression in hippocampal neurons (Lenhard et al., 2002). FGF-2 enhances the activity of the GDNF promoter (Grimm et al., 1998). The enhancement of GDNF expression by FGF-2 can occur through a consensus cAMP response element (CRE) sequence present within the GDNF promoter (Woodbury et al., 1998; Baecker et al., 1999) since FGF-dependent gene activation requires CRE-2 (Tan et al., 1994), and FGF activates a CREB kinase (Tan et al., 1996).

Another dopamine agonist, cabergoline (a D2/weak D1 agonist), has been used as adjunctive therapy with L-DOPA and as de novo treatment for PD patients. Repeated administration of cabergoline to mice attenuates both 6-OHDA-induced nigrostriatal dopaminergic dysfunction and dopaminergic cell death (Yoshioka et al., 2002). The neuroprotection provided by cabergoline relies on the activation of the glutathione system in vivo and scavenging of free radicals in vitro (Yoshida et al., 2002). More recently, another mechanism possibly contributing to the neuroprotective action of cabergoline has been added to the list: cabergoline potently stimulates GDNF synthesis and secretion in primary cultures of mouse astrocytes (Ohta et al., 2004). Cabergoline-induced GDNF increases are significantly blocked by the selective dopamine D2 antagonist sulpiride (Ohta et al., 2004) indicating the involvement of dopamine receptors.

The D3-preferring receptor agonists pramipexole and ropinirole, widely used in clinical practice to treat PD patients, also show putative neurotrophic properties with promising retardation effects on disease progression (Clarke and Guttman, 2002; Parkinson Study Group, 2002b; Barone, 2003; Whone et al., 2003). Pramipexole and ropinirole possess neuroprotective properties, both in vitro 
(Presgraves et al., 2004; Du et al., 2005) and in vivo (Rascol et al., 2000; Parkinson Study Group, 2002b). Incubation of mesencephalic cultures with pramipexole and ropinirole, or with conditioned medium from pramipexole- and ropinirole-treated mesencephalic cultures or substantia nigra astroglia increases the number of dopaminergic neurons in culture (Du et al., 2005). The levels of GDNF and BDNF in the conditioned medium of mesencephalic cultures treated with the D3 dopamine receptor agonists are significantly increased. The observation that GDNF and BDNF neutralizing antibodies greatly reduce the neurotrophic effects of pramipexole and ropinirole(Du et al., 2005) suggest that these dopamine receptor agonists exert neurotrophic effects on cultured dopaminergic neurons by modulating the production of endogenous GDNF and BDNF.

In conclusion, the effects of dopamine receptor agonists both in cell cultures and in animal models of PD show that dopamine receptors present in neurons and astrocytes might control GDNF expression. These receptors may ensure the activity-dependent expression of GDNF and fulfil a maintenance role in dopaminergic circuits.

\subsection{2. $L-D O P A$}

L-DOPA remains the drug of choice in the symptomatic treatment of PD, and GDNF has proven to be a potent factor for the protection of nigral dopaminergic neurons against toxininduced degeneration in vivo. However, in contrast to the effect of dopamine agonists on GDNF expression, the effect of L-DOPA on GDNF levels in the nigrostriatal system has not been extensively addressed. Many in vitro studies showed toxic effects of L-DOPA on midbrain dopaminergic neurons but its toxicity has not been proven in vivo (reviewed by Olanow et al., 2004). In fact, trophic effects of L-DOPA were observed on dopaminergic neurons cocultured with astrocytes (Mena et al., 1997) but, to our knowledge, our group is the only describing the effect of L-DOPA on GDNF levels in the nigrostriatal system. We have shown that LDOPA induces GDNF up-regulation at the mRNA and protein levels in substantia nigra neuron-glia cell cultures, in a process involving soluble mediators that signal astrocytes to increase GDNF expression (Saavedra et al., 2006). We have also addressed the effect of L-DOPA treatment on GDNF levels in the 6-OHDA rat model of PD. Our preliminary data indicate that L-DOPA increases GDNF levels in the striatum (1-day treatment) and in the substantia nigra (5-day treatment) of 6-OHDA-lesioned animals (unpublished results). Results from the recent ELLDOPA clinical trial support the concept that L-DOPA may slow down the progression of PD (Fahn, 2005). It is therefore tempting to relate this neuroprotective effect with our observation that L-DOPA increases GDNF levels.

\subsubsection{MAO inhibitors}

(-)-Deprenyl (selegiline), developed as the first selective inhibitor of monoamine oxidase type-B (MAO-B) in the early $60 \mathrm{~s}$, is widely used for the symptomatic treatment of PD in combination with L-DOPA to inhibit dopamine catabolism (Larsen and Boas, 1997; Przuntek et al., 1999). It has been considered a promising candidate drug for neuroprotective therapy in earlystage PD (Schapira and Olanow, 2004).

Selegiline protects dopaminergic neurons in the MPTP/MPP ${ }^{+}$ model of PD (Cohen et al., 1984; Heikkila et al., 1984; Mytilineou and Cohen, 1985; Tatton and Greenwood, 1991; Koutsilieri et al., 1994). This neuroprotective effect might be related to the induction or potentiation of antioxidant enzymes (Carrillo et al., 1991; Thiffault et al., 1995; Nakaso et al., 2006; Takahata et al., 2006) or anti-apoptotic molecules (Tatton et al., 1996). The neuroprotective effects of selegiline might also involve its ability to up-regulate neurotrophic factor synthesis, including that of GDNF.
Selegiline increases the content of GDNF in the culture medium from mouse astrocytes in a MAO-B-independent manner, as a concentration of selegiline that completely inhibits MAO activity has no effect on the content of neurotrophic factors (Mizuta et al., 2000). In addition, desmethylselegiline, a selegiline metabolite, also elevates GDNF mRNA and protein levels (Mizuta et al., 2000). Intrastriatal injections of selegiline significantly enhance GDNF mRNA expression in rats, whereas the same concentrations of selegiline do not affect MAO-B activity (Tang et al., 1998). Therefore, the effect of selegiline on GDNF expression seems to be independent of its effect on MAO activity but is not clear whether it involves the enhancement of the impulse mediated release of catecholamines, the so called "catecholaminergic activity enhancement" (CAE; Knoll, 1998).

Another MAO-B inhibitor, rasagiline ( $N$-propargyl-( $1 R)$-aminoindan), is used as monotherapy in PD and as adjunctive therapy for patients receiving L-DOPA (Rabey et al., 2000; Parkinson Study Group, 2002a). Rasagiline may slow the rate of progression of PD (Siderowf and Stern, 2006) and displays neuroprotective activity in in vivo models of neurodegenerative diseases (reviewed by Youdim et al., 2005). Several mechanisms have been proposed to explain its neuroprotective action (Mandel et al., 2005). Chronic low doses of rasagiline administered to mice subsequently to MPTP rescue dopaminergic neurons in the substantia nigra pars compacta via activation of the Ras-PI3K-Akt survival pathway, suggesting that rasagiline may possess disease-modifying activity (Sagi et al., 2007). A possible disease-modifying activity of rasagiline is also suggested by clinical trials with early PD patients (Parkinson Study Group, 2004).

Rasagiline increases the mRNA and protein levels of GDNF in SH-SY5Y neuroblastoma cells through the activation of NF- $\kappa B$ (Maruyama et al., 2004). Rasagiline promotes neuronal survival via the neuroprotective activity related to its propargyl moiety, propargylamine, which elevates the gene expression levels of GDNF and BDNF, and markedly reverses the apoptotic effects induced by long-term serum withdrawal in SH-SY5Y neuroblastoma cells. In addition, it up-regulates the anti-apoptotic protein Bcl-2, while down-regulating the pro-apoptotic proteins Bax, Bad and Bim (Bar-Am et al., 2005).

\subsubsection{Dopamine uptake inhibitor (-)-BPAP}

[R-(-)-1-(benzofuran-2-yl)-2-propylaminopentane] ((-)BPAP) was shown to inhibit catecholamine uptake (Shimazu et al., 2003b) and has been considered a promising candidate drug for the symptomatic treatment of PD because it enhances the impulse-evoked release of catecholamines from isolated brainstem, and reverses motor deficits in an acute animal model of PD (Knoll et al., 1999; Shimazu et al., 2001). In addition to its catecholaminergic and serotoninergic activity enhancer effect, (-)BPAP might act as a neuroprotective agent since it up-regulates neurotrophic factor synthesis. (-)-BPAP is able to increase both the mRNA level and the amount of GDNF, NGF, and BDNF secreted to the culture medium by mouse astrocytes (Ohta et al., 2002; Shimazu et al., 2003a).

\subsection{Glutamate antagonists}

Glutamate receptors play crucial roles in the motor circuitry of the basal ganglia. The abundance, structure, and function of striatal NMDA receptors are altered by dopamine depletion, and further modified by the pharmacological treatments used in PD (reviewed by Hallett and Standaert, 2004). In animal models, NMDA receptor antagonists are effective anti-parkinsonian agents and can reduce the motor complications induced by chronic dopaminergic therapy (reviewed by Hallett and Standaert, 2004). NMDA receptor 
antagonists have the ability to increase dopaminergic transmission and attenuate the dopamine/glutamate imbalance (Lannes and Micheletti, 1997; Page et al., 2000; Peeters et al., 2002). In addition to ameliorating PD symptoms, several glutamate antagonists have shown neuroprotective effects in the nigrostriatal system.

Amantadine (1-aminoadamantane) is a NMDA receptor antagonist that has been used for the management of PD and, together with its more potent congener memantine, displays neuroprotective properties in a large number of in vitro and in vivo models (reviewed by Kornhuber et al., 1994; Parsons et al., 1999). In addition to their activity as NMDA receptor antagonists, the stimulation of GDNF expression can also contribute to their influence on neuronal survival and protection. Both amantadine and memantine concentration dependently increase GDNF level in the culture medium from C6 glioma cells with similar potency and efficacy (Caumont et al., 2006a). Since the range of concentrations that induce GDNF release from C6 cells are close to the clinically relevant steady-state plasma concentrations in patients treated with amantadine and memantine, these results show that the neuroprotective effect of these drugs may be related to their ability to stimulate GDNF production by glial cells (Caumont et al., 2006a).

Ifenprodil, originally developed as an effective cerebral vasodilator, was later reported to act as an NR2B-selective NMDA receptor antagonist (reviewed by Williams, 2001). Along this line, ifenprodil has been documented to elicit anti-parkinsonian effects in animal models of PD (Mitchell et al., 1995; Nash et al., 1999, 2000) comparable to those observed with L-DOPA therapy (Nash et al., 2000). Ifenprodil can also exert neuroprotective and/or neurorestorative effects because it strongly enhances the production of GDNF, BDNF and NGF in mouse astrocyte cultures, both at the mRNA and protein level (Toyomoto et al., 2005).

Riluzole (2-amino-6-trifluoromethoxy benzothiazole), a $\mathrm{Na}^{+}$ channel blocker reported to be an antagonist of the excitatory amino acid neurotransmission (Mizoule et al., 1985), is currently used in the therapy of patients with amyotrophic lateral sclerosis (Jackson et al., 2002). Riluzole alleviates the circling behaviour in 6-OHDA-treated rats and decreases the suppression of striatal and nigral dopamine metabolism (Barneoud et al., 1996). Riluzole also delays the appearance of parkinsonian motor abnormalities in a chronic monkey model of MPTP toxicity (Bezard et al., 1998), and exerts neuroprotective and palliative effects on an acute model in the same species (Benazzouz et al., 1995). In mice, riluzole antagonizes the MPTP-induced decrease in dopamine, dihydroxyphenylacetic acid (DOPAC) and homovanillic acid (HVA) levels in the striatum and, by immunohistochemistry, riluzole was shown to protect against MPTP-induced neuronal damage in the substantia nigra (Araki et al., 2001). Since MK-801 treatment prevents the MPTP-induced decrease in DOPAC levels, but not in dopamine levels in the striatum (Araki et al., 2001), the inhibition of NMDA receptors is not the only neuroprotective action of riluzole against MPTP-induced striatal dopamine and DOPAC depletion in mice. Indeed, some studies suggest that riluzole may have direct antioxidant actions in cultured neurons (Koh et al., 1999; Storch et al., 2000). In addition, riluzole might exert neuroprotective effects, at least partially, via the induction of neurotrophic factors as it stimulates the synthesis and release of the neurotrophic factors GDNF, NGF and BDNF in cultured mouse astrocytes (Mizuta et al., 2001), and significantly increases GDNF mRNA and protein levels in C6 glioma cells (Caumont et al., 2006b). This suggests that the regulation of GDNF transcription in glial cells can contribute to the pharmacological properties of riluzole and possibly to its neuroprotective effects on PD animal models. The effects of riluzole on GDNF expression are inhibited by PD98059, an inhibitor of the mitogen-activated protein kinase (MAPK) kinase (also known as MAPK/ERK - extracellular signal regulated kinase - kinase or MEK). Interestingly, other works show the pharmacological induction of GDNF expression and release in glial cells through a MAPK/ERK kinase-dependent pathway (Hisaoka et al., 2001, 2004; Koyama et al., 2003a), as detailed below.

\subsection{Anti-depressants, anti-psychotics and mood stabilizers}

GDNF levels may be altered by anti-depressants (Hisaoka et al., 2001), anti-psychotics (Shao et al., 2006) and mood stabilizers (Angelucci et al., 2003; Castro et al., 2005). It has been hypothesized that these drugs might exert their beneficial action by regulating the synthesis and/or release of neurotrophic factors (Angelucci et al., 2003; Saarelainen et al., 2003; Hashimoto et al., 2004). Anti-depressants significantly increase GDNF mRNA expression and GDNF release in a time- and concentrationdependent manner in C6 cells, and amitriptyline treatment also increases GDNF mRNA expression in rat astrocytes (Hisaoka et al., 2001). Fluoxetine (Prozac) also increases GDNF mRNA expression in cultured rat astrocytes, an effect prevented by ERK inhibitors (Mercier et al., 2004).

In addition, GDNF release increases after exposure to amitriptyline, clomipramine, mianserin, fluoxetine, and paroxetine, but not after treatment with the non-anti-depressant psychotropic drugs haloperidol, diazepam, and diphenhydramine (Hisaoka et al., 2001). Although 5-HT, but not noradrenaline or dopamine, increases ERK activation and GDNF release via 5-HT2A receptors, ketanserin, a 5-HT2A receptor antagonist, has no effect on amitriptyline-induced ERK activation (Hisaoka et al., 2004, 2007) suggesting that GDNF production induced by amitriptyline is independent of monoamine signalling. Moreover, treatment with amitriptyline rapidly increases ERK activity, as well as p38 MAPK and JNK activities. Both the amitriptyline-induced ERK activation and GDNF mRNA expression are blocked by genistein, a general protein tyrosine kinase inhibitor (Hisaoka et al., 2007). In addition, acute amitriptyline treatment increases the phosphorylation of CREB in C6 cells as well as in human astrocytes, but not in SH-SY5Y neuroblastoma cells (Hisaoka et al., 2008). These findings indicate that ERK activation through protein tyrosine kinase regulates anti-depressant-induced GDNF production, and that the GDNF production in glial cells may be a novel action of this antidepressant drug, independent of monoamine signalling (Hisaoka et al., 2007).

The atypical anti-psychotic drugs quetiapine and clozapine, as well as the typical anti-psychotic haloperidol, increase the amount of GDNF secreted from C6 glioma cells into the medium, after $48 \mathrm{~h}$ incubation, without inducing changes in the intracellular content of GDNF (Shao et al., 2006). These effects are observed at drug concentrations starting at $10 \mu \mathrm{mol} / \mathrm{L}$ and, in agreement with the findings by Hisaoka et al. (2001), haloperidol at a concentration of $1 \mu \mathrm{mol} / \mathrm{L}$ does not cause a significant increase in GDNF secretion (Shao et al., 2006).

Chronic treatment with lithium, probably the most effective mood stabilizer, increases GDNF concentrations in the cortex, but a decrease was found in the hippocampus of the Flinders Resistant Line (Angelucci et al., 2003). In contrast, Fukumoto et al. (2001) found no significant effects of lithium on GDNF levels.

Valproic acid (VPA) is a mood stabilizer and an anti-epileptic drug (Perucca, 2002), and increasing evidence demonstrate that VPA has neurotrophic effects in diverse cell types including midbrain dopaminergic neurons. Chronic VPA administration for 14 days increases the expression of BDNF protein in the rat brain but no changes were observed in the expression of GDNF following VPA treatment (Fukumoto et al., 2001). In contrast, Castro et al. (2005) reported significant concentration-dependent increases in 
GDNF mRNA expression in C6 cells after treatment with VPA for $48 \mathrm{~h}$, but not for $24 \mathrm{~h}$. These discrepancies can be due to different time-courses for the induction of the two neurotrophic factors or to differences in the models used (Castro et al., 2005). Moreover, VPA pre-treatment protects midbrain dopaminergic neurons against LPS- or MPP ${ }^{+}$-induced toxicity (Chen et al., 2006b). VPA-induced survival of midbrain dopaminergic neurons in LPS-treated neuronglia cultures involves the inhibition of the release of proinflammatory factors from microglia (Peng et al., 2005). Recently, VPA was reported to up-regulate the expression of GDNF and BDNF in astrocytes and these effects may play a major role in mediating VPA-induced neurotrophic effects on dopaminergic neurons (Chen et al., 2006b). Although the mechanisms of VPA induction of neurotrophic factors are not known, they might involve modification of chromatin structure since VPA was shown to directly inhibit histone deacetylase (HDAC), an enzyme that catalyzes the removal of acetyl groups from histones (Phiel et al., 2001).

PD patients suffer from impaired cognitive functions due to disturbances in the dopaminergic system and hippocampal atrophy (Jokinen et al., 2008 and references therein). Interestingly, several studies demonstrate that VPA (Bredy et al., 2007; Bredy and Barad, 2008) or pentyl-4-yn-VPA, a VPA analogue (Murphy et al., 2001; Foley et al., 2004), facilitate learning and memory. Accumulating evidence show that VPA and other HDAC inhibitors can ameliorate deficits in synaptic plasticity and cognition in several neurologic and psychiatric disorders (reviewed by Abel and Zukin, 2008). This suggests that HDAC inhibition might represent a promising therapeutic tool for the cognitive impairments related to neurodegenerative diseases. Since GDNF can play a role in learning and memory (detailed in Section 10), it is interesting to note that the therapeutic potential of VPA for the treatment of cognitive dysfunction in PD could also involve the VPA-induced GDNF expression in the hippocampus. This effect could be indirect or directly related to VPA's action as an HDAC inhibitor since it is known that histone modifications around individual $B D N F$ gene promoters increase BDNF mRNA expression and are associated with long-term memory (Bredy et al., 2007).

By suppressing neuroinflammation, stimulating the release of trophic factors from astrocytes, and improving cognitive dysfunctions, VPA can prove to be an effective therapeutic tool in PD and possibly in other neurodegenerative diseases.

\subsection{Anti-dementia drugs}

FK960, a novel anti-dementia drug, was found to selectively increase GDNF mRNA and protein levels in cultured rat astrocytes, since the mRNA levels of other neurotrophic factors (BDNF, NGF, NT-3, FGF-2) were not changed (Koyama et al., 2004). The FK960induced increase in GDNF mRNA is mediated by the activation of cFos and CREB with the ERK signal playing a key role in both the cFos expression and CREB phosphorylation (Koyama et al., 2004). Dexamethasone and pyrrolidine dithiocarbamate, which inhibit the NF- $\mathrm{B}$ mediated increase in astrocytic GDNF expression (Koyama et al., 2003a), do not affect the FK960-induced increase in GDNF expression in cultured astrocytes indicating that it is unlikely that NF- $\kappa$ B plays a role in the effect of FK960 on GDNF expression (Koyama et al., 2004).

\subsection{Immunophilin ligands}

Immunophilin ligands are immunosuppressive agents that bind to members of the FK506-binding proteins (FKBPs) (Steiner et al., 1992), followed by the inhibition of calcineurin by the immunophilin/FKBP complex and inhibition of cytokine synthesis, thus preventing T-cell activation (Liu et al., 1992). Some of these immunophilin ligands may enhance and/or mimic neurotrophic factor functions, such as promotion of neuronal survival or prevention of neuronal degeneration (reviewed by Pong and Zaleska, 2003). Since the blood-brain barrier is more permeable to immunophilin ligands than to neurotrophic factors, they are a promising treatment for neurodegenerative diseases, and may be more useful than neurotrophic factors as therapeutic drugs against PD progression. Nevertheless, current clinically available immunophilin ligands, including FK506 and cyclosporine A, are immunosuppressive, which limits their chronic use. However, neither calcineurin inhibition nor binding to FKBP-12 were found to be necessary for the neurotrophic effects of immunophilin ligands (Steiner et al., 1997; Costantini et al., 2001; Guo et al., 2001; Klettner et al., 2001; Zhang et al., 2001a; Tanaka et al., 2002b). This fact, together with the neuroprotective effects of immunophilin ligands in models of neurodegenerative disorders (reviewed by Pong and Zaleska, 2003), has led to the design of small ligands that bind to immunophilins, but are not immunosuppressive since they do not interact with calcineurin (e.g. Armistead et al., 1995; Adalsteinsson and Bruice, 2000).

In addition to its function in the immune system, FK506 (Tacrolimus) also exhibits neuroprotective and neurotrophic effects, including stimulation of axonal re-growth and enhancement of functional recovery in a variety of neurodegenerative disease models (reviewed by Sosa et al., 2005). Several studies report that FK506 and related non-immunosuppressive immunophilin ligands, such as GPI-1046 and V10367, have neurotrophic/ neuroprotective effects on dopaminergic neurons following MPTPor 6-OHDA-induced lesion (Steiner et al., 1997; Costantini et al., 1998, 2001; Ross et al., 2001; Zhang et al., 2001a; Tanaka et al., 2002a). Neurotrophic effects to dopaminergic neurons are also observed in vitro (Costantini and Isacson, 2000; Guo et al., 2001).

Some of the neurotrophic and neuroprotective effects of FK506 might be a consequence of the stimulation of GDNF expression as FK506 (as well as GPI-1046) significantly increases GDNF content in the mouse substantia nigra, but not in the striatum, when administered subcutaneously for 7 days. In addition, FK506 increases striatal BDNF content, suggesting that the immunophilin ligand-induced neurotrophic-like activity may be dependent on GDNF or BDNF expression (Tanaka et al., 2003). Moreover, treatment of U251 human glioma cells with FK506 (GPI-1046 or V10367) promotes GDNF release (Tanaka et al., 2004). Despite the therapeutic potential of FK506 in ameliorating neuronal injury, and the fact that FK506 penetrates the blood-brain barrier reasonably well, it cannot be used in therapy for neurological disorders due to its immunosuppressive effects. Nevertheless, it has been used as a model to develop new immunophilin ligands lacking the limitations of FK506 for clinical application.

Leucine-isoleucine (Leu-Ile), a hydrophobic dipeptide that partially resembles the site on FK506 that binds to immunophilin (Schreiber, 1991), induces GDNF expression both in vitro and in vivo. Leu-Ile significantly increases GDNF and BDNF contents in the conditioned medium from cultured hippocampal neurons after $24 \mathrm{~h}$ (Nitta et al., 2004). In mesencephalic cell cultures, Leu-Ile protects both dopaminergic and non-dopaminergic neurons against cell death that naturally occurs in low density cultures, but the effect is lost when cell cultures are prepared from mice lacking the GDNF or BDNF gene (Nitta et al., 2004). When administered intraperitoneally (ip) or icv once a day for 5 days, Leu-Ile increases GDNF and BDNF content in the striatum of mice. In addition, peripheral administration of Leu-Ile inhibits dopaminergic denervation induced by an intrastriatal unilateral injection of 6-OHDA, and reduces rotational behaviour after methamphetamine (Nitta et al., 2004). The ability of Leu-Ile to cross the bloodbrain barrier and to promote GDNF expression without exhibiting 
immunosuppressive properties make it a novel tool for the treatment of PD or other neurodegenerative diseases. Moreover, since GDNF has been implicated as a negative regulator of drugand alcohol-induced dependence (reviewed by Ron and Janak, 2005) and Leu-Ile induces GDNF expression, it has been proposed as a therapeutic agent for addiction (Niwa et al., 2007).

\subsection{Hormones with neurotrophic activity}

\subsubsection{Melatonin}

Pharmacological doses of melatonin have been shown to be neuroprotective in the 6-OHDA and in the MPTP models of PD (Joo et al., 1998; Thomas and Mohanakumar, 2004). Delivery of melatonin at physiological doses by mini-pump also protects against a 6-OHDA-induced decrease in mitochondrial complex I activity (Dabbeni-Sala et al., 2001). Furthermore, 6-OHDA-lesioned animals treated with a high physiological dose of melatonin exhibit a significant reduction in apomorphine-induced rotational behaviour and concomitant protection of striatal $\mathrm{TH}$ immunoreactivity (Sharma et al., 2006). The neuroprotection promoted by melatonin is thought to involve its antioxidant and free radical scavenging effects (Reiter et al., 2004; Rodriguez et al., 2004; Vega-Naredo et al., 2005). However, the neuroprotective properties of melatonin might also be mediated through GDNF up-regulation. A marked, concentration-dependent, increase in GDNF mRNA and protein levels is observed in rat $\mathrm{C} 6$ cells following treatment with physiological (0.05-1 nM) or higher (10 and $100 \mathrm{nM})$ concentrations of melatonin (Armstrong and Niles, 2002). The melatonin receptor (MT) 1 has been implicated, as the selective MT2 antagonist did not block the melatonin-induced increase in GDNF expression (Armstrong and Niles, 2002). Low physiological concentrations of melatonin also caused a significant induction of GDNF mRNA expression in a neural stem cell line (Niles et al., 2004). Intrastriatal injections of melatonin significantly enhance GDNF mRNA expression in the striatum at threshold doses lower than those needed to alter the antioxidant enzyme systems (Tang et al., 1998) and GDNF levels are also elevated in the locus coeruleus of melatonin-treated rats (Chen et al., 2003). Melatonin also induces astroglial GDNF expression in the mouse hippocampus (Lee et al., 2006).

Induction of GDNF by melatonin may be a direct effect mediated by activation of melatonin G-protein-coupled receptors, which are negatively coupled to the adenylyl cyclase-cAMP pathway, thereby mediating the suppression of cAMP synthesis (Dubocovich et al., 2003). As a result, the activation of these receptors leads to decreases in protein kinase (PK) A activity and protein phosphorylation, with consequent changes in the activity of transcription factors and gene expression (Masana and Dubocovich, 2001). In fact, elevation of cAMP levels with forskolin, dibutyryl-cAMP (db-cAMP) or 3isobutyl-1-methylxanthine (IBMX) represses GDNF secretion in C6 cells (Suter-Crazzolara and Unsicker, 1996; Verity et al., 1998). Therefore, it is likely that a decrease in cAMP mediated by melatonin receptors may induce GDNF expression.

Melatonin can also increase GDNF expression via PKC since it can activate PKC directly (Anton-Tay et al., 1998; Hunt et al., 2001). Interestingly, melatonin may induce GDNF expression through modulation of PKA and PKC activities, although PKA and PKC seem to have opposing effects on GDNF expression. In addition, melatonin, via the MT1 receptor, can activate the MAPK-ERK pathway (Witt-Enderby et al., 2000), which has been shown to upregulate the transcription of vascular endothelial growth factor via specificity protein (Sp)1 and activating protein (AP)-2 sites (Milanini et al., 1998). This is relevant as both Sp1 and AP-2 binding sites are present in the GDNF promoter (Woodbury et al., 1998; Baecker et al., 1999) thereby providing another means by which melatonin can induce GDNF up-regulation.
Collectively, the above data show that the stimulation of GDNF expression may be involved in some of the neuroprotective effects of melatonin.

\subsubsection{Vitamin $D_{3}$}

Several studies have shown that 1,25 -dihydroxyvitamin $D_{3}$, the active form of vitamin $D_{3}$, enhances endogenous GDNF expression. Although no changes in GDNF mRNA expression in rat glial cells in culture were observed by Remy et al. (2001) after treatment with 1,25-dihydroxyvitamin $D_{3}$, it is a potent inducer of GDNF mRNA expression in C6 cells (Naveilhan et al., 1996). It also increases extracellular GDNF protein levels in C6 cells (Verity et al., 1998) as well as in the glioblastoma cell line U-87MG, while having no effect on a neuroblastoma cell line (Verity et al., 1999). These observations suggest that the effect of 1,25-dihydroxyvitamin $\mathrm{D}_{3}$ on GDNF expression might be cell type dependent. There are also evidences that 1,25-dihydroxyvitamin $\mathrm{D}_{3}$ increases GDNF levels in vivo (Wang et al., 2000; Sanchez et al., 2002). This neurotrophic effect might contribute to the finding that pretreatment with 1,25-dihydroxyvitamin $D_{3}$ protects against 6OHDA-mediated depletion of dopamine and its metabolites in the substantia nigra, while in vitro it protects primary mesencephalic neurons against 6-OHDA- or $\mathrm{H}_{2} \mathrm{O}_{2}$-induced cell death (Wang et al., 2001b). An interesting observation is that rats born from vitamin $\mathrm{D}_{3}$-deficient dams have profound alterations in the brain at birth, including reductions in brain content of GDNF and NGF (Eyles et al., 2003), and exhibit persistent changes in the adult brain (Feron et al., 2005).

\subsubsection{Oestrogen}

Oestrogens have been shown to interfere with embryonic neuronal differentiation and survival of nigrostriatal dopaminergic neurons (reviewed by Kipp et al., 2006), and to regulate the expression of neurotrophic factors, which might mediate their neuroprotective effects (reviewed by Morale et al., 2006). Pretreatment with oestrogen provides significant neuroprotection against superoxide-, $\mathrm{H}_{2} \mathrm{O}_{2}$ - or glutamate-induced neurotoxicity in primary neuronal mesencephalic cultures (Sawada et al., 1998a). In vivo studies show beneficial effects of oestrogens against the toxicity induced by 6-OHDA (Murray et al., 2003) or MPTP (Dluzen et al., 1996; Callier et al., 2001; Ramirez et al., 2003; D'Astous et al., 2004; Jourdain et al., 2005) in the nigrostriatal system. Oestrogens rescue spinal motoneurons from AMPA-induced toxicity through an increase in the production and release of GDNF by astrocytes (Platania et al., 2005). Oestrogens also increase the expression of GDNF in hypothalamic cell cultures, in neurons but not in astrocytes, through non-classical oestrogen signalling as the application of the nuclear receptor antagonist ICI 182,780 does not prevent oestrogen-induced GDNF expression (Ivanova et al., 2002). The oestrogen-induced GDNF up-regulation in hypothalamic cells is prevented by cAMP/PKA and calcium signalling antagonists whereas inhibitors of PKC, PI3K or MAPK are ineffective, suggesting that intracellular $\mathrm{Ca}^{2+}$ and cAMP/PKA signalling are required for GDNF increases in neuronal cells in response to oestrogen. Both cascades converge to the transcription factor CREB (Nichols et al., 1992), so it is relevant that the promoter region of GDNF gene contains a binding site for CREB (Woodbury et al., 1998; Baecker et al., 1999). Oestrogen-dependent regulation of GDNF also occurs in the midbrain (reviewed by Kipp et al., 2006). Using neonatal midbrain astroglial and embryonic neuronal cultures oestrogen was reported to induce GDNF transcription in astrocytes but not in neurons, an effect that was not prevented by ICI 182,780 but was abrogated by interrupting the intracellular $\mathrm{Ca}^{2+}$-signalling or the MAPK signal transduction system (reviewed by Kipp et al., 2006). We should also mention that preliminary data 
from our group show that exposure to oestrogen up-regulates GDNF levels in postnatal cultures from ventral midbrain and potentiates L-DOPA- or $\mathrm{H}_{2} \mathrm{O}_{2}$-induced GDNF up-regulation in the same cultures. In agreement with the results reviewed by Kipp et al. (2006), we found that oestrogen-induced GDNF up-regulation was not affected by ICI 182,780 nor abolished by the non-permeant (conjugated to albumin) form of oestrogen (unpublished results).

Given the relevance of oestrogen to dopaminergic neurons of the nigrostriatal system (reviewed by Kipp et al., 2006) and their positive impact on GDNF expression (Ivanova et al., 2002; Platania et al., 2005), the effect of oestrogen exposure on GDNF levels in the nigrostriatal system deserves further investigation, both in naïve animals and in PD models.

\section{Inducers of GDNF expression brought from the traditional medicine}

Growing evidence indicate that Chinese herbs and extracts attenuate the degeneration of dopaminergic neurons and ameliorate the parkinsonism induced by MPTP and 6-OHDA (reviewed by Chen et al., 2007). Several mechanisms have been proposed to contribute to the neuroprotective effect of Chinese herbs and extracts. These include their function as antioxidants to alleviate oxidative stress, inhibitors of MAO-B to decrease neurotoxicity, scavengers of free radicals, chelators of harmful metals, modulators of cell survival genes and apoptotic signals (reviewed by Chen et al., 2007). As a result, Chinese herbs and extracts are receiving increasing attention as therapeutic agents for the treatment of PD patients. The efficacy and safety of their use in adjunct or monotherapy in PD management is under consideration (reviewed by Chung et al., 2006). Unfortunately, the effect on GDNF expression has not yet been addressed for many of them. It would be very interesting to investigate if these and other herbal extracts are able to increase GDNF expression, as well as whether their protective effects in PD animal models are mediated, or not, by the up-regulation of GDNF expression. Next we revise the sparse literature on GDNF induction by herbs or herbal compounds.

Rehmannia glutinosa, a traditional Chinese medicine herb frequently used in the therapy of dementia, induces GDNF gene expression in C6 cells and in primary cortical astrocytes (Yu et al., 2006). The effect of Rehmannia glutinosa on GDNF mRNA upregulation in C6 cells is completely attenuated by the presence of a PKC inhibitor and a MEK1 inhibitor. However, none of the PKC inhibitors significantly changes the effect of Rehmannia glutinosa on ERK1/2 phosphorylation, suggesting that the stimulation of GDNF gene expression by Rehmannia glutinosa could be independently up-regulated through PKC and ERK1/2 pathways in C6 cells (Yu et al., 2006).

Smilagenin is a compound extracted from Rhizoma anemarrhenae and Radix asparagi, medicinal herbs frequently used in the traditional Chinese medicine. A recent work shows that smilagenin, when added prior to $\mathrm{MPP}^{+}$, protects cultured mesencephalic dopaminergic neurons against $\mathrm{MPP}^{+}$-induced toxicity. GDNF mRNA levels, but not those of GFR $\alpha 1$ or Ret, are markedly elevated in the presence of smilagenin. Moreover, the neuroprotective effect is partially lost in the presence of GDNF and/or GFR $\alpha 1$ antibodies (Zhang et al., 2008).

Ibogaine is a psychoactive compound extracted from Tabernanthe iboga and used for decades in African folklore medicine and rituals. Many studies indicate that ibogaine reduces craving and withdrawal symptoms of several drugs of abuse (reviewed by Ron and Janak, 2005). This anti-addiction drug increases GDNF levels in dopaminergic-like SH-SY5Y cells and up-regulates the GDNF pathway as assessed by the phosphorylation of the GDNF receptor Ret and the downstream kinase ERK1 (He et al., 2005). A MEK inhibitor inhibits ibogaine-induced GDNF up-regulation (He and Ron, 2006). In addition, after systemic administration to rodents, ibogaine increases GDNF expression in the VTA (He et al., 2005). Since GDNF has been implicated as a negative regulator of drug and alcohol addiction (reviewed by Ron and Janak, 2005), the effect of ibogaine on GDNF expression likely contributes to its positive impact on the treatment of addiction. However, despite its properties, ibogaine is not approved as an addiction treatment because it induces hallucinations.

Finally, royal jelly, a honeybee secretion with a variety of biological activities, selectively stimulates, after oral administration, the GDNF mRNA expression in the hippocampus and cortex in the adult mouse. The expression of other neurotrophic factors or GFR $\alpha 1$ is not affected (Hashimoto et al., 2005b). Administration of royal jelly has no effect on GDNF expression in the midbrain, but the effect on the striatum was not addressed (Hashimoto et al., 2005b).

Given the accumulating evidence on the neuroprotective effect that herbs from the traditional medicine have in animal models of $\mathrm{PD}$, and the ability to induce GDNF expression that some of them have already shown, it may prove useful to study their impact on GDNF levels in the nigrostriatal system, as they might reveal to be important GDNF inducers.

\section{From receptors to GDNF gene: signalling pathways controlling GDNF expression}

Signal transduction pathways might also constitute targets to neuroprotective therapies. From the data reviewed above, a view emerges involving MAPK, PKC, PKA and $\mathrm{Ca}^{2+}$ leading to activation of several transcription factors, some of which are known to have response elements in the promoter of GDNF gene (Fig. 3). Moreover, some of those signalling pathways control the release of GDNF.

\subsection{Role of MAPK}

A role for the MAPK pathway in the regulation of GDNF transcription is supported by studies showing that agents such as riluzole, amitriptyline, ET-1 or the medicinal herb Rehmannia glutinosa, acting in different receptor systems, induce GDNF expression through the activation of the MAPK pathway. For instance, the glutamate receptor antagonist riluzole is able to promote GDNF expression in a MEK-dependent manner since the inhibitor PD98059 completely reverses that effect (Caumont et al., 2006b). This inhibitor also prevents the increases in astrocytic GDNF mRNA induced by ET-1 (Koyama et al., 2003a). The amitriptyline-evoked increase in both GDNF mRNA and GDNF release are selective and completely inhibited by MEK inhibitors (Hisaoka et al., 2001). Indeed, treatment with amitriptyline rapidly increases ERK activity, as well as p38 MAPK and JNK activities. Furthermore, different classes of anti-depressants also rapidly increase ERK activity. The extent of acute ERK activation and GDNF release are significantly correlated to each other for individual anti-depressants, suggesting an important role for acute ERK activation in GDNF production (Hisaoka et al., 2007). Additionally, the stimulation of GDNF expression in C6 cells by Rehmannia glutinosa is attenuated by the presence of a MEK1 inhibitor indicating that GDNF can be up-regulated through ERK1/2 pathways in C6 cells (Yu et al., 2006).

A direct relationship between the activation of the MAPK pathway and the expression of GDNF was not established for VPA or melatonin. Nevertheless, a correlation between the ability to increase GDNF levels and to activate the MAPK pathway can be depicted. VPA has been shown to activate the MAPK-ERK pathway 


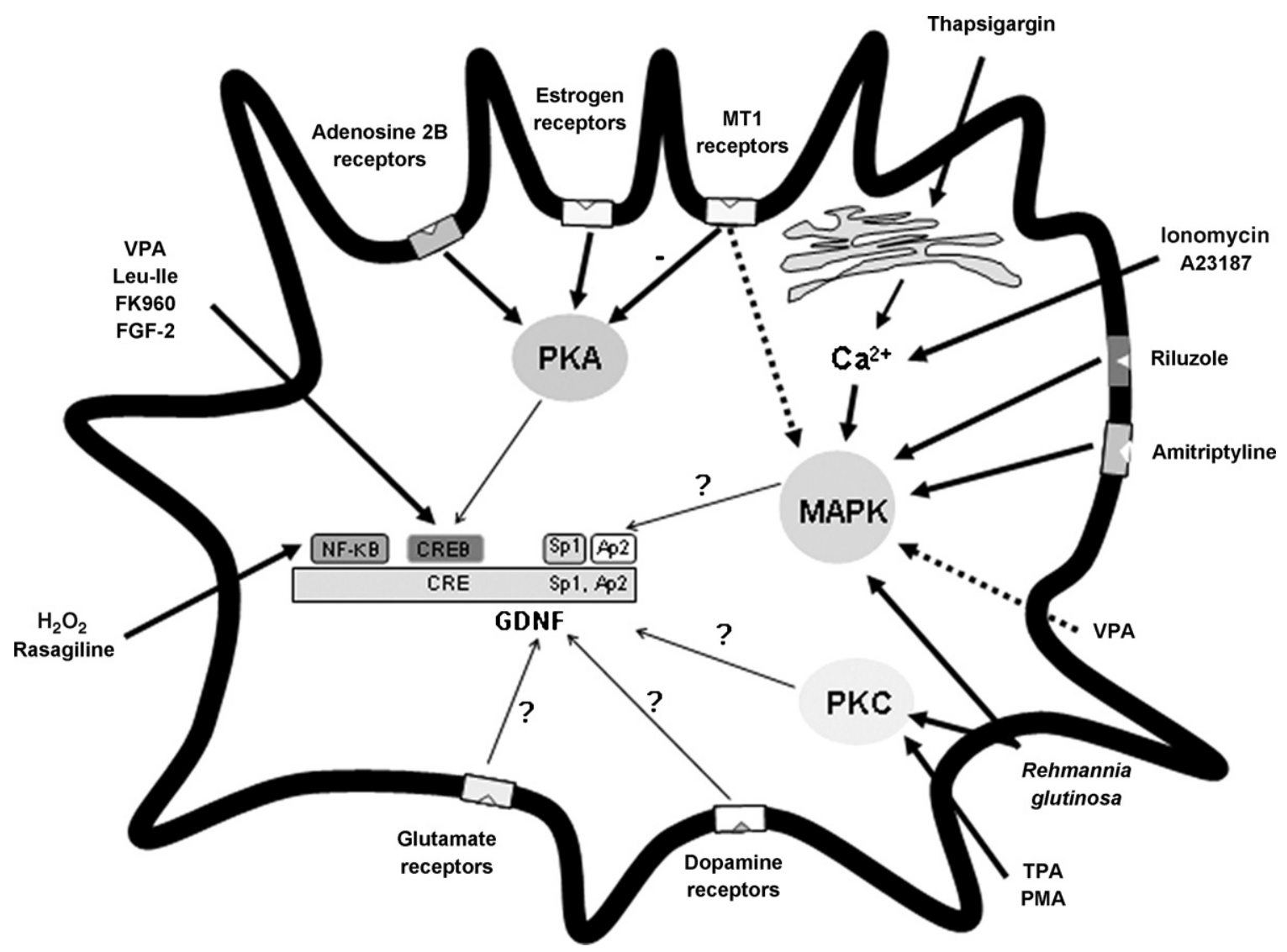

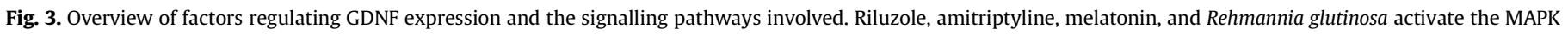

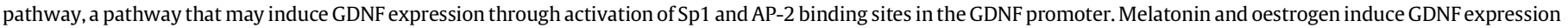

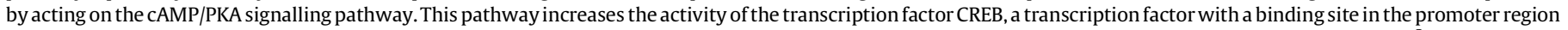

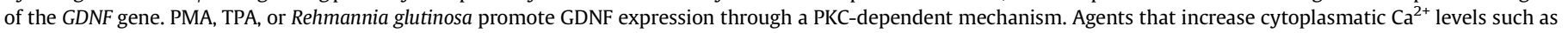

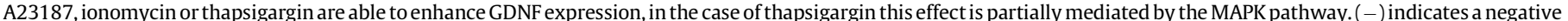

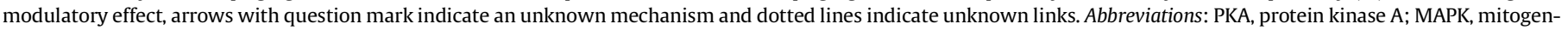

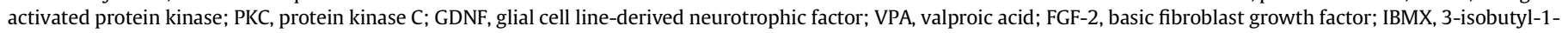

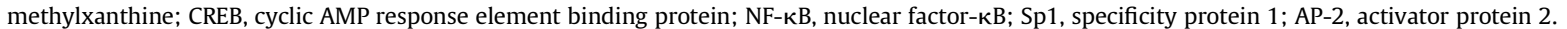

in human neuroblastoma SH-SY5Y cells (Yuan et al., 2001) suggesting that this mechanism could be responsible for the VPA-induced GDNF up-regulation observed in other studies (Castro et al., 2005; Chen et al., 2006b). Melatonin, also known to increase the expression of GDNF (Tang et al., 1998; Armstrong and Niles, 2002; Chen et al., 2003; Lee et al., 2006), is able, via the MT1 receptor, to activate the MAPK-ERK pathway (Witt-Enderby et al., 2000).

The increase of GDNF expression mediated by the activation of the MAPK-ERK pathway is likely related to the activation of Sp1 and AP-2 binding sites in the GDNF promoter (Woodbury et al., 1998; Baecker et al., 1999) since this signalling pathway has been shown to up-regulate the transcription of vascular endothelial growth factor via Sp1 and AP-2 sites (Milanini et al., 1998).

\subsection{Role of $P K C$}

PKC plays a key role in gene activation and production of GDNF. The phorbol ester 12-O-tetradecanoylphorbol-13-acetate (TPA), which activates PKC, increases GDNF mRNA levels in primary rat glial cells in culture (Remy et al., 2001). In fact, TPA increases the activity of the GDNF promoter (Grimm et al., 1998). Interestingly, activation of PKC by TPA enhances the neurotrophic effects of glial conditioned medium on dopaminergic neurons (Engele and Lehner, 1995), an effect possibly related to increased GDNF expression. These results are consistent with the finding that GDNF levels increase after activation of PKC in C6 cells (Matsushita et al., 1997; Verity et al., 1998; Nishiguchi et al., 2003). In addition, phorbol myristate acetate (PMA), another activator of PKC, increases GDNF mRNA levels in cultured Schwann cells (Kinameri and Matsuoka, 2003). In contrast, after exposure to PKC inhibitors a dramatic down-regulation of GDNF mRNA occurs in human astrocyte cell cultures (Moretto et al., 1996). Moreover, GDNF mRNA up-regulation induced by the traditional Chinese medicine herb Rehmannia glutinosa in C6 cells is inhibited by R0-31-8220, a pan-specific PKC inhibitor, thus supporting the involvement of PKC in the control of GDNF gene expression by extracts of this herb (Yu et al., 2006). The increase in GDNF expression promoted by melatonin can also occur via PKC, as this kinase can be directly activated by melatonin (Anton-Tay et al., 1998; Hunt et al., 2001). Interestingly, melatonin may induce GDNF expression also through modulation of PKA activity, although PKA and PKC seem to have opposing effects on GDNF expression.

\subsection{Role of PKA}

Treatments that elevate cellular cAMP levels (e.g. forskolin, IBMX) or the permeant analogue db-cAMP, have no effect on GDNF mRNA levels (Matsushita et al., 1997; Kinameri and Matsuoka, 2003) and inhibit GDNF release in C6 cells (Suter-Crazzolara and Unsicker, 1996; Verity et al., 1998), while stimulating GDNF release in U-87MG glioblastoma and SK-N-AS neuroblastoma cells 
(Verity et al., 1999). These conflicting results, together with the observation that cAMP enhances the activity of the GDNF promoter (Grimm et al., 1998), suggest that the impact of cAMP/PKA pathway on GDNF expression might be dependent on the cell type and/or on the interaction of different signalling pathways. Whereas elevated cellular cAMP levels induce no change in GDNF mRNA levels, they strongly stimulate GFR $\alpha 1$ and Ret mRNA expression in primary rat glial cells in culture (Remy et al., 2001) suggesting that high levels of cAMP might enhance GDNF signalling through increased expression of its receptors instead of increasing ligand availability.

In one hand, the negative coupling of GDNF expression and cAMP levels is in accordance with the ability of melatonin to increase GDNF expression. Melatonin activates G-protein-coupled MT receptors, which are negatively coupled to the adenylyl cyclase-cAMP pathway, resulting in the decrease of cAMP synthesis and PKA activity (Dubocovich et al., 2003). On the other hand, GDNF up-regulation induced by oestrogen in hypothalamic neurons in culture is prevented by cAMP/PKA antagonists supporting a role for the activation of the CAMP/PKA pathway in GDNF up-regulation in response to oestrogen (Ivanova et al., 2002). This regulatory effect mediated by the cAMP/PKA signalling pathway increases the activity of the transcription factor CREB (Nichols et al., 1992). The ability of the cAMP/PKA signalling pathway to increase GDNF expression is consistent with the presence of a binding site for the transcription factor CREB in the promoter region of the GDNF gene (Woodbury et al., 1998; Baecker et al., 1999).

\subsection{Role of $\mathrm{Ca}^{2+}$}

Several evidences suggest that increased intracellular free $\mathrm{Ca}^{2+}$ levels are involved in GDNF transcription, and these observations might account for both the activity-dependent GDNF expression and the injury-induced GDNF up-regulation. $\mathrm{Ca}^{2+}$ ionophores, like A23187 or ionomycin, increase GDNF levels in C6 cells (Verity et al., 1998; Nishiguchi et al., 2003) and GDNF mRNA levels in cultured Schwann cells (Kinameri and Matsuoka, 2003), but have no effect on GDNF release in U-87MG glioblastoma cells (Verity et al., 1999). The involvement of $\mathrm{Ca}^{2+}$ in GDNF expression is also demonstrated by a study showing that thapsigargin-induced endoplasmic reticulum $\mathrm{Ca}^{2+}$ discharge triggers GDNF mRNA expression in C6 cells through both MAPK-dependent and independent pathways, but not the NF- $\kappa B$ pathway (Oh-Hashi et al., 2006).

The contribution of intracellular $\mathrm{Ca}^{2+}$ to the stimulation of GDNF transcription is also supported by data showing that, in astrocyte cultures, oestrogen-induced GDNF increase is abolished when intracellular $\mathrm{Ca}^{2+}$-signalling is inhibited with BAPTA, a chelator of intracellular $\mathrm{Ca}^{2+}$ stores (reviewed by Kipp et al., 2006). Furthermore, BAPTA blocks dopamine- and ET-1-stimulated increases in GDNF transcript (Kinor et al., 2001; Koyama et al., 2003a).

\subsection{Transcription factors}

\subsubsection{Role of $N F-\kappa B$}

$\mathrm{H}_{2} \mathrm{O}_{2}$ increases GDNF mRNA levels in rat astrocytes (Yamagata et al., 2002; Koyama et al., 2003a) and induces GDNF release (Verity et al., 1998; Yamagata et al., 2002). $\mathrm{H}_{2} \mathrm{O}_{2}$ also up-regulates GDNF mRNA and protein levels in substantia nigra neuron-glia cell cultures thereby protecting dopaminergic neurons from $\mathrm{H}_{2} \mathrm{O}_{2}$ induced toxicity (Saavedra et al., 2006). These results are consistent with the observation that $\mathrm{H}_{2} \mathrm{O}_{2}$ activates the transcription factor NF-кB (Meyer et al., 1993), and with the presence of a binding sequence for NF- $\mathrm{B}$ on GDNF promoter (Woodbury et al., 1998; Baecker et al., 1999; Tanaka et al., 2000). In fact, $\mathrm{H}_{2} \mathrm{O}_{2}$ induced GDNF expression in cultured astrocytes is prevented by inhibitors of NF- KB activation (Koyama et al., 2003a), and GDNF secretion from $\mathrm{C} 6$ cells is repressed by treatment with dexamethasone, which inhibits the activation of NF-кB (Verity et al., 1998). Interestingly, the trophic effects of glial conditioned medium on dopaminergic neurons decrease in the presence of dexamethasone (Engele and Lehner, 1995).

In addition to $\mathrm{H}_{2} \mathrm{O}_{2}$, also rasagiline increases GDNF mRNA and protein levels through the activation of NF- $\kappa B$ (Maruyama et al., 2004). Rasagiline induces the phosphorylation of the inhibitory subunit (IкB) of NF- $\kappa$ B, and the translocation of the active p65 subunit from the cytoplasm to the nucleus in SH-SY5Y neuroblastoma cells. Inhibition of IкB kinase simultaneously suppresses the activation of NF- $\kappa B$ and the increase in GDNF expression induced by rasagiline, further supporting the involvement of the NF- $\mathrm{B}$ pathway in the regulation of GDNF levels by rasagiline (Maruyama et al., 2004).

\subsubsection{Role of CREB}

Leu-Ile stimulates GDNF expression in neuronal hippocampal cultures through mechanisms involving the activation of the heatshock protein (Hsp)90/Akt/CREB signalling pathway (Cen et al., 2006). There is enhanced interaction between phospho-Akt and Hsp90 and an Hsp90 inhibitor prevents the Leu-Ile-induced increase in CREB protein phosphorylation, indicating that CREB is a downstream target of Hsp90/Akt signalling. In addition, Leu-Ile increases the binding activity of phospho-CREB to CRE, and inhibition of CREB blocks the increase in GDNF levels induced by Leu-Ile. These results show that CREB plays a key role in transcriptional regulation of GDNF expression upon Leu-Ile treatment (Cen et al., 2006). Similarly, FK960 induces GDNF expression in a CREB-dependent mode (Koyama et al., 2004). VPA activates CREB in the rat hippocampus and frontal cortex (Einat et al., 2003), so it can promote GDNF expression through mechanisms associated with the CREB pathway. The antidepressant amitriptyline might also induce GDNF expression in a CREB-dependent manner as it increases the levels of phosphoCREB (Hisaoka et al., 2008). Moreover, enriched environment increases the phosphorylation of CREB and induces GDNF expression (Young et al., 1999), and these two events might be related as a binding site for the transcription factor CREB is present in the promoter region of the GDNF gene (Woodbury et al., 1998; Baecker et al., 1999).

\subsection{A GDNF loop?}

Auto-regulation of growth factor expression and secretion has been documented, namely for BDNF, which positively regulates its expression (Xiong et al., 2002), secretion (Canossa et al., 1997), and the dendritic targeting of its mRNA (Righi et al., 2000). Very recently, the induction of a long-lasting auto-regulatory cycle by which GDNF positively regulates its own expression was first described in SH-SY5Y cells exposed to ibogaine, and this mechanism was suggested to explain the long-lasting actions of ibogaine on GDNF expression (He and Ron, 2006). The upregulation of GDNF expression via GDNF itself needs further investigation, but some observations support the finding reported by He and Ron (2006).

As previously mentioned, the MAP kinase pathway has been shown to up-regulate the transcription of vascular endothelial growth factor via the Sp1 and AP-2 binding sites (Milanini et al., 1998), and the analysis of the promoter region of the human GDNF gene reveals putative $\mathrm{Sp} 1$ and $\mathrm{AP}-2$ transcription factor binding 
sites (Woodbury et al., 1998; Baecker et al., 1999). Since the autoregulatory increase in GDNF expression is inhibited by a MEK inhibitor (He and Ron, 2006), the activation of the MAPK pathway can contribute to the positive regulation of GDNF expression by itself, via the Sp1 and AP-2 transcription factor binding sites within its promoter.

On the other hand, several reports show that GDNF is able to induce CREB phosphorylation in different systems (Feng et al., 1999; Trupp et al., 1999; Hayashi et al., 2000; Pezeshki et al., 2001; Yang and Nelson, 2004; Iwase et al., 2005), including Ret-deficient cells (Poteryaev et al., 1999). Moreover, a binding site for the transcription factor CREB is present in the promoter region of the GDNF gene (Woodbury et al., 1998; Baecker et al., 1999).

In addition, GDNF promotes NF- $\mathrm{KB}$ activation in several models (Hayashi et al., 2000; Kalechman et al., 2003; Takahashi et al., 2004), namely by increasing the degradation of $І \kappa B$, the protein inhibitor of NF-KB activation (Kalechman et al., 2003), and the involvement of this transcription factor in GDNF expression has been strongly suggested, as discussed before.

\subsection{Negative regulation of GDNF expression}

To understand how the endogenous GDNF expression is regulated it is necessary not only to uncover the mechanisms by which several molecules trigger GDNF up-regulation, but also how
GDNF expression can be repressed (Fig. 4). This can be a useful tool for both up- and down-regulation strategies. The literature on GDNF repression is considerably sparse when compared to the number of reports on molecules or conditions that induce GDNF expression, as well as their mechanisms of action. Despite this, and the fact that in many cases the mechanism of repression is unclear, this issue deserves attention and therefore this section will focus on mechanisms of GDNF repression.

Reactive oxygen/nitrogen species may activate NF- $\mathrm{B}$ (reviewed by Gloire et al., 2006), and the involvement of NF- $\kappa B$ in GDNF expression is strongly suggested (Verity et al., 1998; Woodbury et al., 1998; Baecker et al., 1999; Tanaka et al., 2000; Koyama et al., 2003a; Maruyama et al., 2004). Therefore, one should expect that molecules that reduce oxidative stress, or inactivate NF- $\kappa \mathrm{B}$, would repress GDNF expression. In fact, treatment with the synthetic glucocorticosteroid methylprednisolone sodium succinate (MPSS) after spinal cord injury suppresses GDNF expression (Nakashima et al., 2004). In addition, ONO-1714, a newly developed specific inhibitor of inducible nitric oxide synthase (iNOS), diminishes the early stage production of GDNF upon spinal cord injury (Nakashima et al., 2005). Moreover, hyperbaric oxygen treatment reduces iNOS and GDNF mRNA and protein expression after spinal cord lesion due to the attenuation of hypoxic insult (Yu et al., 2004). These data are consistent with the observation that NO donors increase GDNF in C6 cells (Verity et al.,

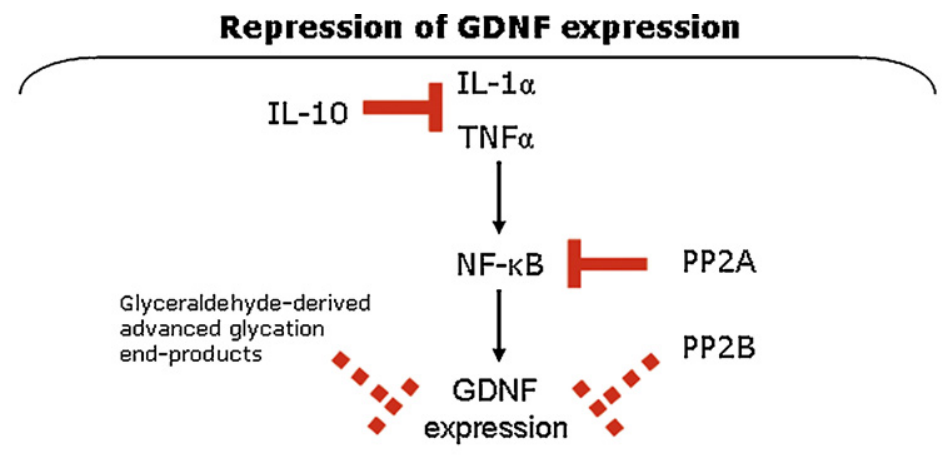

Repression of GDNF signalling

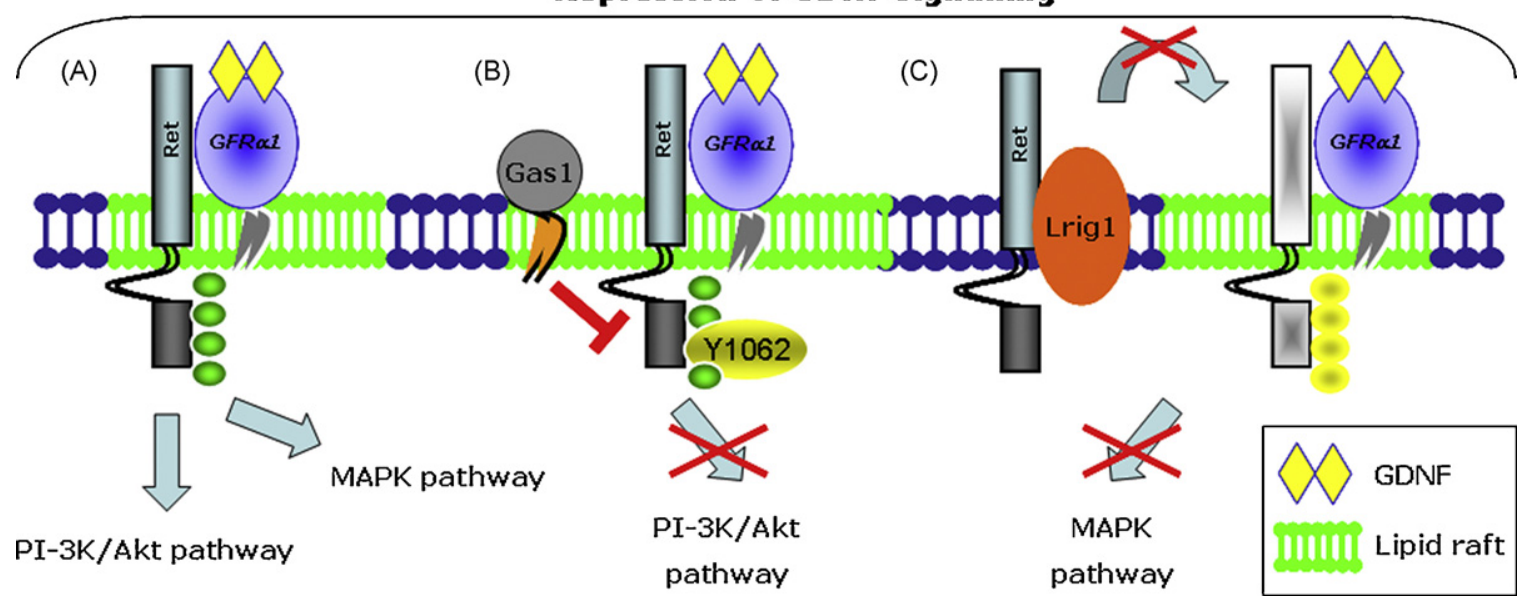

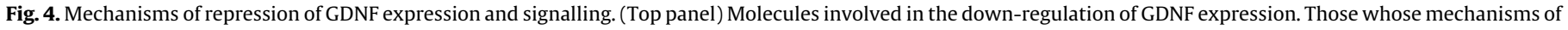

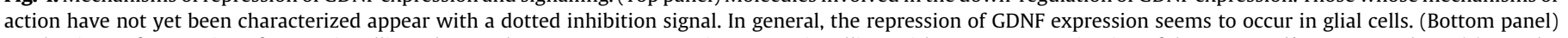

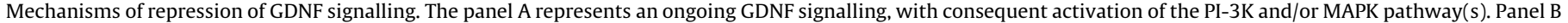

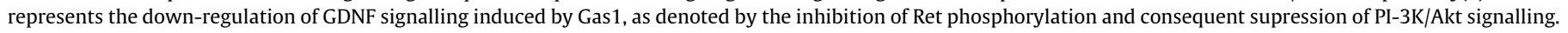

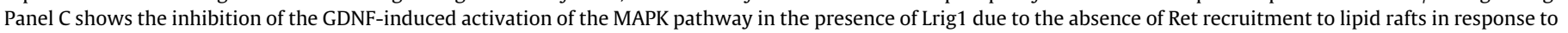

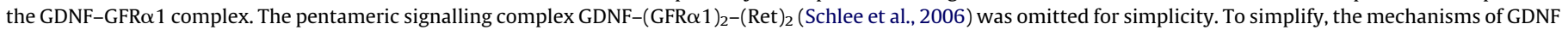

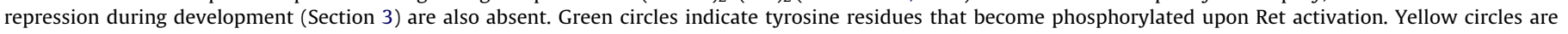
indicative of unphosphorylated tyrosine residues. Gas1 inhibits the phosphorylation of the Ret residue tyrosine (Y) 1062. 
1998), and with the increase in GDNF expression observed in ischemic/hypoxic injury (Wei et al., 2000; Miyazaki et al., 2001; Ikeda et al., 2002).

Another molecule found to inhibit GDNF expression is IL-10. IL10 negatively regulates GDNF production in rat glomerular mesangial cells as the maximal GDNF expression occurs in the presence of a low amount of IL-10 and, conversely, a low GDNF production occurs when IL-10 production is optimal. In addition, neutralizing IL-10 increases GDNF at time points where increased levels of IL-10 are produced, but addition of IL-10 inhibits GDNF secretion (Kalechman et al., 2003). This is further supported by the finding that AS101 increases GDNF production in rat glomerular mesangial cells (Kalechman et al., 2003) and GDNF mRNA levels in peripheral blood leukocytes and head kidney cells (Okun et al., 2006). AS101 is an immunomodulator (Sredni et al., 1987) that directly inhibits the transcription of IL-10 followed by the increase of specific cytokines including IL- $1 \alpha$ and TNF- $\alpha$ (Sredni et al., 1987; Kalechman et al., 1995, 1997; Strassmann et al., 1997). AS101 increases GDNF levels in rat astrocyte cultures and in the human SVG astrocyte cell line, while LPS-induced IL-10 secretion in the presence of AS101 is inhibited in both cell types (Sredni et al., 2007). Moreover, inhibition of IL-10 by AS101, or its neutralization by IL-10 neutralizing antibodies results in GDNF up-regulation in primary astrocytes. Conversely, the addition of IL-10 inhibits GDNF production (Sredni et al., 2007). In 6-OHDA-lesioned rats, GDNF mRNA levels are greater in the substantia nigra of AS101-treated rats compared to controls, whereas the levels of IL-10 mRNA and protein were significantly lower in the AS101-treated rats (Sredni et al., 2007). It should be stressed that the infusion of AS101 into the substantia nigra using an osmotic minipump improves motor function and sustains dopaminergic neurons in the 6-OHDA rat model of PD, whereas its peripheral administration reduces MPTPinduced damage to dopaminergic neurons and improves behavioural outcome (Sredni et al., 2007). Given the ability of AS101 to protect nigrostriatal dopaminergic neurons in animal models of PD, namely by neurotrophic, anti-apoptotic and anti-inflammatory mechanisms, it was proposed as a promising agent to treat PD (Sredni et al., 2007). Since the effect of IL-10/AS101 does not seem to be cell type-specifically regulated, it may explain the deprivation of neurotrophic factors in several CNS diseases where elevated expression of IL-10 is described (Vitkovic et al., 2001), although the levels of pro-inflammatory agents are usually increased in those diseases. The principal function of IL-10 appears to be limitation and ultimately termination of inflammatory responses (Moore et al., 2001). Therefore, the observation that AS101, which inhibits IL-10 and induces pro-inflammatory molecules, increases GDNF expression is consistent with the findings that pro-inflammatory molecules induce GDNF up-regulation (Appel et al., 1997; Verity et al., 1998, 1999; McNaught and Jenner, 2000; Remy et al., 2003; Hashimoto et al., 2005c; Kuno et al., 2006).

Also type-2A protein phosphatases (PP) seem to negatively regulate GDNF expression as GDNF levels increase upon their inhibition (Verity et al., 1998). This effect might be related to the activation of NF- $\kappa B$ since NF- $\kappa B$ activity is controlled largely by its phosphorylation state. Therefore, both kinases and phosphatases contribute to a given activation level. Indeed, several evidences point to the involvement of PP2A in the regulation of NF- $\kappa B$ activity. Recently, in a screen for phosphatases that modulate NF$\kappa B$ activity, co-immunoprecipitation studies identified associations of PP2A with IKK and NF-KB (Li et al., 2006c). Moreover, other studies report that up-regulation of PP2A activity and downregulation of NF- $\kappa \mathrm{B}$ activation are related (Egger et al., 2003) possibly because increased phosphatase activity is associated with stabilization of the non-phosphorylated form and reduction in nuclear binding of NF- $\mathrm{kB}$ (Yamashita et al., 1999). In addition, okadaic acid, an inhibitor of PP1 and PP2A, induces sustained activation of NF- $\kappa B$ and degradation of the nuclear $\mathrm{I} \kappa \mathrm{B} \alpha$ (Miskolci et al., 2003), consistent with increased nuclear binding of NF- $\kappa B$ in the presence of okadaic acid (Sontag et al., 1997; Yamashita et al., 1999). Altogether, these results support that the negative regulation of GDNF expression by PP2A can occur via inactivation of NF- $\kappa B$. In addition, also PP2B (calcineurin) seems to negatively regulate GDNF expression since FK506, a PP2B inhibitor, induces GDNF up-regulation and release (Section 7.5).

The expression of GDNF is also decreased in astrocytes by treatment with glyceraldehyde-derived advanced glycation endproducts (Miyajima et al., 2005), and this might have relevance in the context of the blood-brain barrier since GDNF reduces its permeability (Igarashi et al., 1999).

HIV-1 glycoprotein 120 (gp120) causes neurotoxicity in the rat striatum by reducing BDNF levels (Nosheny et al., 2004). Recently, intrastriatal administration of gp120 was reported to induce retrograde degeneration of nigrostriatal neurons, and to reduce nigral GDNF, but not BDNF, immunoreactivity. The lack of effect of gp120 on striatal GDNF suggest that gp120 may not affect GDNF synthesis, but that decreased GDNF levels in the substantia nigra may be due to a reduced transport from the striatum. It was therefore proposed that dysfunction of the nigrostriatal dopaminergic system associated with HIV may be caused by a reduction of neurotrophic factor support induced by gp120 due to interference with neurotrophic factor accumulation, release, or signalling (Nosheny et al., 2006). However, the mechanism involved in the gp120-induced GDNF reduced levels in the substantia nigra remains to be elucidated.

In addition to molecules that induce or repress GDNF expression, it is also important to know whether other molecules might regulate the intracellular pathways activated by GDNF, and thereby enhance or decrease its effects. For example, loss of the receptor tyrosine kinase antagonist Sprouty1 causes defects in kidney development in mice due to increased sensitivity of the Wolffian duct to GDNF/Ret signalling resulting in the development of multiple ureters and multiplex kidneys (Basson et al., 2005). Recently, new players acting negatively on GDNF signalling were described (Fig. 4). Lrig1, a transmembrane protein containing leucine-rich repeats and Ig-like domains, interacts with Ret thereby inhibiting its recruitment to lipid rafts, the binding to the GDNF-GFR $\alpha 1$ complex, receptor autophosphorylation, and MAPK activation in response to GDNF (Ledda et al., 2008). Growth Arrest Specific 1 (Gas1) is a molecule involved in cell cycle arrest and widely expressed during development, but also induced during, and participating in, excitotoxic neuronal death (Mellstrom et al., 2002). Interestingly, Gas1 shows high structural similarity to the GFR $\alpha$ (Cabrera et al., 2006; Schueler-Furman et al., 2006). Recently, Gas1 was shown to significantly inhibit GDNF-induced phosphorylation of the Ret tyrosine 1062 in SH-SY5Y neuroblastoma cells, resulting in extensively reduced GDNF-induced Akt activation (Lopez-Ramirez et al., 2008; Fig. 4). In contrast, Cabrera et al. (2006) found that Gas1 binds Ret in a ligand-independent manner, and sequesters Ret into lipid rafts leading to modified signalling downstream Ret. This occurs through a mechanism involving the adaptor protein Shc as well as ERK, ultimately blocking Akt activation. Consequently, Gas1 induction compromises Ret-mediated GDNF-dependent survival effects. However, no changes in Ret phosphorylation were observed, possibly because a general anti-phosphotyrosine antibody was used, whereas Lopez-Ramirez et al. (2008) used a specific anti-Ret phosphotyrosine 1062 antibody.

Summing up, the mechanisms of the repression of GDNF expression and signalling are beginning to be uncovered. This aspect of the neurotrophic factors field is actually very recent, and 
we are convinced that this topic will receive more attention in the future.

\section{GDNF, from regulation to function}

In this section, we will focus on the mechanisms of GDNFinduced neuroprotection in relation to the molecules that induce its expression. Usually the reviews on GDNF emphasize its neuroprotective/neurorestorative properties and therapeutic potential. We will therefore take this opportunity to review and pull together the mechanisms contributing to GDNF's action.

GDNF up-regulation is observed after excitotoxic insults (Section 4) or in response to pro-inflammatory molecules (Section 5.1). These observations are consistent with GDNF having important anti-apoptotic and anti-excitotoxic actions. GDNF has been shown to up-regulate $\mathrm{Bcl}-2$ and $\mathrm{Bcl}-\mathrm{X}_{\mathrm{L}}$ levels in many distinct injury models (Sawada et al., 2000; Ghribi et al., 2001; Cheng et al., 2002; Lenhard et al., 2002; Kilic et al., 2005), resulting in a reduction of caspase activation (Sawada et al., 2000; Ghribi et al., 2001; Kilic et al., 2005). Consistent with these results, many studies report reduced number of lesion-induced TUNEL-positive cells in the presence of GDNF (Ghribi et al., 2001; Hermann et al., 2001; Zhang et al., 2001b; Jin et al., 2003; Ding et al., 2004; Dong et al., 2007). GDNF also regulates the levels of X-linked inhibitor of apoptosis (XIAP) and neuronal apoptosis inhibitory protein (NAIP; Perrelet et al., 2002). Furthermore, GDNF has an anti-excitotoxic effect on cortical neurons through the selective attenuation of NMDA-induced excitotoxic neuronal death by reducing NMDAinduced $\mathrm{Ca}^{2+}$ influx (Nicole et al., 2001). GDNF also down-regulates the NMDA receptor subunit 1 (Bonde et al., 2003), and there are evidences that GDNF increases the expression of glutamate transporters in vitro and in vivo (Naskar et al., 2000; Bonde et al., 2003; Delyfer et al., 2005; Koeberle and Bahr, 2008).

GDNF expression is also regulated by reactive oxygen/nitrogen species (Section 9.7), and many observations support a role for GDNF in protecting cells against free radicals-induced injury. GDNF decreases 6-OHDA-induced oxidative stress and reduces the loss of dopamine in the striatum and in the substantia nigra (Smith and Cass, 2007). Moreover, in the presence of a GDNF antibody dopaminergic cell viability decreases in substantia nigra $\mathrm{H}_{2} \mathrm{O}_{2}$ treated cultures, showing that endogenous GDNF up-regulation in response to $\mathrm{H}_{2} \mathrm{O}_{2}$ is able to protect dopaminergic neurons in culture (Saavedra et al., 2006). Furthermore, in neuron-glia substantia nigra cell cultures, GDNF up-regulation in response to $\mathrm{H}_{2} \mathrm{O}_{2}$ down-regulates the expression of heme oxygenase- $1, \mathrm{a}$ marker of oxidative stress (Saavedra et al., 2005). These observations are consistent with the finding that GDNF significantly elevates the activity of superoxide dismutase, catalase, glutathione peroxidase (Chao and Lee, 1999; Cheng et al., 2004), and the levels of reduced glutathione (Onyango et al., 2005). Accordingly, GDNF suppresses the accumulation of oxygen radicals in vitro (Irie and Hirabayashi, 1999; Sawada et al., 2000) and in vivo (Cheng et al., 2004). In addition, GDNF decreases NOS expression (Hermann et al., 2001) and activity (Wang et al., 2002). These observations are consistent with GDNF decreasing the oxidative damage to lipids, proteins, and DNA (Dong et al., 2007).

GDNF expression increases in response to neurotransmitters and is therefore regulated in an activity-dependent manner (Section 4). At the same time, several works show that GDNF contributes to synaptic transmission. GDNF enhances the excitability of midbrain dopaminergic neurons by inhibiting A-type $\mathrm{K}^{+}$ channels, a fast action mediated by MAPK activation (Yang et al., 2001). GDNF also potentiates the activation of $\mathrm{Ca}^{2+}$ channels and excitatory transmission in midbrain neurons (Wang et al., 2003). In addition, it was reported that long-term treatment of neuromus- cular synapses with GDNF potentiates spontaneous and evoked neurotransmitter release and facilitates $\mathrm{Ca}^{2+}$ influx by enhancing $\mathrm{Ca}^{2+}$ currents, an effect mediated by the up-regulation of the $\mathrm{Ca}^{2+}$ binding protein frequenin (Wang et al., 2001a). GDNF increases the synaptic efficacy of dopaminergic neurons in culture by promoting the establishment of new functional synaptic terminals (Bourque and Trudeau, 2000), and recently a role for GDNF signalling in hippocampal synaptogenesis was described (Ledda et al., 2007). Therefore, GDNF can also play a role in learning and memory processes. In fact, increased GDNF levels are associated with improved water maze performance in rats (Young et al., 1999), whereas mice with a deletion of one copy of the GDNF gene show impaired water maze performance (Gerlai et al., 2001). Moreover, low GDNF expression may be involved in hippocampal dysfunctions such as age-related learning impairment and neuronal death observed in murine models of accelerated ageing (Miyazaki et al., 2003). Recent findings support these observations since lentiviral vector-induced GDNF expression in hippocampal astrocytes improves cognitive deficits in aged rats (Pertusa et al., 2007). Furthermore, GDNF infusion into the brain increases the proliferation of progenitor cells in the hippocampus (Chen et al., 2005c), a process that as been associated with learning and memory (reviewed by Leuner et al., 2006). Possibly, the increased neurogenesis in response to dietary restriction, enriched environment or physical exercise (Lee et al., 2000, 2002; Kitamura et al., 2006; Olson et al., 2006) can occur via increased GDNF expression, as all these environmental manipulations were shown to regulate GDNF expression (Section 6).

In summary, GDNF functions are determined by the molecular context that induces its expression. Thus, one can envisage that by knowing more about the regulation of GDNF expression it is possible to uncover unknown GDNF functions.

\section{Concluding remarks}

The last years have registered increasing interest in the application of neurotrophic factors to the therapeutic field, and to neurodegenerative diseases in particular. PD is in list of neurodegenerative diseases whose treatment with trophic factors as been the focus of extensive research, including clinical trials using GDNF and, more recently, neurturin (Peterson and Nutt, 2008). Several efforts are being made in order to overcome the problems associated with the delivery, targeting, safety, and distribution of trophic factors to the CNS. Lately, a new trend is growing. Increasing attention is now being payed to molecules that induce the endogenous expression of trophic factors, or enhance their signalling, as alternative therapeutic options for PD. Therefore, in addition to a therapeutic tool itself, GDNF constitutes also a target for the development of new therapeutics.

In this manuscript we reviewed a large number of compounds that trigger the endogenous GDNF synthesis and thus might constitute useful targets to develop neuroprotective therapies for PD. For many GDNF inducers the signalling pathway responsible for their effects on GDNF expression is already uncovered, and this issue was also addressed in this work. Among the compounds that trigger the endogenous GDNF expression are the natural neurotransmitters that control the activity-dependent expression of neurotrophic factors, which changes with the neurodegenerative process. Many of the established and novel drugs for PD management increase GDNF expression, namely several dopamine receptor agonists and enhancers. The extent to which their therapeutic effect is due to the control of symptoms or neuroprotection is not clear yet. Neurotransmitters, like cytokines, also mediate the neuron-glia cross-talk crucial in the response to injury. Although some inflammatory players might be protective 
through the induction of the expression of GDNF and other neurotrophic factors, it is widely accepted that controlling inflammation is beneficial. This is because inflammation can actively cause neuronal damage and death, and the microglial response to neuronal damage results in a self-propelling cycle of neuron death (reviewed by Block and Hong, 2005).

In this work we also discuss the contribution that, by inducing the endogenous GDNF expression, herbal extracts from the traditional medicine can bring to the neuroprotection of dopaminergic neurons, and as potential therapeutic tools for PD. Moreover, many of these compounds are able to attenuate the degeneration of dopaminergic neurons, and the motor symptoms in models of PD. Although the induction of GDNF expression has not been addressed in many cases, Chinese herbs or herbal extracts may promote neuronal survival and neurite growth, and facilitate functional recovery of brain injures by distinct mechanisms (reviewed by Chen et al., 2007). They might therefore represent an attractive choice for clinical trials with PD patients, so it is worth to investigate whether their trophic effects are mediated, or not, by the up-regulation of GDNF expression.

Mounting evidence support the positive impact that a healthy life style, including an appropriate diet, physical exercise and an active social life, has on the expression of neurotrophic factors, including GDNF. Therefore, this non-drug and non-invasive approach to increase the endogenous GDNF expression may help preventing the onset of degeneration or, in combination with pharmacological treatments, reduce the severity of the motor symptoms. Moreover, given its involvement in synaptic plasticity and synaptogenesis, GDNF can play a role also in learning and memory. One may therefore speculate that increasing the endogenous GDNF expression would also contribute to fight the cognitive decline observed in PD patients.

Another aspect focused in this review is a new perspective about the biology of neurotrophic factors that is the negative regulation of their expression, as well as the repression of their intracellular signalling. However, we still have a great need to learn further about this subject. Knowing more about the repression of GDNF expression, and the mechanisms that inhibit its intracellular signalling, will prove beneficial to the understanding of pathophysiological conditions, due either to increased or decreased GDNF expression/signalling. We consider that this subject deserves further attention in the upcoming future.

In summary, in this work we provide an overview of the evidence showing that it is possible to manipulate the endogenous GDNF expression, that this can have clinical implication for the management of PD and prove to be useful as an alternative or a complement to pharmacological or more invasive approaches. We hope that this synopsis stimulates the research in the field of the endogenous expression of trophic factors, mainly focused on the potential therapeutic application to the treatment of neurodegenerative diseases.

\section{Acknowledgements}

Ana Saavedra thanks the Foundation for Science and Technology, Portugal, for her post-doctoral fellowship (SFRH/BPD/28252/ 2006). We also thank Daniel del Toro, Laura Rué and Dr. Xavier Xifró for their helpful comments on the manuscript. We are very grateful to Ana Pinto for English language revision.

\section{References}

Abel, T., Zukin, R.S., 2008. Epigenetic targets of HDAC inhibition in neurodegenerative and psychiatric disorders. Curr. Opin. Pharmacol. 8, 57-64.

Adalsteinsson, H., Bruice, T.C., 2000. Generation and evaluation of putative neuroregenerative drugs. Part 2. Screening virtual libraries of novel polyke- tides which possess the binding domain of rapamycin. Bioorg. Med. Chem. 8, 625-635.

Albeck, D.S., Hoffer, B.J., Quissell, D., Sanders, L.A., Zerbe, G., Granholm, A.C., 1997. A non-invasive transport system for GDNF across the blood-brain barrier. Neuroreport 8, 2293-2298.

Alfano, I., Vora, P., Mummery, R.S., Mulloy, B., Rider, C.C., 2007. The major determinant of the heparin binding of glial cell-line-derived neurotrophic factor is near the $\mathrm{N}$-terminus and is dispensable for receptor binding. Biochem. J. 404, 131140.

Anastasia, A., de Erausquin, G.A., Wojnacki, J., Masco, D.H., 2007. Protection of dopaminergic neurons by electroconvulsive shock in an animal model of Parkinson's disease. J. Neurochem. 103, 1542-1552.

Angelucci, F., Aloe, L., Jimenez-Vasquez, P., Mathe, A.A., 2003. Lithium treatment alters brain concentrations of nerve growth factor, brain-derived neurotrophic factor and glial cell line-derived neurotrophic factor in a rat model of depression. Int. J. Neuropsychopharmacol. 6, 225-231.

Anton-Tay, F., Ramirez, G., Martinez, I., Benitez-King, G., 1998. In vitro stimulation of protein kinase C by melatonin. Neurochem. Res. 23, 601-606.

Appel, E., Kolman, O., Kazimirsky, G., Blumberg, P.M., Brodie, C., 1997. Regulation of GDNF expression in cultured astrocytes by inflammatory stimuli. Neuroreport $8,3309-3312$.

Araki, T., Kumagai, T., Tanaka, K., Matsubara, M., Kato, H., Itoyama, Y., Imai, Y., 2001. Neuroprotective effect of riluzole in MPTP-treated mice. Brain Res. 918, 176181.

Arenas, E., Trupp, M., Akerud, P., Ibanez, C.F., 1995. GDNF prevents degeneration and promotes the phenotype of brain noradrenergic neurons in vivo. Neuron 15, $1465-1473$.

Armistead, D.M., Badia, M.C., Deininger, D.D., Duffy, J.P., Saunders, J.O., Tung, R.D., Thomson, J.A., DeCenzo, M.T., Futer, O., Livingston, D.J., Murcko, M.A., Yamashita, M.M., Navia, M.A., 1995. Design, synthesis and structure of non-macrocyclic inhibitors of FKBP12, the major binding protein for the immunosuppressant FK506. Acta Crystallogr. D: Biol. Crystallogr. 51, 522-528.

Armstrong, K.J., Niles, L.P., 2002. Induction of GDNF mRNA expression by melatonin in rat C6 glioma cells. Neuroreport 13, 473-475.

Backman, C.M., Shan, L., Zhang, Y.J., Hoffer, B.J., Leonard, S., Troncoso, J.C., Vonsatel, P., Tomac, A.C., 2006. Gene expression patterns for GDNF and its receptors in the human putamen affected by Parkinson's disease: a real-time PCR study. Mol. Cell. Endocrinol. 252, 160-166.

Baecker, P.A., Lee, W.H., Verity, A.N., Eglen, R.M., Johnson, R.M., 1999. Characterization of a promoter for the human glial cell line-derived neurotrophic factor gene. Brain Res. Mol. Brain Res. 69, 209-222.

Baloh, R.H., Tansey, M.G., Lampe, P.A., Fahrner, T.J., Enomoto, H., Simburger, K.S. Leitner, M.L., Araki, T., Johnson Jr., E.M., Milbrandt, J., 1998. Artemin, a novel member of the GDNF ligand family, supports peripheral and central neurons and signals through the GFRalpha3-RET receptor complex. Neuron 21, 12911302.

Bar-Am, O., Weinreb, O., Amit, T., Youdim, M.B., 2005. Regulation of Bcl-2 family proteins, neurotrophic factors, and APP processing in the neurorescue activity of propargylamine. Faseb J. 19, 1899-1901.

Barneoud, P., Mazadier, M., Miquet, J.M., Parmentier, S., Dubedat, P., Doble, A., Boireau, A., 1996. Neuroprotective effects of riluzole on a model of Parkinson's disease in the rat. Neuroscience 74, 971-983.

Barone, P., 2003. Clinical strategies to prevent and delay motor complications. Neurology 61, S12-S16.

Barroso-Chinea, P., Cruz-Muros, I., Aymerich, M.S., Rodriguez-Diaz, M., AfonsoOramas, D., Lanciego, J.L., Gonzalez-Hernandez, T., 2005. Striatal expression of GDNF and differential vulnerability of midbrain dopaminergic cells. Eur. J. Neurosci. 21, 1815-1827.

Basson, M.A., Akbulut, S., Watson-Johnson, J., Simon, R., Carroll, T.J., Shakya, R., Gross, I., Martin, G.R., Lufkin, T., McMahon, A.P., Wilson, P.D., Costantini, F.D., Mason, I.J., Licht, J.D., 2005. Sprouty1 is a critical regulator of GDNF/RETmediated kidney induction. Dev. Cell 8, 229-239.

Batchelor, P.E., Liberatore, G.T., Wong, J.Y., Porritt, M.J., Frerichs, F., Donnan, G.A., Howells, D.W., 1999. Activated macrophages and microglia induce dopaminergic sprouting in the injured striatum and express brain-derived neurotrophic factor and glial cell line-derived neurotrophic factor. J. Neurosci. 19, 17081716.

Bauer, M., Suppmann, S., Meyer, M., Hesslinger, C., Gasser, T., Widmer, H.R., Ueffing, M., 2002. Glial cell line-derived neurotrophic factor up-regulates GTP-cyclohydrolase I activity and tetrahydrobiopterin levels in primary dopaminergic neurones. J. Neurochem. 82, 1300-1310.

Benazzouz, A., Boraud, T., Dubedat, P., Boireau, A., Stutzmann, J.M., Gross, C., 1995. Riluzole prevents MPTP-induced parkinsonism in the rhesus monkey: a pilot study. Eur. J. Pharmacol. 284, 299-307.

Benn, S.C., Woolf, C.J., 2004. Adult neuron survival strategies-slamming on the brakes. Nat. Rev. Neurosci. 5, 686-700.

Bespalov, M.M., Saarma, M., 2007. GDNF family receptor complexes are emerging drug targets. Trends Pharmacol. Sci. 28, 68-74.

Bezard, E., Dovero, S., Belin, D., Duconger, S., Jackson-Lewis, V., Przedborski, S. Piazza, P.V., Gross, C.E., Jaber, M., 2003b. Enriched environment confers resistance to 1-methyl-4-phenyl-1,2,3,6-tetrahydropyridine and cocaine: involvement of dopamine transporter and trophic factors. J. Neurosci. 23, 1099911007.

Bezard, E., Gross, C.E., Brotchie, J.M., 2003a. Presymptomatic compensation in Parkinson's disease is not dopamine-mediated. Trends Neurosci. 26, 215-221. 
Bezard, E., Stutzmann, J.M., Imbert, C., Boraud, T., Boireau, A., Gross, C.E., 1998. Riluzole delayed appearance of parkinsonian motor abnormalities in a chronic MPTP monkey model. Eur. J. Pharmacol. 356, 101-104.

Bilang-Bleuel, A., Revah, F., Colin, P., Locquet, I., Robert, J.J., Mallet, J., Horellou, P., 1997. Intrastriatal injection of an adenoviral vector expressing glial-cell-linederived neurotrophic factor prevents dopaminergic neuron degeneration and behavioral impairment in a rat model of Parkinson disease. Proc. Natl. Acad. Sci. U.S.A. 94, 8818-8823.

Bizon, J.L., Lauterborn, J.C., Gall, C.M., 1999. Subpopulations of striatal interneurons can be distinguished on the basis of neurotrophic factor expression. J. Comp. Neurol. 408, 283-298.

Bjerken, S.A., Boger, H.A., Nelson, M., Hoffer, B.J., Granholm, A.C., Stromberg, I., 2007. Effects of glial cell line-derived neurotrophic factor deletion on ventral mesencephalic organotypic tissue cultures. Brain Res. 1133, 10-19.

Block, M.L., Hong, J.S., 2005. Microglia and inflammation-mediated neurodegeneration: multiple triggers with a common mechanism. Prog. Neurobiol. 76, 77-98.

Blum, M., Weickert, C.S., 1995. GDNF mRNA expression in normal postnatal development, aging, and in Weaver mutant mice. Neurobiol. Aging 16, 925-929.

Boado, R.J., Zhang, Y., Zhang, Y., Wang, Y., Pardridge, W.M., 2007. GDNF fusion protein for targeted-drug delivery across the human blood-brain barrier. Biotechnol. Bioeng. 100, 387-396.

Boger, H.A., Middaugh, L.D., Huang, P., Zaman, V., Smith, A.C., Hoffer, B.J., Tomac, A.C., Granholm, A.C., 2006. A partial GDNF depletion leads to earlier age-related deterioration of motor function and tyrosine hydroxylase expression in the substantia nigra. Exp. Neurol. 202, 336-347.

Bonde, C., Sarup, A., Schousboe, A., Gegelashvili, G., Noraberg, J., Zimmer, J., 2003. GDNF pre-treatment aggravates neuronal cell loss in oxygen-glucose deprived hippocampal slice cultures: a possible effect of glutamate transporter upregulation. Neurochem. Int. 43, 381-388.

Bouchard, M., 2004. Transcriptional control of kidney development. Differentiation 72, 295-306.

Bourque, M.J., Trudeau, L.E., 2000. GDNF enhances the synaptic efficacy of dopaminergic neurons in culture. Eur. J. Neurosci. 12, 3172-3180.

Bozzi, Y., Borrelli, E., 1999. Absence of the dopamine D2 receptor leads to a decreased expression of GDNF and NT-4 mRNAs in restricted brain areas. Eur. J. Neurosci. 11, 1275-1284.

Bredy, T.W., Barad, M., 2008. The histone deacetylase inhibitor valproic acid enhances acquisition, extinction, and reconsolidation of conditioned fear. Learn. Mem. 15, 39-45.

Bredy, T.W., Wu, H., Crego, C., Zellhoefer, J., Sun, Y.E., Barad, M., 2007. Histone modifications around individual $B D N F$ gene promoters in prefrontal cortex are associated with extinction of conditioned fear. Learn. Mem. 14, 268-276.

Bresjanac, M., Antauer, G., 2000. Reactive astrocytes of the quinolinic acid-lesioned rat striatum express GFRalpha1 as well as GDNF in vivo. Exp. Neurol. 164, 5359.

Brodbeck, S., Englert, C., 2004. Genetic determination of nephrogenesis: the Pax/ Eya/Six gene network. Pediatr. Nephrol. 19, 249-255.

Brodbeck, S., Besenbeck, B., Englert, C., 2004. The transcription factor Six2 activates expression of the Gdnf gene as well as its own promoter. Mech. Dev. 121, 12111222.

Brophy, P.D., Ostrom, L., Lang, K.M., Dressler, G.R., 2001. Regulation of ureteric bud outgrowth by Pax2-dependent activation of the glial derived neurotrophic factor gene. Development 128, 4747-4756.

Buj-Bello, A., Buchman, V.L., Horton, A., Rosenthal, A., Davies, A.M., 1995. GDNF is an age-specific survival factor for sensory and autonomic neurons. Neuron 15, 821-828.

Burke, R.E., 2003. Postnatal developmental programmed cell death in dopamine neurons. Ann. NY Acad. Sci. 991, 69-79.

Burke, R.E., Antonelli, M., Sulzer, D., 1998. Glial cell line-derived neurotrophic growth factor inhibits apoptotic death of postnatal substantia nigra dopamine neurons in primary culture. J. Neurochem. 71, 517-525.

Cabrera, J.R., Sanchez-Pulido, L., Rojas, A.M., Valencia, A., Manes, S., Naranjo, J.R. Mellstrom, B., 2006. Gas1 is related to the glial cell-derived neurotrophic factor family receptors alpha and regulates Ret signaling. J. Biol. Chem. 281, 1433014339.

Cadet, P., Zhu, W., Mantione, K., Rymer, M., Dardik, I., Reisman, S., Hagberg, S., Stefano, G.B., 2003. Cyclic exercise induces anti-inflammatory signal molecule increases in the plasma of Parkinson's patients. Int. J. Mol. Med. 12, 485-492.

Callier, S., Morissette, M., Grandbois, M., Pelaprat, D., Di, P.T., 2001. Neuroprotective properties of 17beta-estradiol, progesterone, and raloxifene in MPTP C57Bl/6 mice. Synapse 41, 131-138

Canossa, M., Griesbeck, O., Berninger, B., Campana, G., Kolbeck, R., Thoenen, H., 1997. Neurotrophin release by neurotrophins: implications for activity-dependent neuronal plasticity. Proc. Natl. Acad. Sci. U.S.A. 94, 13279-13286.

Cao, J.P., Yu, J.K., Li, C., Sun, Y., Yuan, H.H., Wang, H.J., Gao, D.S., 2008. Integrin beta1 is involved in the signaling of glial cell line-derived neurotrophic factor. J. Comp. Neurol. 509, 203-210.

Carro, E., Torres-Aleman, I., 2006. Serum insulin-like growth factor I in brain function. Keio J. Med. 55, 59-63.

Carrillo, M.C., Kanai, S., Nokubo, M., Kitani, K., 1991. (-)Deprenyl induces activities of both superoxide dismutase and catalase but not of glutathione peroxidase in the striatum of young male rats. Life Sci. 48, 517-521.

Castro, L.M., Gallant, M., Niles, L.P., 2005. Novel targets for valproic acid: upregulation of melatonin receptors and neurotrophic factors in C6 glioma cells. J. Neurochem. 95, 1227-1236.
Caumont, A.S., Octave, J.N., Hermans, E., 2006a. Amantadine and memantine induce the expression of the glial cell line-derived neurotrophic factor in C6 glioma cells. Neurosci. Lett. 394, 196-201.

Caumont, A.S., Octave, J.N., Hermans, E., 2006b. Specific regulation of rat glial cell line-derived neurotrophic factor gene expression by riluzole in C6 glioma cells. J. Neurochem. 97, 128-139.

Cen, X., Nitta, A., Ohya, S., Zhao, Y., Ozawa, N., Mouri, A., Ibi, D., Wang, L., Suzuki, M. Saito, K., Ito, Y., Kawagoe, T., Noda, Y., Ito, Y., Furukawa, S., Nabeshima, T., 2006. An analog of a dipeptide-like structure of FK506 increases glial cell line-derived neurotrophic factor expression through cAMP response element-binding protein activated by heat shock protein 90/Akt signaling pathway. J. Neurosci. 26, 3335-3344.

Chadi, G., Moller, A., Rosen, L., Janson, A.M., Agnati, L.A., Goldstein, M., Ogren, S.O., Pettersson, R.F., Fuxe, K., 1993. Protective actions of human recombinant basic fibroblast growth factor on MPTP-lesioned nigrostriatal dopamine neurons after intraventricular infusion. Exp. Brain Res. 97, 145-158.

Chao, C.C., Lee, E.H., 1999. Neuroprotective mechanism of glial cell line-derived neurotrophic factor on dopamine neurons: role of antioxidation. Neuropharmacology 38, 913-916.

Chauhan, N.B., Siegel, G.J., Lee, J.M., 2001. Depletion of glial cell line-derived neurotrophic factor in substantia nigra neurons of Parkinson's disease brain. J. Chem. Neuroanat. 21, 277-288.

Chen, H., Zhang, S.M., Schwarzschild, M.A., Hernan, M.A., Ascherio, A., 2005a. Physical activity and the risk of Parkinson disease. Neurology 64, 664-669.

Chen, K.B., Lin, A.M., Chiu, T.H., 2003. Oxidative injury to the locus coeruleus of rat brain: neuroprotection by melatonin. J. Pineal Res. 35, 109-117.

Chen, L.W., Wang, Y.Q., Wei, L.C., Shi, M., Chan, Y.S., 2007. Chinese herbs and herbal extracts for neuroprotection of dopaminergic neurons and potential therapeutic treatment of Parkinson's disease. CNS Neurol. Disord. Drug Targets 6, 273281.

Chen, L.W., Yung, K.L., Chan, Y.S., 2005b. Reactive astrocytes as potential manipulation targets in novel cell replacement therapy of Parkinson's disease. Curr. Drug Targets 6, 821-833.

Chen, L.W., Zhang, J.P., Kwok-Yan, S.D., Chan, Y.S., 2006a. Localization of nerve growth factor, neurotrophin-3, and glial cell line-derived neurotrophic factor in nestin-expressing reactive astrocytes in the caudate-putamen of 1-methyl-4phenyl-1,2,3,6-tetrahydropyridine-treated C57/Bl mice. J. Comp. Neurol. 497, 898-909.

Chen, P.S., Peng, G.S., Li, G., Yang, S., Wu, X., Wang, C.C., Wilson, B., Lu, R.B., Gean, P.W., Chuang, D.M., Hong, J.S., 2006b. Valproate protects dopaminergic neurons in midbrain neuron/glia cultures by stimulating the release of neurotrophic factors from astrocytes. Mol. Psychiatry 11, 1116-1125.

Chen, Y., Ai, Y., Slevin, J.R., Maley, B.E., Gash, D.M., 2005c. Progenitor proliferation in the adult hippocampus and substantia nigra induced by glial cell line-derived neurotrophic factor. Exp. Neurol. 196, 87-95.

Cheng, H., Fu, Y.S., Guo, J.W., 2004. Ability of GDNF to diminish free radical production leads to protection against kainate-induced excitotoxicity in hippocampus. Hippocampus 14, 77-86.

Cheng, H., Wu, J.P., Tzeng, S.F., 2002. Neuroprotection of glial cell line-derived neurotrophic factor in damaged spinal cords following contusive injury. J Neurosci. Res. 69, 397-405.

Choi-Lundberg, D.L., Bohn, M.C., 1995. Ontogeny and distribution of glial cell linederived neurotrophic factor (GDNF) mRNA in rat. Brain Res. Dev. Brain Res. 85, 80-88.

Chung, V., Liu, L., Bian, Z., Zhao, Z., Leuk, F.W., Kum, W.F., Gao, J., Li, M., 2006. Efficacy and safety of herbal medicines for idiopathic Parkinson's disease: a systematic review. Mov. Disord. 21, 1709-1715.

Ciccarelli, R., Di Iorio, P., Bruno, V., Battaglia, G., D’Alimonte, I., D’Onofrio, M. Nicoletti, F., Caciagli, F. 1999. Activation of A(1) adenosine or mGlu3 metabotropic glutamate receptors enhances the release of nerve growth factor and S100 beta protein from cultured astrocytes. Glia 27, 275-281.

Clarke, C.E., Guttman, M., 2002. Dopamine agonist monotherapy in Parkinson's disease. Lancet 360, 1767-1769.

Cohen, A.D., Tillerson, J.L., Smith, A.D., Schallert, T., Zigmond, M.J., 2003. Neuroprotective effects of prior limb use in 6-hydroxydopamine-treated rats: possible role of GDNF. J. Neurochem. 85, 299-305.

Cohen, G., Pasik, P., Cohen, B., Leist, A., Mytilineou, C., Yahr, M.D., 1984. Pargyline and deprenyl prevent the neurotoxicity of 1-methyl-4-phenyl-1,2,3,6-tetrahydropyridine (MPTP) in monkeys. Eur. J. Pharmacol. 106, 209-210.

Collier, T.J., Dung, L.Z., Carvey, P.M., Fletcher-Turner, A., Yurek, D.M., Sladek Jr., J.R. Kordower, J.H., 2005. Striatal trophic factor activity in aging monkeys with unilateral MPTP-induced parkinsonism. Exp. Neurol. 191 (Suppl. 1), S60-S67.

Costantini, F., Shakya, R., 2006. GDNF/Ret signaling and the development of the kidney. Bioessays 28, 117-127.

Costantini, L.C., Isacson, O., 2000. Immunophilin ligands and GDNF enhance neurite branching or elongation from developing dopamine neurons in culture. Exp. Neurol. 164, 60-70.

Costantini, L.C., Chaturvedi, P., Armistead, D.M., McCaffrey, P.G., Deacon, T.W., Isacson, O., 1998. A novel immunophilin ligand: distinct branching effects on dopaminergic neurons in culture and neurotrophic actions after oral administration in an animal model of Parkinson's disease. Neurobiol. Dis. 5, 97-106.

Costantini, L.C., Cole, D., Chaturvedi, P., Isacson, O., 2001. Immunophilin ligands can prevent progressive dopaminergic degeneration in animal models of Parkinson's disease. Eur. J. Neurosci. 13, 1085-1092. 
Cotman, C.W., Berchtold, N.C., 2002. Exercise: a behavioral intervention to enhance brain health and plasticity. Trends Neurosci. 25, 295-301.

Dabbeni-Sala, F., Di, S.S., Franceschini, D., Skaper, S.D., Giusti, P., 2001. Melatonin protects against 6-OHDA-induced neurotoxicity in rats: a role for mitochondrial complex I activity. Faseb J. 15, 164-170.

Darlington, C.L., 2005. Astrocytes as targets for neuroprotective drugs. Curr. Opin. Invest. Drugs 6, 700-703.

D’Astous, M., Morissette, M., Di, P.T., 2004. Effect of estrogen receptor agonists treatment in MPTP mice: evidence of neuroprotection by an ER alpha agonist. Neuropharmacology 47, 1180-1188.

Delyfer, M.N., Simonutti, M., Neveux, N., Leveillard, T., Sahel, J.A., 2005. Does GDNF exert its neuroprotective effects on photoreceptors in the rd1 retina through the glial glutamate transporter GLAST? Mol. Vis. 11, 677-687.

Diehl, J.A., Tong, W., Sun, G., Hannink, M., 1995. Tumor necrosis factor-alphadependent activation of a RelA homodimer in astrocytes. Increased phosphorylation of RelA and MAD-3 precede activation of RelA. J. Biol. Chem. 270, 27032707.

Dietz, G.P., Valbuena, P.C., Dietz, B., Meuer, K., Mueller, P., Weishaupt, J.H., Bahr, M. 2006. Application of a blood-brain-barrier-penetrating form of GDNF in a mouse model for Parkinson's disease. Brain Res. 1082, 61-66.

Ding, Y.M., Jaumotte, J.D., Signore, A.P., Zigmond, M.J., 2004. Effects of 6-hydroxydopamine on primary cultures of substantia nigra: specific damage to dopamine neurons and the impact of glial cell line-derived neurotrophic factor. J. Neurochem. 89, 776-787.

Dluzen, D.E., McDermott, J.L., Liu, B., 1996. Estrogen alters MPTP-induced neurotoxicity in female mice: effects on striatal dopamine concentrations and release. J. Neurochem. 66, 658-666.

Dong, A., Shen, J., Krause, M., Hackett, S.F., Campochiaro, P.A., 2007. Increased expression of glial cell line-derived neurotrophic factor protects against oxidative damage-induced retinal degeneration. J. Neurochem. 103, 1041-1052.

Du, F., Li, R., Huang, Y., Li, X., Le, W., 2005. Dopamine D3 receptor-preferring agonists induce neurotrophic effects on mesencephalic dopamine neurons. Eur. J. Neurosci. 22, 2422-2430.

Duan, W., Mattson, M.P., 1999. Dietary restriction and 2-deoxyglucose administration improve behavioral outcome and reduce degeneration of dopaminergic neurons in models of Parkinson's disease. J. Neurosci. Res. 57, 195-206.

Dubocovich, M.L., Rivera-Bermudez, M.A., Gerdin, M.J., Masana, M.I., 2003. Molecular pharmacology, regulation and function of mammalian melatonin receptors. Front. Biosci. 8, d1093-d1108.

Egger, T., Schuligoi, R., Wintersperger, A., Amann, R., Malle, E., Sattler, W., 2003. Vitamin E (alpha-tocopherol) attenuates cyclo-oxygenase 2 transcription and synthesis in immortalized murine BV-2 microglia. Biochem. J. 370, 459-467.

Egnaczyk, G.F., Pomonis, J.D., Schmidt, J.A., Rogers, S.D., Peters, C., Ghilardi, J.R. Mantyh, P.W., Maggio, J.E., 2003. Proteomic analysis of the reactive phenotype of astrocytes following endothelin-1 exposure. Proteomics 3, 689-698.

Einat, H., Yuan, P., Gould, T.D., Li, J., Du, J., Zhang, L., Manji, H.K., Chen, G., 2003. The role of the extracellular signal-regulated kinase signaling pathway in mood modulation. J. Neurosci. 23, 7311-7316.

Engele, J., Lehner, M., 1995. Regulation of glial-derived dopaminergic growth factors by glucocorticoids and protein kinase C. Exp. Neurol. 133, 18-24.

Enomoto, H., 2005. Regulation of neural development by glial cell line-derived neurotrophic factor family ligands. Anat. Sci. Int. 80, 42-52.

Esquela, A.F., Lee, S.J., 2003. Regulation of metanephric kidney development by growth/differentiation factor 11. Dev. Biol. 257, 356-370.

Eyles, D., Brown, J., Kay-Sim, A., McGrath, J., Feron, F., 2003. Vitamin $\mathrm{D}_{3}$ and brain development. Neuroscience 118, 641-653.

Faherty, C.J., Raviie, S.K., Herasimtschuk, A., Smeyne, R.J., 2005. Environmental enrichment in adulthood eliminates neuronal death in experimental parkinsonism. Brain Res. Mol. Brain Res. 134, 170-179.

Fahn, S., 2005. Does levodopa slow or hasten the rate of progression of Parkinson's disease? J. Neurol. 252 (Suppl. 4), IV37-IV42.

Feng, L., Wang, C.Y., Jiang, H., Oho, C., Dugich-Djordjevic, M., Mei, L., Lu, B., 1999. Differential signaling of glial cell line-derived neurothrophic factor and brainderived neurotrophic factor in cultured ventral mesencephalic neurons. Neuroscience $93,265-273$.

Feron, F., Burne, T.H., Brown, J., Smith, E., McGrath, J.J., Kay-Sim, A., Eyles, D.W., 2005 Developmental Vitamin $\mathrm{D}_{3}$ deficiency alters the adult rat brain. Brain Res. Bull. $65,141-148$

Finch, C.E., 2004. The neurotoxicology of hard foraging and fat-melts. Proc. Natl Acad. Sci. U.S.A. 101, 17887-17888.

Fisher, B.E., Petzinger, G.M., Nixon, K., Hogg, E., Bremmer, S., Meshul, C.K., Jakowec M.W., 2004. Exercise-induced behavioral recovery and neuroplasticity in the 1 methyl-4-phenyl-1,2,3,6-tetrahydropyridine-lesioned mouse basal ganglia. J. Neurosci. Res. 77, 378-390.

Foley, A.G., Gallagher, H.C., Murphy, K.J., Regan, C.M., 2004. Pentyl-4-yn-valproic acid reverses age-associated memory impairment in the Wistar rat. Neurobiol. Aging 25, 539-546.

Fukumoto, T., Morinobu, S., Okamoto, Y., Kagaya, A., Yamawaki, S., 2001. Chronic lithium treatment increases the expression of brain-derived neurotrophic factor in the rat brain. Psychopharmacology (Berl.) 158, 100-106.

Gage, H., Storey, L., 2004. Rehabilitation for Parkinson's disease: a systematic review of available evidence. Clin. Rehabil. 18, 463-482.

Gash, D.M., Zhang, Z., Ai, Y., Grondin, R., Coffey, R., Gerhardt, G.A., 2005. Trophic factor distribution predicts functional recovery in parkinsonian monkeys. Ann. Neurol. 58, 224-233.
Gerlai, R., McNamara, A., Choi-Lundberg, D.L., Armanini, M., Ross, J., Powell-Braxton, L., Phillips, H.S., 2001. Impaired water maze learning performance without altered dopaminergic function in mice heterozygous for the GDNF mutation. Eur. J. Neurosci. 14, 1153-1163.

Ghribi, O., Herman, M.M., Forbes, M.S., DeWitt, D.A., Savory, J., 2001. GDNF protects against aluminum-induced apoptosis in rabbits by upregulating $\mathrm{Bcl}-2$ and $\mathrm{Bcl}-$ $\mathrm{XL}$ and inhibiting mitochondrial Bax translocation. Neurobiol. Dis. 8, 764-773.

Gill, S.S., Patel, N.K., Hotton, G.R., O’Sullivan, K., McCarter, R., Bunnage, M., Brooks, D.J., Svendsen, C.N., Heywood, P., 2003. Direct brain infusion of glial cell linederived neurotrophic factor in Parkinson disease. Nat. Med. 9, 589-595.

Glatt, S.L., Hubble, J.P., Lyons, K., Paolo, A., Troster, A.I., Hassanein, R.E., Koller, W.C., 1996. Risk factors for dementia in Parkinson's disease: effect of education. Neuroepidemiology 15, 20-25.

Gloire, G., Legrand-Poels, S., Piette, J., 2006. NF-kappaB activation by reactive oxygen species: fifteen years later. Biochem. Pharmacol. 72, 1493-1505.

Gomez-Pinilla, F., Dao, L., So, V., 1997. Physical exercise induces FGF-2 and its mRNA in the hippocampus. Brain Res. 764, 1-8.

Granholm, A.C., Reyland, M., Albeck, D., Sanders, L., Gerhardt, G., Hoernig, G., Shen, L., Westphal, H., Hoffer, B., 2000. Glial cell line-derived neurotrophic factor is essential for postnatal survival of midbrain dopamine neurons. J. Neurosci. 20 3182-3190.

Grieshammer, U., Le, M., Plump, A.S., Wang, F., Tessier-Lavigne, M., Martin, G.R., 2004. Slit2-mediated Robo2 signaling restricts kidney induction to a single site. Dev. Cell 6, 709-717.

Grimm, L., Holinski-Feder, E., Teodoridis, J., Scheffer, B., Schindelhauer, D., Meitinger, T., Ueffing, M., 1998. Analysis of the human GDNF gene reveals an inducible promoter, three exons, a triplet repeat within the 3'-UTR and alternative splice products. Hum. Mol. Genet. 7, 1873-1886.

Grunblatt, E., Mandel, S., Maor, G., Youdim, M.B., 2001a. Gene expression analysis in $\mathrm{N}$-methyl-4-phenyl-1,2,3,6-tetrahydropyridine mice model of Parkinson's disease using cDNA microarray: effect of $R$-apomorphine. J. Neurochem. 78, 1-12.

Grunblatt, E., Mandel, S., Maor, G., Youdim, M.B., 2001b. Effects of $R$ - and $S$ apomorphine on MPTP-induced nigro-striatal dopamine neuronal loss. J. Neurochem. 77, 146-156.

Guo, H., Tang, Z., Yu, Y., Xu, L., Jin, G., Zhou, J., 2002. Apomorphine induces trophic factors that support fetal rat mesencephalic dopaminergic neurons in cultures. Eur. J. Neurosci. 16, 1861-1870.

Guo, X., Dawson, V.L., Dawson, T.M., 2001. Neuroimmunophilin ligands exert neuroregeneration and neuroprotection in midbrain dopaminergic neurons. Eur. J. Neurosci. 13, 1683-1693.

Hallett, P.J., Standaert, D.G., 2004. Rationale for and use of NMDA receptor antagonists in Parkinson's disease. Pharmacol. Ther. 102, 155-174.

Hashimoto, K., Shimizu, E., Iyo, M., 2004. Critical role of brain-derived neurotrophic factor in mood disorders. Brain Res. Brain Res. Rev. 45, 104-114.

Hashimoto, M., Kanda, M., Ikeno, K., Hayashi, Y., Nakamura, T., Ogawa, Y., Fukumitsu, H., Nomoto, H., Furukawa, S., 2005b. Oral administration of royal jelly facilitates mRNA expression of glial cell line-derived neurotrophic factor and neurofilament $\mathrm{H}$ in the hippocampus of the adult mouse brain. Biosci. Biotechnol. Biochem. 69, 800-805.

Hashimoto, M., Nitta, A., Fukumitsu, H., Nomoto, H., Shen, L., Furukawa, S., 2005a. Involvement of glial cell line-derived neurotrophic factor in activation processes of rodent macrophages. J. Neurosci. Res, 79, 476-487.

Hashimoto, M., Nitta, A., Fukumitsu, H., Nomoto, H., Shen, L., Furukawa, S., 2005c. Inflammation-induced GDNF improves locomotor function after spinal cord injury. Neuroreport 16, 99-102.

Hayashi, H., Ichihara, M., Iwashita, T., Murakami, H., Shimono, Y., Kawai, K., Kurokawa, K., Murakumo, Y., Imai, T., Funahashi, H., Nakao, A., Takahashi, M., 2000. Characterization of intracellular signals via tyrosine 1062 in RET activated by glial cell line-derived neurotrophic factor. Oncogene 19, 4469-4475.

He, D.Y., Ron, D., 2006. Autoregulation of glial cell line-derived neurotrophic factor expression: implications for the long-lasting actions of the anti-addiction drug, Ibogaine. Faseb J. 20, 2420-2422.

He, D.Y., McGough, N.N., Ravindranathan, A., Jeanblanc, J., Logrip, M.L., Phamluong, K., Janak, P.H., Ron, D., 2005. Glial cell line-derived neurotrophic factor mediates the desirable actions of the anti-addiction drug ibogaine against alcohol consumption. J. Neurosci. 25, 619-628.

Hearn, C.J., Murphy, M., Newgreen, D., 1998. GDNF and ET-3 differentially modulate the numbers of avian enteric neural crest cells and enteric neurons in vitro. Dev. Biol. 197, 93-105.

Heikkila, R.E., Manzino, L., Cabbat, F.S., Duvoisin, R.C., 1984. Protection against the dopaminergic neurotoxicity of 1-methyl-4-phenyl-1,2,5,6-tetrahydropyridine by monoamine oxidase inhibitors. Nature 311, 467-469.

Henderson, C.E., Phillips, H.S., Pollock, R.A., Davies, A.M., Lemeulle, C., Armanini, M. Simmons, L., Moffet, B., Vandlen, R.A., Simpson, L.C. [corrected to Simmons, L.], et al., 1994. GDNF: a potent survival factor for motoneurons present in peripheral nerve and muscle. Science 266, 1062-1064.

Hermann, D.M., Kilic, E., Kugler, S., Isenmann, S., Bahr, M., 2001. Adenovirusmediated glial cell line-derived neurotrophic factor (GDNF) expression protects against subsequent cortical cold injury in rats. Neurobiol. Dis. 8, 964-973.

Heuckeroth, R.O., Lampe, P.A., Johnson, E.M., Milbrandt, J., 1998. Neurturin and GDNF promote proliferation and survival of enteric neuron and glial progenitors in vitro. Dev. Biol. 200, 116-129.

Hida, H., Jung, C.G., Wu, C.Z., Kim, H.J., Kodama, Y., Masuda, T., Nishino, H., 2003. Pleiotrophin exhibits a trophic effect on survival of dopaminergic neurons in vitro. Eur. J. Neurosci. 17, 2127-2134. 
Hisaoka, K., Maeda, N., Tsuchioka, M., Takebayashi, M., 2008. Antidepressants induce acute CREB phosphorylation and CRE-mediated gene expression in glia cells: a possible contribution to GDNF production. Brain Res. 1196, 53-58.

Hisaoka, K., Nishida, A., Koda, T., Miyata, M., Zensho, H., Morinobu, S., Ohta, M., Yamawaki, S., 2001. Antidepressant drug treatments induce glial cell linederived neurotrophic factor (GDNF) synthesis and release in rat C6 glioblastoma cells. J. Neurochem. 79, 25-34.

Hisaoka, K., Nishida, A., Takebayashi, M., Koda, T., Yamawaki, S., Nakata, Y., 2004. Serotonin increases glial cell line-derived neurotrophic factor release in rat C6 glioblastoma cells. Brain Res. 1002, 167-170.

Hisaoka, K., Takebayashi, M., Tsuchioka, M., Maeda, N., Nakata, Y., Yamawaki, S., 2007. Antidepressants increase glial cell line-derived neurotrophic factor production through monoamine independent activation of protein tyrosine kinase and extracellular signal-regulated kinase in glial cells. J. Pharmacol. Exp. Ther. $321,148-157$.

Ho, A., Blum, M., 1997. Regulation of astroglial-derived dopaminergic neurotrophic factors by interleukin-1 beta in the striatum of young and middle-aged mice. Exp. Neurol. 148, 348-359.

Ho, A., Gore, A.C., Weickert, C.S., Blum, M., 1995. Glutamate regulation of GDNF gene expression in the striatum and primary striatal astrocytes. Neuroreport 6, $1454-1458$.

Howells, D.W., Porritt, M.J., Wong, J.Y., Batchelor, P.E., Kalnins, R., Hughes, A.J., Donnan, G.A., 2000. Reduced BDNF mRNA expression in the Parkinson's disease substantia nigra. Exp. Neurol. 166, 127-135.

Hsuan, S.L., Klintworth, H.M., Xia, Z., 2006. Basic fibroblast growth factor protects against rotenone-induced dopaminergic cell death through activation of extracellular signal-regulated kinases $1 / 2$ and phosphatidylinositol-3 kinase pathways. J. Neurosci. 26, 4481-4491.

Hughes, P.E., Alexi, T., Walton, M., Williams, C.E., Dragunow, M., Clark, R.G., Gluckman, P.D., 1999. Activity and injury-dependent expression of inducible transcription factors, growth factors and apoptosis-related genes within the central nervous system. Prog. Neurobiol. 57, 421-450.

Humpel, C., Hoffer, B., Stromberg, I., Bektesh, S., Collins, F., Olson, L., 1994. Neurons of the hippocampal formation express glial cell line-derived neurotrophic factor messenger RNA in response to kainate-induced excitation. Neuroscience 59, 791-795.

Hunot, S., Bernard, V., Faucheux, B., Boissiere, F., Leguern, E., Brana, C., Gautris, P.P., Guerin, J., Bloch, B., Agid, Y., Hirsch, E.C., 1996. Glial cell line-derived neurotrophic factor (GDNF) gene expression in the human brain: a post-mortem in situ hybridization study with special reference to Parkinson's disease. J. Neural Transm. 103, 1043-1052.

Hunt, A.E., Al-Ghoul, W.M., Gillette, M.U., Dubocovich, M.L., 2001. Activation of MT(2) melatonin receptors in rat suprachiasmatic nucleus phase advances the circadian clock. Am. J. Physiol.: Cell Physiol. 280, C110-C118.

Igarashi, Y., Utsumi, H., Chiba, H., Yamada-Sasamori, Y., Tobioka, H., Kamimura, Y. Furuuchi, K., Kokai, Y., Nakagawa, T., Mori, M., Sawada, N., 1999. Glial cell linederived neurotrophic factor induces barrier function of endothelial cells forming the blood-brain barrier. Biochem. Biophys. Res. Commun. 261, 108-112.

Iida, M., Miyazaki, I., Tanaka, K., Kabuto, H., Iwata-Ichikawa, E., Ogawa, N., 1999. Dopamine D2 receptor-mediated antioxidant and neuroprotective effects of ropinirole, a dopamine agonist. Brain Res. 838, 51-59.

Ikeda, T., Koo, H., Xia, Y.X., Ikenoue, T., Choi, B.H., 2002. Bimodal upregulation of glial cell line-derived neurotrophic factor (GDNF) in the neonatal rat brain following ischemic/hypoxic injury. Int. J. Dev. Neurosci. 20, 555-562.

Inoue, T., Tsui, J., Wong, N., Wong, S.Y., Suzuki, F., Kwok, Y.N., 1999. Expression of glial cell line-derived neurotrophic factor and its mRNA in the nigrostriatal pathway following MPTP treatment. Brain Res. 826, 306-308.

Irie, F., Hirabayashi, Y., 1999. Ceramide prevents motoneuronal cell death through inhibition of oxidative signal. Neurosci. Res. 35, 135-144.

Ivanova, T., Karolczak, M., Beyer, C., 2002. Estradiol stimulates GDNF expression in developing hypothalamic neurons. Endocrinology 143, 3175-3178.

Iwase, T., Jung, C.G., Bae, H., Zhang, M., Soliven, B., 2005. Glial cell line-derived neurotrophic factor-induced signaling in Schwann cells. J. Neurochem. 94, 1488-1499.

Jackson, M., Llado, J., Rothstein, J.D., 2002. Therapeutic developments in the treatment of amyotrophic lateral sclerosis. Expert Opin. Invest. Drugs 11, 13431364.

Jadavji, N.M., Kolb, B., Metz, G.A., 2006. Enriched environment improves motor function in intact and unilateral dopamine-depleted rats. Neuroscience 140 , 1127-1138

Jaumotte, J.D., Zigmond, M.J., 2005. Dopaminergic innervation of forebrain by ventral mesencephalon in organotypic slice co-cultures: effects of GDNF. Brain Res. Mol. Brain Res. 134, 139-146.

Jin, G., Omori, N., Li, F., Nagano, I., Manabe, Y., Shoji, M., Abe, K., 2003. Protection against ischemic brain damage by GDNF affecting cell survival and death signals. Neurol. Res. 25, 249-253.

Jokinen, P., Brück, A., Aalto, S., Forsback, S., Parkkola, R., Rinne, J.O., 2008. Impaired cognitive performance in Parkinson's disease is related to caudate dopaminergic hypofunction and hippocampal atrophy. Parkinsonism. Rel. Disord. doi:10.1016/j.parkreldis.2008.03.005.

Joo, W.S., Jin, B.K., Park, C.W., Maeng, S.H., Kim, Y.S., 1998. Melatonin increases striatal dopaminergic function in 6-OHDA-lesioned rats. Neuroreport 9, 41234126.

Jourdain, S., Morissette, M., Morin, N., Di, P.T., 2005. Oestrogens prevent loss of dopamine transporter (DAT) and vesicular monoamine transporter (VMAT2) in substantia nigra of 1-methyl-4-phenyl-1,2,3,6-tetrahydropyridine mice. J. Neuroendocrinol. 17, 509-517.

Kalechman, Y., Gafter, U., Da, J.P., Albeck, M., Arcon-Segovia, D., Sredni, B., 1997. Delay in the onset of systemic lupus erythematosus following treatment with the immunomodulator AS101: association with IL-10 inhibition and increase in TNF-alpha levels. J. Immunol. 159, 2658-2667.

Kalechman, Y., Sredni, B., Weinstein, T., Freidkin, I., Tobar, A., Albeck, M., Gafter, U. 2003. Production of the novel mesangial autocrine growth factors GDNF and IL10 is regulated by the immunomodulator AS101. J. Am. Soc. Nephrol. 14, 620630.

Kalechman, Y., Zuloff, A., Albeck, M., Strassmann, G., Sredni, B., 1995. Role of endogenous cytokines secretion in radioprotection conferred by the immunomodulator ammonium trichloro(dioxyethylene-0-0')tellurate. Blood 85, 15551561.

Kastin, A.J., Akerstrom, V., Pan, W., 2003. Glial cell line-derived neurotrophic factor does not enter normal mouse brain. Neurosci. Lett. 340, 239-241.

Kholodilov, N., Yarygina, O., Oo, T.F., Zhang, H., Sulzer, D., Dauer, W., Burke, R.E. 2004. Regulation of the development of mesencephalic dopaminergic systems by the selective expression of glial cell line-derived neurotrophic factor in their targets. J. Neurosci. 24, 3136-3146.

Kilic, E., Kilic, U., Hermann, D.M., 2005. TAT-GDNF in neurodegeneration and ischemic stroke. CNS Drug Rev. 11, 369-378.

Kinameri, E., Matsuoka, I., 2003. Autocrine action of BMP2 regulates expression of GDNF-mRNA in sciatic Schwann cells. Brain Res. Mol. Brain Res. 117, 221-227.

Kinor, N., Geffen, R., Golomb, E., Zinman, T., Yadid, G., 2001. Dopamine increases glial cell line-derived neurotrophic factor in human fetal astrocytes. Glia 33 143-150.

Kipp, M., Karakaya, S., Pawlak, J., Raujo-Wright, G., Arnold, S., Beyer, C., 2006. Estrogen and the development and protection of nigrostriatal dopaminergic neurons: concerted action of a multitude of signals, protective molecules, and growth factors. Front. Neuroendocrinol. 27, 376-390.

Kirik, D., Georgievska, B., Bjorklund, A., 2004. Localized striatal delivery of GDNF as a treatment for Parkinson disease. Nat. Neurosci. 7, 105-110.

Kitamura, T., Mishina, M., Sugiyama, H., 2006. Dietary restriction increases hippocampal neurogenesis by molecular mechanisms independent of NMDA receptors. Neurosci. Lett. 393, 94-96.

Klettner, A., Baumgrass, R., Zhang, Y., Fischer, G., Burger, E., Herdegen, T., Mielke, K., 2001. The neuroprotective actions of FK506 binding protein ligands: neuronal survival is triggered by de novo RNA synthesis, but is independent of inhibition of JNK and calcineurin. Brain Res. Mol. Brain Res. 97, 21-31.

Knoll, J., 1998. (-)Deprenyl (selegiline), a catecholaminergic activity enhancer (CAE) substance acting in the brain. Pharmacol. Toxicol. 82, 57-66.

Knoll, J., Yoneda, F., Knoll, B., Ohde, H., Miklya, I., 1999. (-)1-(Benzofuran-2-yl)-2propylaminopentane, [(-)BPAP], a selective enhancer of the impulse propagation mediated release of catecholamines and serotonin in the brain. Br. J. Pharmacol. 128, 1723-1732.

Kobayashi, H., Kawakami, K., Asashima, M., Nishinakamra, R., 2007. Six1 and Six4 are essential for Gdnf expression in the metanephric mesenchyme and ureteric bud formation, while Six1 deficiency alone causes mesonephric-tubule defects. Mech. Dev. 124, 290-303.

Kobori, N., Waymire, J.C., Haycock, J.W., Clifton, G.L., Dash, P.K., 2004. Enhancement of tyrosine hydroxylase phosphorylation and activity by glial cell line-derived neurotrophic factor. J. Biol. Chem. 279, 2182-2191.

Koeberle, P.D., Bahr, M., 2008. The upregulation of GLAST-1 is an indirect antiapoptotic mechanism of GDNF and neurturin in the adult CNS. Cell Death Differ. $15,471-483$

Koh, J.Y., Kim, D.K., Hwang, J.Y., Kim, Y.H., Seo, J.H., 1999. Antioxidative and proapoptotic effects of riluzole on cultured cortical neurons. J. Neurochem. $72,716-723$.

Kornhuber, J., Weller, M., Schoppmeyer, K., Riederer, P., 1994. Amantadine and memantine are NMDA receptor antagonists with neuroprotective properties. J. Neural Transm. Suppl. 43, 91-104.

Kotzbauer, P.T., Lampe, P.A., Heuckeroth, R.O., Golden, J.P., Creedon, D.J., Johnson Jr., E.M., Milbrandt, J., 1996. Neurturin, a relative of glial-cell-line-derived neurotrophic factor. Nature 384, 467-470.

Koutsilieri, E., O'Callaghan, J.F., Chen, T.S., Riederer, P., Rausch, W.D., 1994. Selegiline enhances survival and neurite outgrowth of $\mathrm{MPP}(+)$-treated dopaminergic neurons. Eur. J. Pharmacol. 269, R3-R4.

Koyama, Y., Egawa, H., Osakada, M., Baba, A., Matsuda, T., 2004. Increase by FK960, a novel cognitive enhancer, in glial cell line-derived neurotrophic factor production in cultured rat astrocytes. Biochem. Pharmacol. 68, 275-282.

Koyama, Y., Tsujikawa, K., Matsuda, T., Baba, A., 2003a. Endothelin-1 stimulates glial cell line-derived neurotrophic factor expression in cultured rat astrocytes. Biochem. Biophys. Res. Commun. 303, 1101-1105.

Koyama, Y., Tsujikawa, K., Matsuda, T., Baba, A., 2003b. Intracerebroventricular administration of an endothelin ETB receptor agonist increases expressions of GDNF and BDNF in rat brain. Eur. J. Neurosci. 18, 887-894.

Kramer, E.R., Aron, L., Ramakers, G.M., Seitz, S., Zhuang, X., Beyer, K., Smidt, M.P., Klein, R., 2007. Absence of Ret signaling in mice causes progressive and late degeneration of the nigrostriatal system. PLoS Biol. 5, e39.

Kume, T., Deng, K., Hogan, B.L., 2000. Murine forkhead/winged helix genes Foxc1 (Mf1) and Foxc2 (Mfh1) are required for the early organogenesis of the kidney and urinary tract. Development 127, 1387-1395.

Kuno, R., Yoshida, Y., Nitta, A., Nabeshima, T., Wang, J., Sonobe, Y., Kawanokuchi, J., Takeuchi, H., Mizuno, T., Suzumura, A., 2006. The role of TNF-alpha and its 
receptors in the production of NGF and GDNF by astrocytes. Brain Res. 1116, 12 18.

Kyriazis, M., 2003. Neuroprotective, anti-apoptotic effects of apomorphine. J. Antiaging Med. 6, 21-28.

Lannes, B., Micheletti, G., 1997. Sensitization of the striatal dopaminergic system induced by chronic administration of a glutamate antagonist in the rat. Neurosci. Biobehav. Rev. 21, 417-424.

Larsen, K.E., Benn, S.C., Ay, I., Chian, R.J., Celia, S.A., Remington, M.P., Bejarano, M. Liu, M., Ross, J., Carmillo, P., Sah, D., Phillips, K.A., Sulzer, D., Pepinsky, R.B., Fishman, P.S., Brown Jr., R.H., Francis, J.W., 2006. A glial cell line-derived neurotrophic factor (GDNF):tetanus toxin fragment $C$ protein conjugate improves delivery of GDNF to spinal cord motor neurons in mice. Brain Res. $1120,1-12$.

Larsen, J.P., Boas, J., 1997. The effects of early selegiline therapy on long-term levodopa treatment and parkinsonian disability: an interim analysis of a Norwegian-Danish 5-year study. Norwegian-Danish Study Group. Mov. Disord. $12,175-182$.

Ledda, F., Bieraugel, O., Fard, S.S., Vilar, M., Paratcha, G., 2008. Lrig1 is an endogenous inhibitor of Ret receptor tyrosine kinase activation, downstream signaling, and biological responses to GDNF. J. Neurosci. 28, 39-49.

Ledda, F., Paratcha, G., Sandoval-Guzman, T., Ibanez, C.F., 2007. GDNF and GFRalpha1 promote formation of neuronal synapses by ligand-induced cell adhesion. Nat. Neurosci. 10, 293-300.

Lee, J., Duan, W., Mattson, M.P., 2002. Evidence that brain-derived neurotrophic factor is required for basal neurogenesis and mediates, in part, the enhancement of neurogenesis by dietary restriction in the hippocampus of adult mice. J. Neurochem. 82, 1367-1375.

Lee, J., Duan, W., Long, J.M., Ingram, D.K., Mattson, M.P., 2000. Dietary restriction increases the number of newly generated neural cells, and induces BDNF expression, in the dentate gyrus of rats. J. Mol. Neurosci. 15, 99-108.

Lee, S.H., Chun, W., Kong, P.J., Han, J.A., Cho, B.P., Kwon, O.Y., Lee, H.J., Kim, S.S. 2006. Sustained activation of Akt by melatonin contributes to the protection against kainic acid-induced neuronal death in hippocampus. J. Pineal Res. 40 , $79-85$

Lehman, D.A., Toole, T., Lofald, D., Hirsch, M.A., 2005. Training with verbal instructional cues results in near-term improvement of gait in people with Parkinson disease. J. Neurol. Phys. Ther. 29, 2-8.

Lenhard, T., Schober, A., Suter-Crazzolara, C., Unsicker, K., 2002. Fibroblast growth factor-2 requires glial-cell-line-derived neurotrophic factor for exerting its neuroprotective actions on glutamate-lesioned hippocampal neurons. Mol. Cel Neurosci. 20, 181-197.

Leuner, B., Gould, E., Shors, T.J., 2006. Is there a link between adult neurogenesis and learning? Hippocampus 16, 216-224.

Levy, Y.S., Gilgun-Sherki, Y., Melamed, E., Offen, D., 2005. Therapeutic potential of neurotrophic factors in neurodegenerative diseases. BioDrugs 19, 97-127.

Li, A., Guo, H., Luo, X., Sheng, J., Yang, S., Yin, Y., Zhou, J., Zhou, J., 2006a. Apomorphine-induced activation of dopamine receptors modulates FGF-2 expression in astrocytic cultures and promotes survival of dopaminergic neurons. Faseb J. 20, 1263-1265.

Li, L., Su, Y., Zhao, C., Zhao, H., Liu, G., Wang, J., Xu, Q., 2006b. The role of Ret receptor tyrosine kinase in dopaminergic neuron development. Neuroscience 142, 391400.

Li, S., Wang, L., Berman, M.A., Zhang, Y., Dorf, M.E., 2006c. RNAi screen in mouse astrocytes identifies phosphatases that regulate NF-kappaB signaling. Mol. Cell 24, 497-509.

Li, X., Oghi, K.A., Zhang, J., Krones, A., Bush, K.T., Glass, C.K., Nigam, S.K., Aggarwal, A.K., Maas, R., Rose, D.W., Rosenfeld, M.G., 2003. Eya protein phosphatase activity regulates Six1-Dach-Eya transcriptional effects in mammalian organogenesis, Nature 426, 247-254.

Liberatore, G.T., Wong, J.Y., Porritt, M.J., Donnan, G.A., Howells, D.W., 1997. Expression of glial cell line-derived neurotrophic factor (GDNF) mRNA following mechanical injury to mouse striatum. Neuroreport 8, 3097-3101.

Liberto, C.M., Albrecht, P.J., Herx, L.M., Yong, V.W., Levison, S.W., 2004. Pro-regenerative properties of cytokine-activated astrocytes. J. Neurochem. 89, 1092 1100.

Lim, E., 2005. A walk through the management of Parkinson's disease. Ann. Acad. Med. Singapore 34, 188-195

Lin, L.F., Doherty, D.H., Lile, J.D., Bektesh, S., Collins, F., 1993. GDNF: a glial cell linederived neurotrophic factor for midbrain dopaminergic neurons. Science 260 1130-1132.

Lin, L.F., Zhang, T.J., Collins, F., Armes, L.G., 1994. Purification and initial characterization of rat B49 glial cell line-derived neurotrophic factor. J. Neurochem. 63, 758-768.

Liu, J., Albers, M.W., Wandless, T.J., Luan, S., Alberg, D.G., Belshaw, P.J., Cohen, P., MacKintosh, C., Klee, C.B., Schreiber, S.L., 1992. Inhibition of T cell signaling by immunophilin-ligand complexes correlates with loss of calcineurin phosphatase activity. Biochemistry 31, 3896-3901.

Logroscino, G., Marder, K., Cote, L., Tang, M.X., Shea, S., Mayeux, R., 1996. Dietary lipids and antioxidants in Parkinson's disease: a population-based, case-contro study. Ann. Neurol. 39, 89-94.

Logroscino, G., Sesso, H.D., Paffenbarger Jr., R.S., Lee, I.M., 2006. Physical activity and risk of Parkinson's disease: a prospective cohort study. J. Neurol. Neurosurg. Psychiatry 77, 1318-1322.

Lopez-Martin, E., Caruncho, H.J., Rodriguez-Pallares, J., Guerra, M.J., LabandeiraGarcia, J.L., 1999. Striatal dopaminergic afferents concentrate in GDNF-positive patches during development and in developing intrastriatal striatal grafts. J. Comp. Neurol. 406, 199-206.

Lopez-Ramirez, M.A., Dominguez-Monzon, G., Vergara, P., Segovia, J., 2008. Gas1 reduces Ret tyrosine 1062 phosphorylation and alters GDNF-mediated intracellular signaling. Int. J. Dev. Neurosci. 26, 497-503.

Mabandla, M., Kellaway, L., St. Clair, G.A., Russell, V.A., 2004. Voluntary running provides neuroprotection in rats after 6-hydroxydopamine injection into the medial forebrain bundle. Metab. Brain Dis. 19, 43-50.

Mandel, S., Grunblatt, E., Maor, G., Youdim, M.B., 2002. Early and late gene changes in MPTP mice model of Parkinson's disease employing cDNA microarray. Neurochem. Res. 27, 1231-1243.

Mandel, S., Weinreb, O., Amit, T., Youdim, M.B., 2005. Mechanism of neuroprotective action of the anti-Parkinson drug rasagiline and its derivatives. Brain Res. Brain Res. Rev. 48, 379-387.

Manson, A.J., Hanagasi, H., Turner, K., Patsalos, P.N., Carey, P., Ratnaraj, N., Lees, A.J., 2001. Intravenous apomorphine therapy in Parkinson's disease: clinical and pharmacokinetic observations. Brain 124, 331-340.

Marco, S., Canudas, A.M., Canals, J.M., Gavalda, N., Perez-Navarro, E., Alberch, J., 2002. Excitatory amino acids differentially regulate the expression of GDNF, neurturin, and their receptors in the adult rat striatum. Exp. Neurol. 174, 243252.

Martin, B., Mattson, M.P., Maudsley, S., 2006. Caloric restriction and intermittent fasting: two potential diets for successful brain aging. Ageing Res. Rev. 5, 332353.

Maruyama, W., Nitta, A., Shamoto-Nagai, M., Hirata, Y., Akao, Y., Yodim, M., Furukawa, S., Nabeshima, T., Naoi, M., 2004. N-Propargyl-1 (R)-aminoindan, rasagiline, increases glial cell line-derived neurotrophic factor (GDNF) in neuroblastoma SH-SY5Y cells through activation of NF-kappaB transcription factor. Neurochem. Int. 44, 393-400

Masana, M.I., Dubocovich, M.L., 2001. Melatonin receptor signaling: finding the path through the dark. Sci. STKE 2001, E39.

Maswood, N., Young, J., Tilmont, E., Zhang, Z., Gash, D.M., Gerhardt, G.A., Grondin, R., Roth, G.S., Mattison, J., Lane, M.A., Carson, R.E., Cohen, R.M., Mouton, P.R., Quigley, C., Mattson, M.P., Ingram, D.K., 2004. Caloric restriction increases neurotrophic factor levels and attenuates neurochemical and behavioral deficits in a primate model of Parkinson's disease. Proc. Natl. Acad. Sci. U.S.A. 101, 18171-18176.

Matsushita, N., Fujita, Y., Tanaka, M., Nagatsu, T., Kiuchi, K., 1997. Cloning and structural organization of the gene encoding the mouse glial cell line-derived neurotrophic factor, GDNF. Gene 203, 149-157.

Mattson, M.P., 2005. Energy intake, meal frequency, and health: a neurobiological perspective. Annu. Rev. Nutr. 25, 237-260.

Mattson, M.P., Magnus, T., 2006. Ageing and neuronal vulnerability. Nat. Rev. Neurosci. 7, 278-294

Mattson, M.P., Duan, W., Wan, R., Guo, Z., 2004. Prophylactic activation of neuroprotective stress response pathways by dietary and behavioral manipulations. NeuroRx 1, 111-116.

McNaught, K.S., Jenner, P., 2000. Dysfunction of rat forebrain astrocytes in culture alters cytokine and neurotrophic factor release. Neurosci. Lett. 285, 61-65.

Mellstrom, B., Cena, V., Lamas, M., Perales, C., Gonzalez, C., Naranjo, J.R., 2002. Gas1 is induced during and participates in excitotoxic neuronal death. Mol. Cell. Neurosci. 19, 417-429.

Mena, M.A., Davila, V., Sulzer, D., 1997. Neurotrophic effects of L-DOPA in postnatal midbrain dopamine neuron/cortical astrocytes cocultures. J. Neurochem. 69, $1398-1408$

Mercier, G., Lennon, A.M., Renouf, B., Dessouroux, A., Ramauge, M., Courtin, F., Pierre, M., 2004. MAP kinase activation by fluoxetine and its relation to gene expression in cultured rat astrocytes. J. Mol. Neurosci. 24, 207-216.

Meyer, M., Schreck, R., Baeuerle, P.A., 1993. $\mathrm{H}_{2} \mathrm{O}_{2}$ and antioxidants have opposite effects on activation of NF-kappa B and AP-1 in intact cells: AP-1 as secondary antioxidant-responsive factor. EMBO J. 12, 2005-2015.

Milanini, J., Vinals, F., Pouyssegur, J., Pages, G., 1998. p42/p44 MAP kinase module plays a key role in the transcriptional regulation of the vascular endothelial growth factor gene in fibroblasts. J. Biol. Chem. 273, 18165-18172.

Milbrandt, J., de Sauvage, F.J., Fahrner, T.J., Baloh, R.H., Leitner, M.L., Tansey, M.G., Lampe, P.A., Heuckeroth, R.O., Kotzbauer, P.T., Simburger, K.S., Golden, J.P., Davies, J.A., Vejsada, R., Kato, A.C., Hynes, M., Sherman, D., Nishimura, M., Wang, L.C., Vandlen, R., Moffat, B., Klein, R.D., Poulsen, K., Gray, C., Garces, A., Johnson Jr., E.M., 1998. Persephin, a novel neurotrophic factor related to GDNF and neurturin. Neuron 20, 245-253.

Miskolci, V., Castro-Alcaraz, S., Nguyen, P., Vancura, A., Davidson, D., Vancurova, I., 2003. Okadaic acid induces sustained activation of NFkappaB and degradation of the nuclear IkappaBalpha in human neutrophils. Arch. Biochem. Biophys. $417,44-52$

Mitchell, I.J., Hughes, N., Carroll, C.B., Brotchie, J.M., 1995. Reversal of parkinsonian symptoms by intrastriatal and systemic manipulations of excitatory amino acid and dopamine transmission in the bilateral 6-OHDA lesioned marmoset. Behav. Pharmacol. 6, 492-507.

Miyajima, H., Osanai, M., Chiba, H., Nishikiori, N., Kojima, T., Ohtsuka, K., Sawada, N. 2005. Glyceraldehyde-derived advanced glycation end-products preferentially induce VEGF expression and reduce GDNF expression in human astrocytes. Biochem. Biophys. Res. Commun. 330, 361-366.

Miyazaki, H., Nagashima, K., Okuma, Y., Nomura, Y., 2001. Expression of glial cell line-derived neurotrophic factor induced by transient forebrain ischemia in rats. Brain Res. 922, 165-172. 
Miyazaki, H., Okuma, Y., Nomura, J., Nagashima, K., Nomura, Y., 2003. Age-related alterations in the expression of glial cell line-derived neurotrophic factor in the senescence-accelerated mouse brain. J. Pharmacol. Sci. 92, 28-34.

Mizoule, J., Meldrum, B., Mazadier, M., Croucher, M., Ollat, C., Uzan, A., Legrand, J.J., Gueremy, C., Le, F.G., 1985. 2-Amino-6-trifluoromethoxy benzothiazole, a possible antagonist of excitatory amino acid neurotransmission. I. Anticonvulsant properties. Neuropharmacology 24, 767-773.

Mizuta, I., Ohta, M., Ohta, K., Nishimura, M., Mizuta, E., Kuno, S., 2001. Riluzole stimulates nerve growth factor, brain-derived neurotrophic factor and glial cell line-derived neurotrophic factor synthesis in cultured mouse astrocytes. Neurosci. Lett. 310, 117-120.

Mizuta, I., Ohta, M., Ohta, K., Nishimura, M., Mizuta, E., Hayashi, K., Kuno, S., 2000. Selegiline and desmethylselegiline stimulate NGF, BDNF, and GDNF synthesis in cultured mouse astrocytes. Biochem. Biophys. Res. Commun. 279, 751-755.

Mogi, M., Harada, M., Kondo, T., Riederer, P., Nagatsu, T., 1996. Interleukin-2 but not basic fibroblast growth factor is elevated in parkinsonian brain. Short communication. J. Neural Transm. 103, 1077-1081.

Mogi, M., Togari, A., Kondo, T., Mizuno, Y., Kogure, O., Kuno, S., Ichinose, H., Nagatsu, T., 2001. Glial cell line-derived neurotrophic factor in the substantia nigra from control and parkinsonian brains. Neurosci. Lett. 300, 179-181.

Mogi, M., Togari, A., Kondo, T., Mizuno, Y., Komure, O., Kuno, S., Ichinose, H., Nagatsu, T., 1999. Brain-derived growth factor and nerve growth factor concentrations are decreased in the substantia nigra in Parkinson's disease. Neurosci. Lett. 270, 45-48.

Moore, K.W., de Waal, M.R., Coffman, R.L., O'Garra, A., 2001. Interleukin-10 and the interleukin-10 receptor. Annu. Rev. Immunol. 19, 683-765.

Moore, M.W., Klein, R.D., Farinas, I., Sauer, H., Armanini, M., et al., 1996. Renal and neuronal abnormalities in mice lacking GDNF. Nature 382, 76-79.

Morale, M.C., Serra, P.A., L'Episcopo, F., Tirolo, C., Caniglia, S., Testa, N., Gennuso, F., Giaquinta, G., Rocchitta, G., Desole, M.S., Miele, E., Marchetti, B., 2006. Estrogen, neuroinflammation and neuroprotection in Parkinson's disease: glia dictates resistance versus vulnerability to neurodegeneration. Neuroscience $138,869-$ 878.

Moretto, G., Walker, D.G., Lanteri, P., Taioli, F., Zaffagnini, S., Xu, R.Y., Rizzuto, N., 1996. Expression and regulation of glial-cell-line-derived neurotrophic factor (GDNF) mRNA in human astrocytes in vitro. Cell Tissue Res. 286, 257-262.

Moynagh, P.N., Williams, D.C., O’Neill, L.A., 1993. Interleukin-1 activates transcription factor NF kappa B in glial cells. Biochem. J. 294 (Pt 2), 343-347.

Murphy, K.J., Fox, G.B., Foley, A.G., Gallagher, H.C., O'Connell, A., Griffin, A., Nau, H., Regan, C.M., 2001. Pentyl-4-yn-valproic acid enhances both spatial and avoidance learning, and attenuates age-related NCAM-mediated neuroplastic decline within the rat medial temporal lobe. J. Neurochem. 78, 704-714.

Murray, H.E., Pillai, A.V., McArthur, S.R., Razvi, N., Datla, K.P., Dexter, D.T., Gillies, G.E., 2003. Dose- and sex-dependent effects of the neurotoxin 6-hydroxydopamine on the nigrostriatal dopaminergic pathway of adult rats: differential actions of estrogen in males and females. Neuroscience 116, 213-222.

Mytilineou, C., Cohen, G., 1985. Deprenyl protects dopamine neurons from the neurotoxic effect of 1-methyl-4-phenylpyridinium ion. J. Neurochem. 45, 1951-1953.

Nakagawa, T., Schwartz, J.P., 2004. Gene expression profiles of reactive astrocytes in dopamine-depleted striatum. Brain Pathol. 14, 275-280.

Nakagawa, T., Yabe, T., Schwartz, J.P., 2005. Gene expression profiles of reactive astrocytes cultured from dopamine-depleted striatum. Neurobiol. Dis. 20, 275282.

Nakajima, K., Hida, H., Shimano, Y., Fujimoto, I., Hashitani, T., Kumazaki, M., Sakurai, T., Nishino, H., 2001. GDNF is a major component of trophic activity in DAdepleted striatum for survival and neurite extension of DAergic neurons. Brain Res. 916, 76-84.

Nakashima, S., Matsuyama, Y., Yu, Y., Katayama, Y., Ito, Z., Ishiguro, N., 2005. Expression of GDNF in spinal cord injury and its repression by ONO-1714. Neuroreport 16, 17-20.

Nakashima, S., Matsuyama, Y., Yu, Y., Kiuchi, K., Ishiguro, N., 2004. Suppression of GDNF production by MPSS treatment following spinal cord injury in the rat. Neuroreport 15, 2337-2340.

Nakaso, K., Nakamura, C., Sato, H., Imamura, K., Takeshima, T., Nakashima, K., 2006. Novel cytoprotective mechanism of anti-parkinsonian drug deprenyl: PI3K and Nrf2-derived induction of antioxidative proteins. Biochem. Biophys. Res. Commun. 339, 915-922.

Nash, J.E., Fox, S.H., Henry, B., Hill, M.P., Peggs, D., McGuire, S., Maneuf, Y., Hille, C., Brotchie, J.M., Crossman, A.R., 2000. Antiparkinsonian actions of ifenprodil in the MPTP-lesioned marmoset model of Parkinson's disease. Exp. Neurol. 165, 136-142.

Nash, J.E., Hill, M.P., Brotchie, J.M., 1999. Antiparkinsonian actions of blockade of NR2B-containing NMDA receptors in the reserpine-treated rat. Exp. Neurol. 155, 42-48.

Naskar, R., Vorwerk, C.K., Dreyer, E.B., 2000. Concurrent downregulation of a glutamate transporter and receptor in glaucoma. Invest. Ophthalmol. Vis. Sci. 41, 1940-1944.

Naughton, C.K., Jain, S., Strickland, A.M., Gupta, A., Milbrandt, J., 2006. Glial cell-line derived neurotrophic factor-mediated RET signaling regulates spermatogonial stem cell fate. Biol. Reprod. 74, 314-321.

Naveilhan, P., Neveu, I., Wion, D., Brachet, P., 1996. 1,25-Dihydroxyvitamin $D_{3}$, an inducer of glial cell line-derived neurotrophic factor. Neuroreport 7, 2171-2175.

Neeper, S.A., Gomez-Pinilla, F., Choi, J., Cotman, C., 1995. Exercise and brain neurotrophins. Nature 373, 109.
Nichols, M., Weih, F., Schmid, W., DeVack, C., Kowenz-Leutz, E., Luckow, B., Boshart M., Schutz, G., 1992. Phosphorylation of CREB affects its binding to high and low affinity sites: implications for cAMP induced gene transcription. EMBO J. 11, 3337-3346.

Nicole, O., Ali, C., Docagne, F., Plawinski, L., MacKenzie, E.T., Vivien, D., Buisson, A., 2001. Neuroprotection mediated by glial cell line-derived neurotrophic factor: involvement of a reduction of NMDA-induced calcium influx by the mitogenactivated protein kinase pathway. J. Neurosci. 21, 3024-3033.

Niles, L.P., Armstrong, K.J., Rincon Castro, L.M., Dao, C.V., Sharma, R., McMillan, C.R. Doering, L.C., Kirkham, D.L., 2004. Neural stem cells express melatonin receptors and neurotrophic factors: colocalization of the MT1 receptor with neuronal and glial markers. BMC Neurosci. 5, 41.

Nishiguchi, M., Tokugawa, K., Yamamoto, K., Akama, T., Nozawa, Y., Chaki, S., Ueki, T., Kameo, K., Okuyama, S., 2003. Increase in secretion of glial cell line-derived neurotrophic factor from glial cell lines by inhibitors of vacuolar ATPase. Neurochem. Int. 42, 493-498.

Nishinakamura, R., Matsumoto, Y., Nakao, K., Nakamura, K., Sato, A., Copeland, N.G. Gilbert, D.J., Jenkins, N.A., Scully, S., Lacey, D.L., Katsuki, M., Asashima, M. Yokota, T., 2001. Murine homolog of SALL1 is essential for ureteric bud invasion in kidney development. Development 128, 3105-3115.

Nitta, A., Nishioka, H., Fukumitsu, H., Furukawa, Y., Sugiura, H., Shen, L., Furukawa, S., 2004. Hydrophobic dipeptide Leu-Ile protects against neuronal death by inducing brain-derived neurotrophic factor and glial cell line-derived neurotrophic factor synthesis. J. Neurosci. Res. 78, 250-258.

Niwa, M., Nitta, A., Yamada, K., Nabeshima, T., 2007. The roles of glial cell linederived neurotrophic factor, tumor necrosis factor-alpha, and an inducer of these factors in drug dependence. J. Pharmacol. Sci. 104, 116-121.

Nosheny, R.L., Bachis, A., Acquas, E., Mocchetti, I., 2004. Human immunodeficiency virus type 1 glycoprotein gp120 reduces the levels of brain-derived neurotrophic factor in vivo: potential implication for neuronal cell death. Eur. J. Neurosci. 20, 2857-2864.

Nosheny, R.L., Bachis, A., Aden, S.A., De Bernardi, M.A., Mocchetti, I., 2006. Intrastriatal administration of human immunodeficiency virus-1 glycoprotein 120 reduces glial cell-line derived neurotrophic factor levels and causes apoptosis in the substantia nigra. J. Neurobiol. 66, 1311-1321.

Nosrat, C.A., Tomac, A., Hoffer, B.J., Olson, L., 1997. Cellular and developmental patterns of expression of Ret and glial cell line-derived neurotrophic factor receptor alpha mRNAs. Exp. Brain Res. 115, 410-422.

O’Dell, S.J., Gross, N.B., Fricks, A.N., Casiano, B.D., Nguyen, T.B., Marshall, J.F., 2007. Running wheel exercise enhances recovery from nigrostriatal dopamine injury without inducing neuroprotection. Neuroscience 144, 1141-1151.

Oh-Hashi, K., Kaneyama, M., Hirata, Y., Kiuchi, K., 2006. ER calcium discharge stimulates GDNF gene expression through MAPK-dependent and -independent pathways in rat C6 glioblastoma cells. Neurosci. Lett. 405, 100-105.

Ohta, K., Fujinami, A., Kuno, S., Sakakimoto, A., Matsui, H., Kawahara, Y., Ohta, M., 2004. Cabergoline stimulates synthesis and secretion of nerve growth factor, brain-derived neurotrophic factor and glial cell line-derived neurotrophic factor by mouse astrocytes in primary culture. Pharmacology 71, 162-168.

Ohta, K., Kuno, S., Mizuta, I., Fujinami, A., Matsui, H., Ohta, M., 2003. Effects of dopamine agonists bromocriptine, pergolide, cabergoline, and SKF-38393 on GDNF, NGF, and BDNF synthesis in cultured mouse astrocytes. Life Sci. 73, 617626.

Ohta, K., Ohta, M., Mizuta, I., Fujinami, A., Shimazu, S., Sato, N., Yoneda, F., Hayashi, K., Kuno, S., 2002. The novel catecholaminergic and serotoninergic activity enhancer $R$-(-)-1-(benzofuran-2-yl)-2-propylaminopentane up-regulates neurotrophic factor synthesis in mouse astrocytes. Neurosci. Lett. 328, 205-208.

Ohta, M., Mizuta, I., Ohta, K., Nishimura, M., Mizuta, E., Hayashi, K., Kuno, S., 2000 Apomorphine up-regulates NGF and GDNF synthesis in cultured mouse astrocytes. Biochem. Biophys. Res. Commun. 272, 18-22.

Ohto, H., Kamada, S., Tago, K., Tominaga, S.I., Ozaki, H., Sato, S., Kawakami, K., 1999 Cooperation of six and eya in activation of their target genes through nuclear translocation of Eya. Mol. Cell. Biol. 19, 6815-6824.

Okun, E., Saida, H., Albeck, M., Sredni, B., Avtalion, R.R., 2006. Upregulation of carp GDNF mRNA by the immunomodulator AS101. Dev. Comp. Immunol. 30, 441446.

Olanow, C.W., Agid, Y., Mizuno, Y., et al., 2004. Levodopa in the treatment of Parkinson's disease: current controversies. Mov. Disord. 19, 997-1005.

Olson, A.K., Eadie, B.D., Ernst, C., Christie, B.R., 2006. Environmental enrichment and voluntary exercise massively increase neurogenesis in the adult hippocampus via dissociable pathways. Hippocampus 16, 250-260.

Onyango, I.G., Tuttle, J.B., Bennett Jr., J.P., 2005. Brain-derived growth factor and glial cell line-derived growth factor use distinct intracellular signaling pathways to protect PD cybrids from $\mathrm{H}_{2} \mathrm{O}_{2}$-induced neuronal death. Neurobiol. Dis. 20, $141-$ 154.

Oo, T.F., Kholodilov, N., Burke, R.E., 2003. Regulation of natural cell death in dopaminergic neurons of the substantia nigra by striatal glial cell line-derived neurotrophic factor in vivo. J. Neurosci. 23, 5141-5148.

Oo, T.F., Ries, V., Cho, J., Kholodilov, N., Burke, R.E., 2005. Anatomical basis of glial cell line-derived neurotrophic factor expression in the striatum and related basal ganglia during postnatal development of the rat. J. Comp. Neurol. 484, 57-67.

Otto, D., Unsicker, K., 1990. Basic FGF reverses chemical and morphological deficits in the nigrostriatal system of MPTP-treated mice. J. Neurosci. 10, 1912-1921.

Otto, D., Unsicker, K., 1993. FGF-2 modulates dopamine and dopamine-related striatal transmitter systems in the intact and MPTP-lesioned mouse. Eur. J. Neurosci. 5, 927-932. 
Page, G., Peeters, M., Maloteaux, J.M., Hermans, E., 2000. Increased dopamine uptake in striatal synaptosomes after treatment of rats with amantadine. Eur. J Pharmacol. 403, 75-80.

Parain, K., Murer, M.G., Yan, Q., Faucheux, B., Agid, Y., Hirsch, E., Raisman-Vozari, R., 1999. Reduced expression of brain-derived neurotrophic factor protein in Parkinson's disease substantia nigra. Neuroreport 10, 557-561.

Parkinson Study Group, 2002a. A controlled trial of rasagiline in early Parkinson disease: the TEMPO study. Arch. Neurol. 59, 1937-1943.

Parkinson Study Group, 2002b. Dopamine transporter brain imaging to assess the effects of pramipexole vs levodopa on Parkinson disease progression. JAMA 287, 1653-1661.

Parkinson Study Group, 2004. A controlled, randomized, delayed-start study of rasagiline in early Parkinson disease. Arch. Neurol. 61, 561-566.

Parkinson, F.E., Sinclair, C.J., Othman, T., Haughey, N.J., Geiger, J.D., 2002. Differences between rat primary cortical neurons and astrocytes in purine release evoked by ischemic conditions. Neuropharmacology 43, 836-846.

Parsons, C.G., Danysz, W., Quack, G., 1999. Memantine is a clinically well tolerated $\mathrm{N}$-methyl-D-aspartate (NMDA) receptor antagonist-a review of preclinical data. Neuropharmacology 38, 735-767.

Pascual, A., Hidalgo-Figueroa, M., Piruat, J.I., Pintado, C.O., Gomez-Diaz, R., LopezBarneo, J., 2008. Absolute requirement of GDNF for adult catecholaminergic neuron survival. Nat. Neurosci. doi:10.1038/nn.2136

Peeters, M., Page, G., Maloteaux, J.M., Hermans, E., 2002. Hypersensitivity of dopamine transmission in the rat striatum after treatment with the NMDA receptor antagonist amantadine. Brain Res. 949, 32-41.

Peng, C., Fan, S., Li, X., Fan, X., Ming, M., Sun, Z., Le, W., 2007. Overexpression of pitx3 upregulates expression of BDNF and GDNF in SH-SY5Y cells and primary ventral mesencephalic cultures. FEBS Lett. 581, 1357-1361.

Peng, G.S., Li, G., Tzeng, N.S., Chen, P.S., Chuang, D.M., Hsu, Y.D., Yang, S., Hong, J.S., 2005. Valproate pretreatment protects dopaminergic neurons from LPSinduced neurotoxicity in rat primary midbrain cultures: role of microglia. Brain Res. Mol. Brain Res. 134, 162-169.

Perrelet, D., Ferri, A., Liston, P., Muzzin, P., Korneluk, R.G., Kato, A.C., 2002. IAPs are essential for GDNF-mediated neuroprotective effects in injured motor neurons in vivo. Nat. Cell Biol. 4, 175-179.

Pertusa, M., Garcia-Matas, S., Mammeri, H., Adell, A., Rodrigo, T., Mallet, J., Cristofol, R., Sarkis, C., Sanfeliu, C., 2008. Expression of GDNF transgene in astrocytes improves cognitive deficits in aged rats. Neurobiol. Aging 29, 1366 1379.

Perucca, E., 2002. Pharmacological and therapeutic properties of valproate: a summary after 35 years of clinical experience. CNS Drugs 16, 695-714.

Peterson, A.L., Nutt, J.G., 2008. Treatment of Parkinson's disease with trophic factors. Neurotherapeutics 5, 270-280.

Pezeshki, G., Franke, B., Engele, J., 2001. Evidence for a ligand-specific signaling through GFRalpha-1, but not GFRalpha-2, in the absence of Ret. J. Neurosci. Res. $66,390-395$.

Phiel, C.J., Zhang, F., Huang, E.Y., Guenther, M.G., Lazar, M.A., Klein, P.S., 2001 Histone deacetylase is a direct target of valproic acid, a potent anticonvulsant, mood stabilizer, and teratogen. J. Biol. Chem. 276, 36734-36741.

Pichel, J.G., Shen, L., Sheng, H.Z., Granholm, A.C., Drago, J., et al., 1996. Defects in enteric innervation and kidney development in mice lacking GDNF. Nature 382, 73-76.

Platania, P., Seminara, G., Aronica, E., Troost, D., Vincenza, C.M., Angela, S.M., 2005. 17beta-Estradiol rescues spinal motoneurons from AMPA-induced toxicity: a role for glial cells. Neurobiol. Dis. 20, 461-470.

Pochon, N.A., Menoud, A., Tseng, J.L., Zurn, A.D., Aebischer, P., 1997. Neuronal GDNF expression in the adult rat nervous system identified by in situ hybridization. Eur. J. Neurosci. 9, 463-471.

Pong, K., Zaleska, M.M., 2003. Therapeutic implications for immunophilin ligands in the treatment of neurodegenerative diseases. Curr. Drug. Targets CNS Neurol Disord. 2, 349-356.

Poteryaev, D., Titievsky, A., Sun, Y.F., Thomas-Crusells, J., Lindahl, M., Billaud, M. Arumae, U., Saarma, M., 1999. GDNF triggers a novel Ret-independent Src kinase family-coupled signaling via a GPI-linked GDNF receptor alpha1. FEBS Lett. 463 , 63-66.

Pothos, E.N., Davila, V., Sulzer, D., 1998. Presynaptic recording of quanta from midbrain dopamine neurons and modulation of the quantal size. J. Neurosci. 18 4106-4118.

Presgraves, S.P., Borwege, S., Millan, M.J., Joyce, J.N., 2004. Involvement of dopamine $\mathrm{D}(2) / \mathrm{D}(3)$ receptors and BDNF in the neuroprotective effects of S32504 and pramipexole against 1-methyl-4-phenylpyridinium in terminally differentiated SH-SY5Y cells. Exp. Neurol. 190, 157-170.

Przuntek, H., Conrad, B., Dichgans, J., Kraus, P.H., Krauseneck, P., Pergande, G., Rinne, U., Schimrigk, K., Schnitker, J., Vogel, H.P., 1999. SELEDO: a 5-year long-term trial on the effect of selegiline in early parkinsonian patients treated with levodopa. Eur. J. Neurol. 6, 141-150.

Rabey, J.M., Sagi, I., Huberman, M., Melamed, E., Korczyn, A., Giladi, N., Inzelberg, R., Djaldetti, R., Klein, C., Berecz, G., 2000. Rasagiline mesylate, a new MAO-B inhibitor for the treatment of Parkinson's disease: a double-blind study as adjunctive therapy to levodopa. Clin. Neuropharmacol. 23, 324-330.

Ramirez, A.D., Liu, X., Menniti, F.S., 2003. Repeated estradiol treatment prevents MPTP-induced dopamine depletion in male mice. Neuroendocrinology 77 , 223-231.

Rascol, O., Brooks, D.J., Korczyn, A.D., De Deyn, P.P., Clarke, C.E., Lang, A.E., 2000. A five-year study of the incidence of dyskinesia in patients with early Parkinson's disease who were treated with ropinirole or levodopa. 056 Study Group. N. Engl. J. Med. 342, 1484-1491.

Reeben, M., Laurikainen, A., Hiltunen, J.O., Castren, E., Saarma, M., 1998. The messenger RNAs for both glial cell line-derived neurotrophic factor receptors, c-ret and GDNFRalpha, are induced in the rat brain in response to kainateinduced excitation. Neuroscience 83, 151-159.

Reiter, R.J., Tan, D.X., Pappolla, M.A., 2004. Melatonin relieves the neural oxidative burden that contributes to dementias. Ann. NY Acad. Sci. 1035, 179-196.

Remy, S., Naveilhan, P., Brachet, P., Neveu, I., 2001. Differential regulation of GDNF, neurturin, and their receptors in primary cultures of rat glial cells. J. Neurosci. Res. 64, 242-251.

Remy, S., Naveilhan, P., Paille, V., Brachet, P., Neveu, I., 2003. Lipopolysaccharide and TNFalpha regulate the expression of GDNF, neurturin and their receptors. Neuroreport 14, 1529-1534.

Righi, M., Tongiorgi, E., Cattaneo, A., 2000. Brain-derived neurotrophic factor (BDNF) induces dendritic targeting of BDNF and tyrosine kinase B mRNAs in hippocampal neurons through a phosphatidylinositol-3 kinase-dependent pathway. J. Neurosci. 20, 3165-3174.

Rodriguez, C., Mayo, J.C., Sainz, R.M., Antolin, I., Herrera, F., Martin, V., Reiter, R.J., 2004. Regulation of antioxidant enzymes: a significant role for melatonin. J. Pineal Res. 36, 1-9.

Ron, D., Janak, P.H., 2005. GDNF and addiction. Rev. Neurosci. 16, 277-285.

Ross, D.T., Guo, H., Howorth, P., Chen, Y., Hamilton, G.S., Steiner, J.P., 2001. The small molecule FKBP ligand GPI 1046 induces partial striatal re-innervation after intranigral 6-hydroxydopamine lesion in rats. Neurosci. Lett. 297, 113-116.

Saarelainen, T., Hendolin, P., Lucas, G., Koponen, E., Sairanen, M., MacDonald, E., Agerman, K., Haapasalo, A., Nawa, H., Aloyz, R., Ernfors, P., Castren, E., 2003. Activation of the TrkB neurotrophin receptor is induced by antidepressant drugs and is required for antidepressant-induced behavioral effects. J. Neurosci. 23, 349-357.

Saavedra, A., Baltazar, G., Duarte, E.P., 2007. Interleukin-1beta mediates GDNF upregulation upon dopaminergic injury in ventral midbrain cell cultures. Neurobiol. Dis. 25, 92-104.

Saavedra, A., Baltazar, G., Carvalho, C.M., Duarte, E.P., 2005. GDNF modulates HO-1 expression in substantia nigra postnatal cell cultures. Free Radic. Biol. Med. 39 1611-1619.

Saavedra, A., Baltazar, G., Santos, P., Carvalho, C.M., Duarte, E.P., 2006. Selective injury to dopaminergic neurons up-regulates GDNF in substantia nigra postnatal cell cultures: role of neuron-glia crosstalk. Neurobiol. Dis. 23, 533-542.

Sagi, Y., Mandel, S., Amit, T., Youdim, M.B., 2007. Activation of tyrosine kinase receptor signaling pathway by rasagiline facilitates neurorescue and restoration of nigrostriatal dopamine neurons in post-MPTP-induced parkinsonism. Neurobiol. Dis. 25, 35-44.

Sajadi, A., Bensadoun, J.C., Schneider, B.L., Lo, B.C., Aebischer, P., 2006. Transient striatal delivery of GDNF via encapsulated cells leads to sustained behavioral improvement in a bilateral model of Parkinson disease. Neurobiol. Dis. 22, 119129 .

Sajithlal, G., Zou, D., Silvius, D., Xu, P.X., 2005. Eya1 acts as a critical regulator for specifying the metanephric mesenchyme. Dev. Biol. 284, 323-336.

Salvatore, M.F., Zhang, J.L., Large, D.M., Wilson, P.E., Gash, C.R., Thomas, T.C., Haycock, J.W., Bing, G., Stanford, J.A., Gash, D.M., Gerhardt, G.A., 2004. Striatal GDNF administration increases tyrosine hydroxylase phosphorylation in the rat striatum and substantia nigra. J. Neurochem. 90, 245-254.

Sanchez, B., Lopez-Martin, E., Segura, C., Labandeira-Garcia, J.L., Perez-Fernandez, R., 2002. 1,25-Dihydroxyvitamin $\mathrm{D}(3)$ increases striatal GDNF mRNA and protein expression in adult rats. Brain Res. Mol. Brain Res. 108, 143-146.

Sanchez, M.P., Silos-Santiago, I., Frisen, J., He, B., Lira, S.A., et al., 1996. Renal agenesis and the absence of enteric neurons in mice lacking GDNF. Nature 382, 70-73.

Sariola, H., Saarma, M., 2003. Novel functions and signalling pathways for GDNF. J. Cell Sci. 116, 3855-3862.

Satake, K., Matsuyama, Y., Kamiya, M., Kawakami, H., Iwata, H., Adachi, K., Kiuchi, K. 2000. Up-regulation of glial cell line-derived neurotrophic factor (GDNF) following traumatic spinal cord injury. Neuroreport 11, 3877-3881.

Sawada, H., Ibi, M., Kihara, T., Urushitani, M., Akaike, A., Kimura, J., Shimohama, S., 1998a. Dopamine D2-type agonists protect mesencephalic neurons from glutamate neurotoxicity: mechanisms of neuroprotective treatment against oxidative stress. Ann. Neurol. 44, 110-119.

Sawada, H., Ibi, M., Kihara, T., Urushitani, M., Akaike, A., Shimohama, S., 1998b. Estradiol protects mesencephalic dopaminergic neurons from oxidative stressinduced neuronal death. J. Neurosci. Res. 54, 707-719.

Sawada, H., Ibi, M., Kihara, T., Urushitani, M., Nakanishi, M., Akaike, A., Shimohama, S., 2000. Neuroprotective mechanism of glial cell line-derived neurotrophic factor in mesencephalic neurons. J. Neurochem. 74, 1175-1184.

Schaar, D.G., Sieber, B.A., Dreyfus, C.F., Black, I.B., 1993. Regional and cell-specific expression of GDNF in rat brain. Exp. Neurol. 124, 368-371.

Schapira, A.H., Olanow, C.W., 2004. Neuroprotection in Parkinson disease: mysteries, myths, and misconceptions. JAMA 291, 358-364.

Schinelli, S., 2006. Pharmacology and physiopathology of the brain endothelin system: an overview. Curr. Med. Chem. 13, 627-638.

Schlee, S., Carmillo, P., Whitty, A., 2006. Quantitative analysis of the activation mechanism of the multicomponent growth-factor receptor Ret. Nat. Chem. Biol. $2,636-644$.

Schmidt-Kastner, R., Tomac, A., Hoffer, B., Bektesh, S., Rosenzweig, B., Olson, L., 1994. Glial cell-line derived neurotrophic factor (GDNF) mRNA upregulation 
in striatum and cortical areas after pilocarine-induced status epilepticus in rats. Brain Res. Mol. Brain Res. 26, 325-330.

Schreiber, S.L., 1991. Chemistry and biology of the immunophilins and their immunosuppressive ligands. Science 251, 283-287.

Schueler-Furman, O., Glick, E., Segovia, J., Linial, M., 2006. Is GAS1 a co-receptor for the GDNF family of ligands? Trends Pharmacol. Sci. 27, 72-77.

Shao, Z., Dyck, L.E., Wang, H., Li, X.M., 2006. Antipsychotic drugs cause glial cell linederived neurotrophic factor secretion from C6 glioma cells. J. Psychiatry Neurosci. 31, 32-37.

Sharma, R., McMillan, C.R., Tenn, C.C., Niles, L.P., 2006. Physiological neuroprotection by melatonin in a 6-hydroxydopamine model of Parkinson's disease. Brain Res. 1068, 230-236.

Sherer, T.B., Fiske, B.K., Svendsen, C.N., Lang, A.E., Langston, J.W., 2006. Crossroads in GDNF therapy for Parkinson's disease. Mov. Disord. 21, 136-141.

Shimazu, S., Takahata, K., Katsuki, H., Tsunekawa, H., Tanigawa, A., Yoneda, F., Knoll, J., Akaike, A., 2001. (-)-1-(Benzofuran-2-yl)-2-propylaminopentane enhances locomotor activity in rats due to its ability to induce dopamine release. Eur. J. Pharmacol. 421, 181-189.

Shimazu, S., Tanigawa, A., Sato, N., Yoneda, F., Hayashi, K., Knoll, J., 2003a. Enhancer substances: selegiline and $R$-(-)-1-(benzofuran-2-yl)-2-propylaminopentane [(-)-BPAP] enhance the neurotrophic factor synthesis on cultured mouse astrocytes. Life Sci. 72, 2785-2792.

Shimazu, S., Tsunekawa, H., Yoneda, F., Katsuki, H., Akaike, A., Janowsky, A., 2003b. Transporter-mediated actions of $R$-(-)-1-(benzofuran-2-yl)-2-propylaminopentane. Eur. J. Pharmacol. 482, 9-16.

Shults, C.W., Ray, J., Tsuboi, K., Gage, F.H., 2000. Fibroblast growth factor-2-producing fibroblasts protect the nigrostriatal dopaminergic system from 6-hydroxydopamine. Brain Res. 883, 192-204.

Siderowf, A., Stern, M., 2006. Clinical trials with rasagiline: evidence for short-term and long-term effects. Neurology 66, S80-S88.

Siegel, G.J., Chauhan, N.B., 2000. Neurotrophic factors in Alzheimer's and Parkinson's disease brain. Brain Res. Brain Res. Rev. 33, 199-227.

Slevin, J.T., Gerhardt, G.A., Smith, C.D., Gash, D.M., Kryscio, R., Young, B., 2005. Improvement of bilateral motor functions in patients with Parkinson disease through the unilateral intraputaminal infusion of glial cell line-derived neurotrophic factor. J. Neurosurg. 102, 216-222.

Smidt, M.P., Smits, S.M., Burbach, J.P., 2004. Homeobox gene Pitx3 and its role in the development of dopamine neurons of the substantia nigra. Cell Tissue Res. 318, 35-43.

Smith, A.D., Zigmond, M.J., 2003. Can the brain be protected through exercise? Lessons from an animal model of parkinsonism. Exp. Neurol. 184, 31-39.

Smith, A.D., Antion, M., Zigmond, M.J., Austin, M.C., 2003. Effect of 6-hydroxydopamine on striatal GDNF and nigral GFRalpha1 and RET mRNAs in the adult rat. Brain Res. Mol. Brain Res. 117, 129-138.

Smith, M.P., Cass, W.A., 2007. GDNF reduces oxidative stress in a 6-hydroxydopamine model of Parkinson's disease. Neurosci. Lett. 412, 259-263.

Soderstrom, K., O'Malley, J., Steece-Collier, K., Kordower, J.H., 2006. Neural repair strategies for Parkinson's disease: insights from primate models. Cell Transplant. 15, 251-265.

Sontag, E., Sontag, J.M., Garcia, A., 1997. Protein phosphatase 2A is a critical regulator of protein kinase $C$ zeta signaling targeted by SV40 small t to promote cell growth and NF-kappaB activation. EMBO J. 16, 5662-5671.

Sosa, I., Reyes, O., Kuffler, D.P., 2005. Immunosuppressants: neuroprotection and promoting neurological recovery following peripheral nerve and spinal cord lesions. Exp. Neurol. 195, 7-15.

Springer, J.E., Mu, X., Bergmann, L.W., Trojanowski, J.Q., 1994. Expression of GDNF mRNA in rat and human nervous tissue. Exp. Neurol. 127, 167-170.

Sredni, B., Caspi, R.R., Klein, A., Kalechman, Y., Danziger, Y., Ben, Y.M., Tamari, T., Shalit, F., Albeck, M., 1987. A new immunomodulating compound (AS-101) with potential therapeutic application. Nature 330, 173-176.

Sredni, B., Geffen-Aricha, R., Duan, W., Albeck, M., Shalit, F., Lander, H.M., Kinor, N., Sagi, O., Albeck, A., Yosef, S., Brodsky, M., Sredni-Kenigsbuch, D., Sonino, T., Longo, D.L., Mattson, M.P., Yadid, G., 2007. Multifunctional tellurium molecule protects and restores dopaminergic neurons in Parkinson's disease models. Faseb J. 21, 1870-1883.

Steiner, B., Winter, C., Hosman, K., Siebert, E., Kempermann, G., Petrus, D.S., Kupsch, A., 2006. Enriched environment induces cellular plasticity in the adult substantia nigra and improves motor behavior function in the 6-OHDA rat model of Parkinson's disease. Exp. Neurol. 199, 291-300.

Steiner, J.P., Dawson, T.M., Fotuhi, M., Glatt, C.E., Snowman, A.M., Cohen, N., Snyder, S.H., 1992. High brain densities of the immunophilin FKBP colocalized with calcineurin. Nature 358, 584-587.

Steiner, J.P., Hamilton, G.S., Ross, D.T., Valentine, H.L., Guo, H., Connolly, M.A., Liang, S., Ramsey, C., Li, J.H., Huang, W., Howorth, P., Soni, R., Fuller, M., Sauer, H., Nowotnik, A.C., Suzdak, P.D., 1997. Neurotrophic immunophilin ligands stimulate structural and functional recovery in neurodegenerative animal models. Proc. Natl. Acad. Sci. U.S.A. 94, 2019-2024.

Storch, A., Burkhardt, K., Ludolph, A.C., Schwarz, J., 2000. Protective effects of riluzole on dopamine neurons: involvement of oxidative stress and cellular energy metabolism. J. Neurochem. 75, 2259-2269.

Strassmann, G., Kambayashi, T., Jacob, C.O., Sredni, D., 1997. The immunomodulator AS-101 inhibits IL-10 release and augments TNF alpha and IL-1 alpha release by mouse and human mononuclear phagocytes. Cell. Immunol. 176, 180-185.

Stromberg, I., Bjorklund, L., Johansson, M., Tomac, A., Collins, F., Olson, L., Hoffer, B. Humpel, C., 1993. Glial cell line-derived neurotrophic factor is expressed in the developing but not adult striatum and stimulates developing dopamine neurons in vivo. Exp. Neurol. 124, 401-412.

Subramony, J.A., 2006. Apomorphine in dopaminergic therapy. Mol. Pharm. 3, 380385.

Suter-Crazzolara, C., Unsicker, K., 1994. GDNF is expressed in two forms in many tissues outside the CNS. Neuroreport 5, 2486-2488.

Suter-Crazzolara, C., Unsicker, K., 1996. GDNF mRNA levels are induced by FGF-2 in rat C6 glioblastoma cells. Brain Res. Mol. Brain. Res. 41, 175-182.

Sutoo, D., Akiyama, K., 2003. Regulation of brain function by exercise. Neurobiol. Dis. 13, 1-14.

Takahashi, H., Funahashi, H., Sawai, H., Sakamoto, M., Matsuo, Y., Yamamoto, M. Okada, Y., Hayakawa, T., Manabe, T., 2004. Glial cell line-derived neurotrophic factor enhances nuclear factor-kappaB activity and invasive potential in human pancreatic cancer cells. Pancreas 29, 22-27.

Takahata, K., Shimazu, S., Katsuki, H., Yoneda, F., Akaike, A., 2006. Effects of selegiline on antioxidant systems in the nigrostriatum in rat. J. Neural Transm. 113, 151-158.

Takayama, H., Ray, J., Raymon, H.K., Baird, A., Hogg, J., Fisher, L.J., Gage, F.H., 1995 Basic fibroblast growth factor increases dopaminergic graft survival and function in a rat model of Parkinson's disease. Nat. Med. 1, 53-58.

Tan, Y., Low, K.G., Boccia, C., Grossman, J., Comb, M.J., 1994. Fibroblast growth factor and cyclic AMP (cAMP) synergistically activate gene expression at a cAMP response element. Mol. Cell. Biol. 14, 7546-7556.

Tan, Y., Rouse, J., Zhang, A., Cariati, S., Cohen, P., Comb, M.J., 1996. FGF and stress regulate CREB and ATF-1 via a pathway involving p38 MAP kinase and MAPKAP kinase-2. EMBO J. 15, 4629-4642.

Tanaka, K., Asanuma, M., Ogawa, N., 2004. Molecular basis of anti-apoptotic effect of immunophilin ligands on hydrogen peroxide-induced apoptosis in human glioma cells. Neurochem. Res. 29, 1529-1536.

Tanaka, K., Fujita, N., Ogawa, N., 2003. Immunosuppressive (FK506) and nonimmunosuppressive (GPI1046) immunophilin ligands activate neurotrophic factors in the mouse brain. Brain Res. 970, 250-253.

Tanaka, K., Fujita, N., Higashi, Y., Ogawa, N., 2002b. Neuroprotective and antioxidant properties of FKBP-binding immunophilin ligands are independent on the FKBP12 pathway in human cells. Neurosci. Lett. 330, 147-150.

Tanaka, K., Yoshioka, M., Miyazaki, I., Fujita, N., Ogawa, N., 2002a. GPI1046 prevents dopaminergic dysfunction by activating glutathione system in the mouse striatum. Neurosci. Lett. 321, 45-48.

Tanaka, M., Ito, S., Kiuchi, K., 2000. Novel alternative promoters of mouse glial cell line-derived neurotrophic factor gene. Biochim. Biophys. Acta 1494, 63-74.

Tanaka, T., Oh-Hashi, K., Shitara, H., Hirata, Y., Kiuchi, K., 2008. NF-kappaB independent signaling pathway is responsible for LPS-induced GDNF gene expression in primary rat glial cultures. Neurosci. Lett. 431, 262-267.

Tang, Y.P., Ma, Y.L., Chao, C.C., Chen, K.Y., Lee, E.H., 1998. Enhanced glial cell linederived neurotrophic factor mRNA expression upon (-)-deprenyl and melatonin treatments. J. Neurosci. Res. 53, 593-604.

Tatton, W.G., Greenwood, C.E., 1991. Rescue of dying neurons: a new action for deprenyl in MPTP parkinsonism. J. Neurosci. Res. 30, 666-672.

Tatton, W.G., Wadia, J.S., Ju, W.Y., Chalmers-Redman, R.M., Tatton, N.A., 1996. (-)Deprenyl reduces neuronal apoptosis and facilitates neuronal outgrowth by altering protein synthesis without inhibiting monoamine oxidase. J. Neural Transm. Suppl. 48, 45-59.

Thiffault, C., Aumont, N., Quirion, R., Poirier, J., 1995. Effect of MPTP and L-deprenyl on antioxidant enzymes and lipid peroxidation levels in mouse brain. J. Neurochem. 65, 2725-2733.

Thomas, B., Mohanakumar, K.P., 2004. Melatonin protects against oxidative stress caused by 1 -methyl-4-phenyl-1,2,3,6-tetrahydropyridine in the mouse nigrostriatum. J. Pineal Res. 36, 25-32.

Tillerson, J.L., Caudle, W.M., Reveron, M.E., Miller, G.W., 2003. Exercise induces behavioral recovery and attenuates neurochemical deficits in rodent models of Parkinson's disease. Neuroscience 119, 899-911.

Tillerson, J.L., Cohen, A.D., Philhower, J., Miller, G.W., Zigmond, M.J., Schallert, T., 2001. Forced limb-use effects on the behavioral and neurochemical effects of 6hydroxydopamine. J. Neurosci. 21, 4427-4435.

Tokugawa, K., Yamamoto, K., Nishiguchi, M., Sekine, T., Sakai, M., Ueki, T., Chaki, S. Okuyama, S., 2003. XIB4035, a novel nonpeptidyl small molecule agonist for GFRalpha-1. Neurochem. Int. 42, 81-86.

Tomac, A., Widenfalk, J., Lin, L.F., Kohno, T., Ebendal, T., Hoffer, B.J., Olson, L., 1995. Retrograde axonal transport of glial cell line-derived neurotrophic factor in the adult nigrostriatal system suggests a trophic role in the adult. Proc. Natl. Acad. Sci. U.S.A. 92, 8274-8278.

Tooyama, I., Kawamata, T., Walker, D., Yamada, T., Hanai, K., Kimura, H., Iwane, M. Igarashi, K., McGeer, E.G., McGeer, P.L., 1993. Loss of basic fibroblast growth factor in substantia nigra neurons in Parkinson's disease. Neurology 43, 372376.

Toyomoto, M., Inoue, S., Ohta, K., Kuno, S., Ohta, M., Hayashi, K., Ikeda, K., 2005 Production of NGF, BDNF and GDNF in mouse astrocyte cultures is strongly enhanced by a cerebral vasodilator, ifenprodil. Neurosci. Lett. 379, 185-189.

Treanor, J.J., Goodman, L., de, S.F., Stone, D.M., Poulsen, K.T., Beck, C.D., Gray, C., Armanini, M.P., Pollock, R.A., Hefti, F., Phillips, H.S., Goddard, A., Moore, M.W Buj-Bello, A., Davies, A.M., Asai, N., Takahashi, M., Vandlen, R., Henderson, C.E. Rosenthal, A., 1996. Characterization of a multicomponent receptor for GDNF. Nature 382, 80-83.

Trupp, M., Arenas, E., Fainzilber, M., Nilsson, A.S., Sieber, B.A., Grigoriou, M., Kilkenny, C., Salazar-Grueso, E., Pachnis, V., Arumae, U., 1996. Functional 
receptor for GDNF encoded by the c-ret proto-oncogene. Nature 381, 785789.

Trupp, M., Belluardo, N., Funakoshi, H., Ibanez, C.F., 1997. Complementary and overlapping expression of glial cell line-derived neurotrophic factor (GDNF), cret proto-oncogene, and GDNF receptor-alpha indicates multiple mechanisms of trophic actions in the adult rat CNS. J. Neurosci. 17, 3554-3567.

Trupp, M., Ryden, M., Jornvall, H., Funakoshi, H., Timmusk, T., Arenas, E., Ibanez, C.F. 1995. Peripheral expression and biological activities of GDNF, a new neurotrophic factor for avian and mammalian peripheral neurons. J. Cell Biol. 130, $137-148$

Trupp, M., Scott, R., Whittemore, S.R., Ibanez, C.F., 1999. Ret-dependent and independent mechanisms of glial cell line-derived neurotrophic factor signaling in neuronal cells. J. Biol. Chem. 274, 20885-20894.

Tsai, C.H., Lo, S.K., See, L.C., Chen, H.Z., Chen, R.S., Weng, Y.H., Chang, F.C., Lu, C.S. 2002. Environmental risk factors of young onset Parkinson's disease: a casecontrol study. Clin. Neurol. Neurosurg. 104, 328-333.

Tsuchioka, M., Takebayashi, M., Hisaoka, K., Maeda, N., Nakata, Y., 2008. Serotonin (5-HT) induces glial cell line-derived neurotrophic factor (GDNF) mRNA expression via the transactivation of fibroblast growth factor receptor 2 (FGFR2) in rat C6 glioma cells. J. Neurochem. 106, 244-257.

Vega-Naredo, I., Poeggeler, B., Sierra-Sanchez, V., Caballero, B., Tomas-Zapico C., Varez-Garcia, O., Tolivia, D., Rodriguez-Colunga, M.J., Coto-Montes, A., 2005 Melatonin neutralizes neurotoxicity induced by quinolinic acid in brain tissue culture. J. Pineal Res. 39, 266-275.

Verity, A.N., Wyatt, T.L., Hajos, B., Eglen, R.M., Baecker, P.A., Johnson, R.M., 1998. Regulation of glial cell line-derived neurotrophic factor release from rat C6 glioblastoma cells. J. Neurochem. 70, 531-539.

Verity, A.N., Wyatt, T.L., Lee, W., Hajos, B., Baecker, P.A., Eglen, R.M., Johnson, R.M. 1999. Differential regulation of glial cell line-derived neurotrophic factor (GDNF) expression in human neuroblastoma and glioblastoma cell lines. J. Neurosci. Res. 55, 187-197.

Visanji, N.P., Orsi, A., Johnston, T.H., Howson, P.A., Dixon, K., Callizot, N., Brotchie, J.M., Rees, D.D., 2008. PYM50028, a novel, orally active, nonpeptide neurotrophic factor inducer, prevents and reverses neuronal damage induced by $\mathrm{MPP}^{+}$in mesencephalic neurons and by MPTP in a mouse model of Parkinson's disease. Faseb J. doi: 10.1096/fj.07-095398.

Vitkovic, L., Maeda, S., Sternberg, E., 2001. Anti-inflammatory cytokines: expression and action in the brain. Neuroimmunomodulation 9, 295-312.

Wang, C.Y., Yang, F., He, X., Chow, A., Du, J., Russell, J.T., Lu, B., 2001a. Ca(2+) binding protein frequenin mediates GDNF-induced potentiation of $\mathrm{Ca}(2+)$ channels and transmitter release. Neuron 32, 99-112.

Wang, J.Y., Wu, J.N., Cherng, T.L., Hoffer, B.J., Chen, H.H., Borlongan, C.V., Wang, Y., 2001b. Vitamin $D(3)$ attenuates 6-hydroxydopamine-induced neurotoxicity in rats. Brain Res. 904, 67-75.

Wang, J., Chen, G., Lu, B., Wu, C.P., 2003. GDNF acutely potentiates $\mathrm{Ca}^{2+}$ channels and excitatory synaptic transmission in midbrain dopaminergic neurons. Neurosignals $12,78-88$.

Wang, X.J., Chen, X.H., Yang, X.Y., Geng, M.Y, Wang L.M., 2007. Acidic oligosaccharide sugar chain, a marine-derived oligosaccharide, activates human glia cell line-derived neurotrophic factor signaling. Neurosci. Lett. 417, 176-180.

Wang, Y., Chang, C.F., Morales, M., Chiang, Y.H., Hoffer, J., 2002. Protective effects of glial cell line-derived neurotrophic factor in ischemic brain injury. Ann. NY Acad. Sci. 962, 423-437.

Wang, Y., Chiang, Y.H., Su, T.P., Hayashi, T., Morales, M., Hoffer, B.J., Lin, S.Z., 2000 Vitamin $\mathrm{D}(3)$ attenuates cortical infarction induced by middle cerebral arterial ligation in rats. Neuropharmacology 39, 873-880.

Wei, G., Wu, G., Cao, X., 2000. Dynamic expression of glial cell line-derived neurotrophic factor after cerebral ischemia. Neuroreport 11, 1177-1183.

Wellik, D.M., Hawkes, P.J., Capecchi, M.R., 2002. Hox11 paralogous genes are essential for metanephric kidney induction. Genes Dev. 16, 1423-1432.

Whone, A.L., Watts, R.L., Stoessl, A.J., Davis, M., Reske, S., Nahmias, C., Lang, A.E. Rascol, O., Ribeiro, M.J., Remy, P., Poewe, W.H., Hauser, R.A., Brooks, D.J., 2003. Slower progression of Parkinson's disease with ropinirole versus levodopa: the REAL-PET study. Ann. Neurol. 54, 93-101.

Williams, K., 2001. Ifenprodil, a novel NMDA receptor antagonist: site and mechanism of action. Curr. Drug Targets 2, 285-298.

Witt-Enderby, P.A., MacKenzie, R.S., McKeon, R.M., Carroll, E.A., Bordt, S.L., Melan, M.A., 2000. Melatonin induction of filamentous structures in non-neuronal cells that is dependent on expression of the human mt1 melatonin receptor. Cell Motil. Cytoskel. 46, 28-42.

Woodbury, D., Schaar, D.G., Ramakrishnan, L., Black, I.B., 1998. Novel structure of the human GDNF gene. Brain Res. 803, 95-104.

Wu, S.S., Frucht, S.J., 2005. Treatment of Parkinson's disease: what's on the horizon? CNS Drugs 19, 723-743.
Xia, C.F., Boado, R.J., Zhang, Y., Chu, C., Pardridge, W.M., 2008. Intravenous glialderived neurotrophic factor gene therapy of experimental Parkinson's disease with Trojan horse liposomes and a tyrosine hydroxylase promoter. J. Gene Med. 10, 306-315.

Xie, Q.W., Kashiwabara, Y., Nathan, C., 1994. Role of transcription factor NF-kappaB/ Rel in induction of nitric oxide synthase. J. Biol. Chem. 269, 4705-4708.

Xiong, H., Futamura, T., Jourdi, H., Zhou, H., Takei N., Verse-Pierluissi, M., Plevy, S., Nawa, H., 2002. Neurotrophins induce BDNF expression through the glutamate receptor pathway in neocortical neurons. Neuropharmacology 42, 903-912.

Xu, P.X., Adams, J., Peters, H., Brown, M.C., Heaney, S., Maas, R., 1999. Eya1-deficient mice lack ears and kidneys and show abnormal apoptosis of organ primordia. Nat. Genet. 23, 113-117.

Yamagata, K., Hakata, K., Maeda, A., Mochizuki, C., Matsufuji, H., Chino, M., Yamori, Y., 2007. Adenosine induces expression of glial cell line-derived neurotrophic factor (GDNF) in primary rat astrocytes. Neurosci. Res. 59, 467-474.

Yamagata, K., Tagami, M., Ikeda, K., Tsumagari, S., Yamori, Y., Nara, Y., 2002. Differential regulation of glial cell line-derived neurotrophic factor (GDNF) mRNA expression during hypoxia and reoxygenation in astrocytes isolated from stroke-prone spontaneously hypertensive rats. Glia 37, 1-7.

Yamashita, M., Dimayuga, P., Kaul, S., Shah, P.K., Regnstrom, J., Nilsson, J., Cercek, B., 1999. Phosphatase activity in the arterial wall after balloon injury: effect of somatostatin analog octreotide. Lab. Invest. 79, 935-944.

Yang, F., Feng, L., Zheng, F., Johnson, S.W., Du, J., Shen, L., Wu, C.P., Lu, B., 2001. GDNF acutely modulates excitability and A-type $\mathrm{K}(+)$ channels in midbrain dopaminergic neurons. Nat. Neurosci. 4, 1071-1078.

Yang, L.X., Nelson, P.G., 2004. Glia cell line-derived neurotrophic factor regulates the distribution of acetylcholine receptors in mouse primary skeletal muscle cells. Neuroscience 128, 497-509.

Yoon, M.C., Shin, M.S., Kim, T.S., Kim, B.K., Ko, I.G., Sung, Y.H., Kim, S.E., Lee, H.H., Kim, Y.P., Kim, C.J., 2007. Treadmill exercise suppresses nigrostriatal dopaminergic neuronal loss in 6-hydroxydopamine-induced Parkinson's rats. Neurosci. Lett. 423, 12-17.

Yoshida, T., Tanaka, M., Suzuki, Y., Sohmiya, M., Okamoto, K., 2002. Antioxidant properties of cabergoline: inhibition of brain auto-oxidation and superoxide anion production of microglial cells in rats. Neurosci. Lett. 330, 1-4.

Yoshioka, M., Tanaka, K., Miyazaki, I., Fujita, N., Higashi, Y., Asanuma, M., Ogawa, N., 2002. The dopamine agonist cabergoline provides neuroprotection by activation of the glutathione system and scavenging free radicals. Neurosci. Res. 43, 259-267.

Youdim, M.B., Maruyama, W., Naoi, M., 2005. Neuropharmacological, neuroprotective and amyloid precursor processing properties of selective MAO-B inhibitor antiparkinsonian drug, rasagiline. Drugs Today (Barc.) 41, 369-391.

Young, D., Lawlor, P.A., Leone, P., Dragunow, M., During, M.J., 1999. Environmental enrichment inhibits spontaneous apoptosis, prevents seizures and is neuroprotective. Nat. Med. 5, 448-453.

Yu, H., Oh-Hashi, K., Tanaka, T., Sai, A., Inoue, M., Hirata, Y., Kiuchi, K., 2006. Rehmannia glutinosa induces glial cell line-derived neurotrophic factor gene expression in astroglial cells via cPKC and ERK1/2 pathways independently. Pharmacol. Res. 54, 39-45.

Yu, Y., Matsuyama, Y., Yanase, M., Ito, S., Adachi, K., Satake, K., Ishiguro, N., Kiuchi, K., 2004. Effects of hyperbaric oxygen on GDNF expression and apoptosis in spinal cord injury. Neuroreport 15, 2369-2373.

Yuan, P.X., Huang, L.D., Jiang, Y.M., Gutkind, J.S., Manji, H.K., Chen, G., 2001. The mood stabilizer valproic acid activates mitogen-activated protein kinases and promotes neurite growth. J. Biol. Chem. 276, 31674-31683.

Yurek, D.M., Fletcher-Turner, A., 2001. Differential expression of GDNF, BDNF, and NT-3 in the aging nigrostriatal system following a neurotoxic lesion. Brain Res. $891,228-235$.

Yurek, D.M., Fletcher-Turner, A., 2002. Temporal changes in the neurotrophic environment of the denervated striatum as determined by the survival and outgrowth of grafted fetal dopamine neurons. Brain Res. 931, 126-134.

Zhang, C., Steiner, J.P., Hamilton, G.S., Hicks, T.P., Poulter, M.O., 2001a. Regeneration of dopaminergic function in 6-hydroxydopamine-lesioned rats by neuroimmunophilin ligand treatment. J. Neurosci. 21, RC156.

Zhang, W.R., Hayashi, T., Iwai, M., Nagano, I., Sato, K., Manabe, Y., Abe, K., 2001b. Time dependent amelioration against ischemic brain damage by glial cell linederived neurotrophic factor after transient middle cerebral artery occlusion in rat. Brain Res. 903, 253-256.

Zhang, Y., Xia, Z., Hu, Y., Orsi, A., Rees, D., 2008. Role of glial cell derived neurotrophic factor in the protective effect of smilagenin on rat mesencephalic dopaminergic neurons damaged by MPP ${ }^{+}$. FEBS Lett. 582, 956-960.

Zhou, J., Yu, Y., Tang, Z., Shen, Y., Xu, L., 2000. Differential expression of mRNAs of GDNF family in the striatum following 6-OHDA-induced lesion. Neuroreport 11, 3289-3293. 